2

3

4

5

6

7 8

9

\title{
Microfracturing and microporosity in shales
}

\author{
Audrey Ougier-Simonin ${ }^{1,2,3}$, François Renard ${ }^{1,2,4}$ \\ Claudine Boehm ${ }^{5}$, and Sandrine Vidal-Gilbert ${ }^{5}$ \\ ${ }^{1}$ Univ. Grenoble Alpes, ISTerre, CS 4070, 38056 cedex 9, Grenoble, France \\ ${ }^{2}$ CNRS, ISTerre, CS 4070, 38056 cedex 9, Grenoble, France \\ ${ }^{3}$ now at British Geological Survey, Environmental Science Centre, Keyworth, Nottingham, United Kingdom \\ NG12 5GG \\ ${ }^{4}$ PGP, Department of Geosciences, University of Oslo, Norway \\ ${ }^{5}$ Total, SA
}

Submitted to

Earth Science Reviews 


\section{Abstract}

Shales are ubiquitous rocks in sedimentary basins, where their low permeability makes them efficient seals for oil and gas reservoirs and underground waste storage repositories (waste waters, $\mathrm{CO}_{2}$, nuclear fuels). Moreover, when they contain organic matter, they form source rocks for hydrocarbons that may escape towards a more porous reservoir during burial, a process referred to as primary migration. And when the hydrocarbons cannot escape, these rocks can be exploited as oil or shale gas reservoirs. While the presence of fractures at the outcrop scale has been described, the existence of fractures at smaller scales, their link with microporosity, the mechanisms that created them, their persistence over geological times, and their effect on the petrophysical properties of shales represent scientific challenges for which drillings in various sedimentary basins over the past decades may hold timely key data..

Here, we review and synthetize the current knowledge on how microfractures and micropores in shales can be imaged and characterized and how they control their anisotropic mechanical properties and permeability. One question is whether such microfractures, when observed in outcrops or in drilled core samples extracted from boreholes, are related to decompaction and do not exist at depth. Another question is whether veins observed in shales represent microfractures that were open long enough to have acted as flow paths across the formation. The mechanisms of microfracture development are described. Some have an internal origin (fracturing by maturation of organic matter, dehydration of clays) while others are caused by external factors (tectonic loading). Importantly, the amount of microfracturing in shales is shown to depend strongly on the content in 1) organic matter, and 2) strong minerals. The nucleation of microfractures depends on the existence of mechanical heterogeneities down to the nanometer scale. Their propagation and linkage to create a percolating network will depend on the presence of heterogeneities at the meso- to macro-scales. Such percolating microfracture networks could control both the long-term sealing capabilities of cap rocks and the further propagation of hydraulic fracturing cracks. Finally, possible areas of research for describing the mechanism of microfracture formation in greater detail and how this impacts the transport and mechanical properties of shales are also discussed. 


\section{Outline}

44 1. Introduction

1.1. What is a shale rock?

1.2. Fractures and microfractures in shale rocks

2. From pores to microfractures in shales

2.1 Characterizing pores and microfractures

2.2 Methods of microfracture identification

3. Processes of microfracture formation in shale rocks 


\section{Introduction}

Shales make up between one-half and two-thirds of all sedimentary rocks in the Earth's shallow crust. They constitute about $80 \%$ of all drilled sections in oil- and gas-drilling operations, mainly because they overlie or underlie most hydrocarbon-bearing reservoirs (Sarout and Guéguen, 2008a), forming cap rocks and source rocks. In this context, shales have been considered as source rocks and seals for conventional petroleum and gas systems for many years (Hunt, 1996). However, the commercial production of shale gas and shale oil since the end of the 1990s has changed this idea. Accordingly mudrocks, and shales in particular, have received renewed attention in recent years because of their emergence as effective unconventional hydrocarbon reservoirs (Curtis, 2002; Montgomery et al., 2005; Jarvie et al., 2007; Pollastro et al., 2007; Loucks et al., 2009).

Today, shales are target rocks for crustal fluid resources such as groundwater and hydrocarbons, but also fields of interest for the storage of carbon dioxide and radioactive wastes. Shales can act either as source rocks for hydrocarbons or/and as cap rocks (top-seals) when located above reservoirs. They prevent fluids from escaping due to their low permeability and by a capillary sealing mechanism controlled by the small pores (Horsrud et al., 1998). The new economic interest has triggered questions around their petrophysical and mechanical properties. However, their low permeability and sensitivity to the nature of contacting fluids make it difficult to handle them under laboratory conditions. In addition, recovery of shales from depth can cause stress-relief microfracturing and gaseous exsolution from pore fluids (Dewhurst et al., 2011), which overprint the natural microporous space geometry and fluid content. The transport properties of low-permeability rocks are fundamentally controlled by the structure of available transport pathways (Keller et al., 2011). Consequently, the identification of porosity and pore size distribution in shales, including microfractures, has become a high research priority as they are key parameters for the commercial evaluation of a potential shale (Ross and Bustin, 2008, 2009; Loucks et al., 2009). Moreover, microfractures control the long-term sealing capacities of cap rocks, the expulsion of hydrocarbon during primary migration, and the potential increase in permeability when reactivated by hydraulic fracturing. These properties are particularly useful in the context of deep buried reservoirs, where dry boreholes are particularly costly. Here, we review the mechanisms by which microfractures have formed during the geological history of shales, synthetize our knowledge on their role on petrophysical properties of the rock and how interwoven they are with (micro)porosity. 
Kranz (1983) wrote a first review article on microfractures in rock and emphasized their importance in controlling transport properties. Anders et al. (2014) updated the current knowledge on microfractures in rocks, discussing their mechanical origin and the modern imaging techniques used to characterize them. These two review studies were focused on all kinds of sedimentary and igneous rocks, with only a few examples concerning shales. Finally, Gale et al. (2014) proposed a comprehensive study of fractures in shales based on observations at the outcrop scale or in core samples extracted from boreholes. However, in these three studies, no comprehensive review was performed on the microfractures in shales. Several studies have been performed to address microfracturing in tight rocks. They focused on technologies related to underground nuclear waste disposal and, more recently, geological storage of $\mathrm{CO}_{2}$ (e.g. Bolton et al., 2000; Yang and Aplin, 2007; Sarout and Guéguen, 2008a; Ababou et al., 2011; Skurtveit et al., 2012; Ghayaza et al., 2013). In the present study, we intend to review current knowledge concerning microfractures in shales through a state-ofthe-art literature survey. We address several questions in order to assess how natural microfractures are generated in shales and how they affect rock properties. In particular, the following questions represent key challenges that are not completely solved yet:

- How do cracks nucleate, propagate, stop and eventually heal in shales?

\subsection{What is a shale rock?}

The term "shale" was first introduced by Hooson (1747) to describe an indurated, laminated, clayey rock; 'shale' is now the ubiquitous term that encompasses the entire class of finegrained clayey sedimentary rocks, whether they are laminated or not. Beside the term shale, 
materials partly based in grain size - argillite, clay, claystone, mud, mudrock, mudstone, pelite, silt, siltstone, slate, or wacke. In the petroleum industry, the term shale is not precisely defined: it may range from weak and soft clay (named gumbo) to strongly cemented and shaly siltstones (Horsrud et al., 1998). Shales have in common that they all contain substantial amounts of clay minerals, which define their typical gray color, and (silty) quartz, carbonates, and smaller quantities of feldspars, iron oxides, organic matter, and, sometimes, fossils (Figure 1). But shales differ from 1) mudstones in that they break into thin chips with roughly parallel tops and bottoms, whereas mudstones break into blocky pieces, and 2) from argillites and slates in that they are fissile but do not show distinctive layering nor true slaty cleavage or foliation (Blatt and Tracy, 1996; Merriman et al., 2003).

Shales generally form by settling from sediment suspension in very slow moving water such as in lakes, lagoons, deltas, floodplains, and in the offshore below wave-base. The fine particles composing them can remain suspended long after the larger and denser particles of sand have been deposited. Along with mudrocks, shales contain roughly $95 \%$ of the organic matter in all sedimentary rocks. However, this amounts to only several percent by mass in an average shale sample. Much of the organic matter is of algal origin (planktonic algae, phytoplankton), but it may also include remains of vascular land plants and bacteria (Hutton, 1987). It is characterized as bitumen or kerogen, depending on its solubility or insolubility in organic solvents (e.g. carbon disulfide), respectively. Finally, during deposition, clays may be reworked by the activity of organisms, such as worms, which form burrows that may be fossilized and introduce millimeter to centimeter-scale heterogeneities in the shales.

Due to the lack of standardization, the meaning of the term "clay" often varies from one scientific community to another. The clay minerals present in shales are largely kaolinite, smectite/montmorillonite, chlorite, and illite (Shaw and Weaver, 1965). In general, the clay minerals of late Tertiary shale are expandable smectites whereas in older rocks that have been buried deeper, especially during the mid- to early-Paleozoic, illite minerals predominate (Blatt and Tracy, 1996; see also Table 1). Black shales, which form in anoxic conditions, result from the presence of carbonaceous material at concentrations higher than $1 \%$. They contain reduced free carbon along with ferrous iron $\left(\mathrm{Fe}^{2+}\right)$ and sulfur $\left(\mathrm{S}^{2-}\right)$, which are markers of a reducing environment (Blatt and Tracy, 1996). The presence of variable amounts of calcium and magnesium carbonates and of authigenic minerals alters the color of the shale.

The response of sedimentary rocks with respect to permeability, water sensitivity and other petrophysical and transport properties is determined by the amount of clay minerals they 
contain (Horsrud et al., 1998). Ignoring the textural significance of the term "clay" and concentrating on the compositional aspect of shales, one may ask how much clay a rock has to contain for it to be defined as a shale. It appears that even something as seemingly simple as defining the minimum/maximum quantity of clay minerals in shale is fraught with difficulty.

\section{[Figure 1 about here]}

Shales are considered to be multi-phase and multi-scale sedimentary rocks. They are composed of clay platelets surrounding inclusions of other, stiffer minerals (quartz, feldspars, carbonates, mica, and pyrite) or more compliant organic phases. These clay platelets are packed together to form so-called clay particles, which create a variably complex network that defines the microscopic and macroscopic scales (Figure 2). The size of individual clays ranges from that of single crystallographic units (9.6 to $19.0 \AA$ for smectite clays, depending on the level of hydration, $9.98 \AA$ for illite, $14.2 \AA$ for chlorite, and $7.14 \AA$ for kaolinite - see Moore, 1997) to that of individual particles. Because clay minerals contain a large quantity of defects, they usually do not produce large crystals and remain small (Meunier, 2006), within the dimensions of 2 micrometers that define them.

The better the clay particles are aligned at the microscale, the more the shale is anisotropic (transversely isotropic) at the macroscale (Sarout and Guéguen, 2008a). Due to their sheetlike structure, clay minerals align preferentially along the (001) crystallographic lattice planes. This alignment is parallel to the bedding plane during sedimentation, compaction, and diagenesis (Ho et al., 1999). This organized distribution of platy clay minerals (Hornby et al., 1994) and compliant organic materials in shales (Vernik and Nur, 1992; Vernik and Liu, 1997; Sondergeld et al., 2000; Vernik and Milovac, 2011) is another source of complexity that produces substantial mechanical anisotropy. It is also responsible for their fissility, the fact that they break to form thin laminae or parallel layers or beds less than one centimeter in thickness. They typically exhibit varying degrees of fissility, breaking into thin layers that are often splintery and usually parallel to the otherwise indistinguishable bedding planes because of the parallel orientation of the clay mineral flakes (Blatt and Tracy, 1996). There are also indications that not only the amount of clay or organics but also the state of organization of the rock controls the anisotropy of the shales (Vanorio et al., 2008). 
In the present study, we consider shales as detrital sedimentary rocks that contain more than $30 \%$ clay minerals, constituting a continuous clay matrix of any clay grade size (Horsrud et al., 1998).

\subsection{Fractures and microfractures in shale rocks}

Natural fractures in shales and mudstones play a role in recovery of unconventional hydrocarbon and in controlling cap rock integrity. Microfractures in fine-grained, lowpermeability rocks serve as hydrocarbon migration pathways when they are connected. Their presence in cap rocks may control potential leakage from a reservoir, and even if the microfractures are closed, they could be reactivated during periods of increased fluid pressure, for example if a reservoir below is under high fluid pressure or if industrial fluid injection is carried out, increasing pressure.

Open fractures from the nanometer to micrometer scale are widely known to affect the physical properties of rocks, such as compressibility, strength, elastic wave velocities and permeability (Walsh, 1965a,b,c; Kranz, 1983)., Microfractures correspond to planar openings produced when the local stress exceeds the local strength of the rock matrix, with dimensions that are much smaller in two directions than in the third one. Typically, the aspect ratio, defined as the width to length ratio, is less than $10^{-2}$ and ranges between $10^{-5}$ and $10^{-3}$ (e.g. Simmons, 1976; Kranz, 1983). The stress concentration at the tip drives the creation of many smaller features in a non-linear process zone. Microfractures lengthen by propagating in such process zones, following one of the three widely acknowledged distinct displacement modes or a combination of them: i) tensile or opening (mode I), ii) in-plane shearing or sliding (mode II) and iii) anti-plane shearing or tearing (mode III). While microfractures, macrofractures and joints refer to a simple opening (mode I), the term fault bears the idea of shear displacement with the opening (modes II and III). In this review, we only focus on simple openings at the grain scale, thus excluding faults and also joints, as these are largerscale phenomena. For the sake of clarity, we use the term microfracture later on and consider it to be a synonym for the term microcrack. These features concern mode I fractures with openings with an aperture in the range of several nanometers to several tens of micrometers, and a length in the range of hundreds to tens of thousands of times the aperture.

Two types of microfracture can be identified in shales. Those parallel to the bedding form along weak planes in the rock, and a second kind forms at an angle to this first type, possibly 
connecting the two types to make the rock permeable in 3D. The existence of these two types of microfracture in a shale is a necessary, but not sufficient, condition to obtain a percolating rock at the scale of a sedimentary bed or a formation.

Fracturing of rocks involves several steps from the nucleation of cracks, their propagation, and their final arrest either as a dead end (tip) or as a connection to another fracture or a discontinuity such as sedimentary bedding (Chandler et al., 2013). Microfracturing processes in shales appear to be controlled by several parameters: mineralogy, clay content, stress field, fluid content, temperature, and size and amount of heterogeneities. Two main families of microfracturing process can be identified in shales depending on whether the stress is applied externally or internally. When tectonic loading is applied externally, a rock can fracture and eventually fail along faults with a well-defined damage zone. Conversely, internal stresses may be related to increased fluid pressure or chemical reactions inside the rock, either due to the decomposition of organic matter or the dehydration of clays, both of which produce fluids and local increases in volume. In both cases, the presence of hard minerals and/or organic content play a significant role in the microfracturing process and capacity.

\section{[Figure 2 about here]}

\section{From pores to microfractures in shales}

The comprehensive and systematic observation and description of microfractures in a shale sample should include various metrics such as 1) coring depth;2) crack aperture; 3) crack length; 4) crack density; 5) crack porosity; and 6) the sealed matter if appropriate (Zeng et al., 2013). Few studies document microfracture localization with coring depth along with the method of core preservation right after it has been released from the drilling pipe. In Zeng et al. (2013) for instance, the fracture characteristics at the macroscale are thoroughly documented, even emphasizing the great variability of the fractures in the Niutitang shale formation (Qiannan basin, China). Yet the same type of information for the microscopic scale is lacking or is not distinguished clearly from the macroscale. The study of crack aperture, length, density and porosity is usually combined with detailed characterization of the porosity of the shale studied (Loucks et al., 2009; Heath et al., 2011; Keller et al., 2011; Huang et al., 2013). The study of elastic anisotropy in shale can also give indirect access to the crack aspect ratio, density and porosity (see section 4). Several properties of shales compiled from several case studies are given in the Table 1. 
In sedimentary rocks, petrophysical properties such as porosity and permeability are directly related to the size, arrangement and composition of the matrix minerals and organic matter. Because the porosity is intimately coupled to flows, capillary processes, permeability and associated deformation, it is essential to characterize the relation between nano- and microstructures and macro-properties in order to gain a complete understanding of the fluidrock interactions and transport properties. The key point in relating porosity and permeability is pore morphology and the associated pore connectivity, in which microfractures play a significant role (Desbois et al., 2010).

\section{[Table 1 about here]}

\subsection{Characterizing pores and microfractures}

While the pores in sandstone and carbonate reservoirs are micrometer-scale, the pores within shale rocks are usually smaller than one micrometer, spanning a wide range of scales from nanometer to micrometer. In particular, the pores found in organic grains range from several to hundreds of nanometers (Chalmers et al., 2009; Loucks et al., 2009; Nelson, 2009; Chalmers et al., 2012a; Chalmers et al., 2012b; Milliken et al., 2013).

From the development of high-resolution imaging techniques during the past decade and because of increasing demands with regard to the petrophysical properties of shales, detailed investigations of the morphology of the porous space have been conducted on various shale samples (e.g. Yven et al. (2007); Loucks et al., 2009; Desbois et al., 2010; Milner et al., 2010; Heath et al., 2011; Chalmers et al., 2012a; Houben et al., 2013; Tian et al., 2013). Depending on their size and morphology, these pores can be considered as preexisting flaws enabling microfracture propagation.

Porosity ranges from nanometer to centimeter scales. As a consequence, several classifications of pore types depending on their size, shape, location, and formation mechanism have emerged to help predict porosity and guide upscaling of measurements (Figures 3 to 5). Although described mostly in terms of categories (e.g. micro-, meso-, and macroporosity), porosity has to be related to the microfacies and microstructure to which it belongs. The overall pore size distribution can then be interpreted and quantified (Yven et al., 2007).

[Figures 3, 4, 5 about here] 
Chalmers et al. (2009) recommended that geoscientists working on shales use the pore size terminology of the International Union of Pure and Applied Chemistry (IUPAC), designed for materials containing nanometer-scale pores (Rouquerol et al., 1994). This categorizes pore sizes on the basis of physical adsorption properties (nitrogen adsorption) and capillary condensation theory (e.g. Sing, 1985; Rouquerol et al., 1994). The porous space is thus subdivided into three categories, regardless of the shape and origin of the features (Rouquerol et al., 1994; Yven et al., 2007; Chalmers et al., 2012a):

i) micropores, with openings smaller than $2 \mathrm{~nm}$, may have a structural origin (in the sense of mineral structure) or a textural origin due to the local arrangement of clay flakes, thus defining a grain-boundary microporosity;

ii) mesopores, with openings ranging from 2 to $50 \mathrm{~nm}$, are rarely structural and intraparticular, but consist of pores resulting from the spatial organization of elementary particles, such as grain joints, intra-aggregate porosity, and even inter-aggregate porosity for materials with a high clay content;

iii) macropores, with openings wider than $50 \mathrm{~nm}$, are all the large-size pores associated with intergranular space.

Using complementary investigation methods and resolution scales, porosity may thus be fully or partly quantified and qualitatively analyzed with images (Table 2). In this classification, microfractures can be accounted for in the three categories.

Using several imaging techniques, Milner et al. (2010) and Huang et al. (2013) classified shale porosity according to the different types of pore formation mechanism instead of pore size (Table 2). Milner et al. (2010) found three types of pore, which they named 1) matrix intergranular pores, 2) organic matter pores and 3) intergranular pores (Figure 3). Huang et al. (2013) distinguished dissolution pores and intracrystalline pores in addition to the three aforementioned kinds of pore (Figure 4). Fossil fragments and paleo-tracks (microchannels, micro-burrows) which can be observed within the shale matrix may exhibit various geometries (Figure 4, Table 2). Lastly, microfractures (or microfissures; products of microfracture coalescence) running through the shale matrix range from micrometer to larger scales (Figures 3 to 7; Table 2). If shear displacement is observed, the discontinuity becomes a fault (shear fracture) and these objects are excluded from the present study.

The pores are observed at several scales from tens of nanometers to several micrometers. For example, using high-resolution synchrotron X-ray microtomography of a shale sample 
collected from a deep borehole, the pore size distribution can be extracted from the 3D images (Figure 6). Two tomography resolutions were used for this sample to identify pore sizes in the 2-200 micrometer range. The micropore distribution follows a linear trend in a $\log -\log$ plot (Figure 6c) and the microfractures appear as large pores that depart from this trend. However, it remains to be determined whether these microfractures were partly open at depth or whether they are the result of borehole coring and depressurization of the shale sample.

\section{[Figures 6 and 7 about here]}

Although it is particularly important to know the mechanisms behind pore formation, this type of classification may not be the most appropriate as, for instance, the same formation mechanism may produce pores with different morphologies and/or sizes depending on the mineralogy of the shale. This is the case with the dissolution mechanism, which can produce at least two types of pores - plus microfractures - according to Milner et al. (2010) and Huang et al. (2013), spanning over two orders of magnitude of length (see Table 2). In addition, identifying pore types according to their formation mechanism may be biased due to the quality and thus interpretation of the images. Finally, the identification of dissolution fractures by Huang et al. (2013) raises the question of how to consider the origin of microfractures in shale - as a product of a (hydro-thermo)-mechanical rupture process or of a chemical process - and how to differentiate them from elongated pores in some circumstances.

Conversely, Desbois et al. $(2009,2010)$ chose to identify and classify pore networks on the basis of pore morphology, size, distribution, connectivity and topology, geometrical relationships between the pores and surrounding grains, and whether or not the characteristics were induced by handling the samples or whether they were naturally present in situ at depth. They distinguished three types of pore morphology (Figure 5): I, which consists of elongated pores between similarly oriented clay sheets $(<100 \mathrm{~nm})$; II, which contains crescent-shaped pores in saddle reefs of folded sheets of clay (100 to $1000 \mathrm{~nm}$ ); and III, which are large jagged pores surrounding clast grains (typically $>1 \mu \mathrm{m}$ ) (Desbois et al., 2010). Microfractures are not taken into account. Following this classification scheme, Heath et al. (2011) extended the distinction to seven descriptive groups (see Figure 5), including pore types I-III (Desbois et al., 2009, 2010), and adding pore types IV-VII: IV, pores in organics with two subtypes, IVa (circular and/or tubular pores) and IVb (slit-like pores); V, which refers to microstylolite or other diagenesis-related pores; VI, for natural or induced microfractures; and VII, which 
designates pores in pyrite framboids (Figure 5). Such a classification seems to cover all pore geometries, includes relationships between porosity and context, and is available for both continental and marine environmental deposit conditions, as suggested by the observations of Houben et al. (2013). It presents some universal characteristics for studying shale porosity. However, the extension including types IV to VII is questionable as it introduces a distinction between identification based purely on pore morphologies (types I to III) and a mix of morphologies and locations/origins (types IV to VII). Besides, according to Heath et al. (2011), type I pores have sheet-like or fracture-like geometries, and types V and VI have a generally planar, slip-like morphology. So, once again, the distinction between elongated pores (type I), diagenesis-related pores (type V) and microfractures (type VI) is largely subject to the observer's opinion rather than to a clear morphological difference. According to Heath et al. (2011), pores of types I to III are remnant pores, i.e. created in the primary depositional environment, while pores of the other types are secondary or related to postdepositional processes. Thus, while elongated pores measuring several micrometers may be the result of the coalescence of nanopores (most often via chemical processes), microfractures can only result from secondary processes occurring after shale deposition, implying tension stresses (thermo-chemo-mechanical processes). All these categories of pores are displayed in Figure 5.

More recently, several studies have proposed to distinguish fractures between themselves, identifying not only micro-tectoclases and microfractures (Zeng et al., 2013; Guo et al., 2014) but also diagenetic shrinkage joints, interlayer lamellation fractures and interlayer sliding fractures. Tectoclases define fractures formed by or associated with the local tectonic environment (Zeng et al., 2013) and can be subdivided into two categories: tension cracks (fracturing in mode I) and shear cracks (fracturing in mode II and III). Micro-tectoclases cut through and connect the porosity - namely interparticle, intraparticle, and dissolution pores (Zeng et al., 2013). They can display different intersection angles with the bedding plane and even cut through bedding (interlayer) fractures (Guo et al., 2014). Following this distinction, microfractures then only refer to chemogenic fractures (Zeng et al., 2013) formed as a result of drying shrinkage, dehydrolysis and more generally thermal contraction, which may be enhanced by contrasting mineral facies. They are the microscale equivalent of diagenetic shrinkage joints. Guo et al., (2014) identified interlayer lamellation fractures as porosity sitting between horizontal bedding lamina planes with parting lineation. If apparent slip traces are observed, then the fractures are designated as interlayer sliding fractures. 
Distinguishing cracks apparently formed by tensile strength failure from those formed by thermo-hydro-chemical processes is at first sight a good classification as it potentially also indicates the origin of crack formation. Yet, these definitions also overlap with those of pores. As a consequence, the distinction between elongated pores and microfractures can remain blurry in many cases. Despite these various attempts to carefully identify and classify the pore space to help predict porosity and guide upscaling of measurements, the origin (natural or induced) of microfractures remains a debated topic.

\section{[Table 2 about here]}

After the formation of a microfracture, several processes may act to close it: a local change in stress state, inelastic deformation of the matrix, and precipitation of minerals. Groundwater or hydrothermal fluid flow may occur, allowing minerals to precipitate and seal the fracture. The materials filling microfractures are mostly calcite, quartz and pyrite, either pure or combined in various percentages (Zeng et al., 2013); dolomite, barite, feldspar and clay minerals can be found more exceptionally. Hydrocarbons, including viscous bitumen, can also fill these fractures. When several generations of filling by various minerals have occurred, cathodoluminescence microscopy is often used to identify them (Gale et al., 2014). However, it is often challenging to identify at which depth the mineralization occurred and for how long the fracture remained open.

Recent developments in geochemical dating, for example using the rhenium/osmium technique, now allow precipitations of small scale objects in shales to be dated (Stein and Hannah, 2015). These isotopes concentrate into the organic matter and their lifetimes span the geological record. They can be used to date the age of shale maturation, and therefore microfracture development. However, how much this dating technique could be improved to measure the duration of the maturation process and not only the age of its onset remains an open topic.

\section{[Figure 8 about here]}

To conclude, pores can be classified according to their size, shape, and mechanism of origin. Some pores form during deposition and burial, others during the long-term maturation of the shales. In all cases, they can act as initial flaws for the propagation of microfractures whose size and shape deviate significantly from those of the initial pores. However, when and for how long such microfractures remained open is still an open question. 


\subsection{Methods of microfracture identification}

\subsubsection{Direct methods}

Traditional two-dimensional imaging techniques such as optical microscopy and scanning electron microscopy (SEM) provide a view of the material from 0.1 micrometers to a few millimeters or even centimeters (Figure 7). Thin sections are used to characterize the texture and to interpret matrix composition, component arrangement, millimeter and smaller scale lamination, as well as the distribution of organics (Milner et al., 2010). According to these authors, they also provide context and relative reliability for SEM samples as porosity in shale is mainly visible at lower scale (Figure 1). Backscatter SEM (with argon-ion milled samples) offers access to smaller fields of investigation than optical microscopy. The grayscale is proportional to the density; the very flat surface highlights the arrangement of the fabric elements and the visible porosity (including microfractures) has well-defined outlines (Milner et al., 2010).

More recently, different multi-scale imaging techniques have been coupled to elucidate and characterize the spatial organization of shale porosity, from optical microscopy (Figure 1a) to micro- or nano-tomography including, but not exclusively:

- $\quad$ (synchrotron) X-ray microtomography (Figures 2b, 2d, 3a, 8f-g, 9d-f, 10);

- field emission/environmental/secondary electron/backscatter electron/ cryogenic temperature scanning electron microscopy (FE/E/SE/BSE/cryo-SEM), see Figures 1b, 1c, 3, 4a, 4c, and 8 a-c;

- transmission electron microscopy (TEM);

- broad ion beam/focused ion beam scanning electron microscopy (BIB/FIB-SEM), see Figure 1d.

These techniques are a means of directly imaging shale porosity in 2D or 3D (Figures 9, 10) and provide qualitative and quantitative analyses and descriptions of their porous space (size, shape, as well as organization of elementary particles and of the porous network within the material). The challenge when dealing with shale samples is that they contain water that should not evaporate and disrupt the sample's microstructure during the measurements. This is less critical for 3D non-destructive imaging such as X-ray microtomography, but can be crucial for 2D high-resolution imaging, where microscopes will be working with wet environmental conditions. 
The X-ray microtomography technique (Figures 9c-f, and 10) is useful for characterizing microfractures in detail. Their connectivity can be measured, separating between dead-end microfractures and a percolating network. When imaging individual microfractures, their branching properties and the roughness of their walls can be clearly quantified and used later for simulations of flow in realistic 3D porous media.

\section{[Figure 9 and 10 about here]}

All these 2D and 3D analytical methods explore the porous environment of shales in different but often complementary ways. Models and classifications have been developed on the basis of the overall information collected at each step. These methods are complementary to other methods where the porosity is measured by an independent set of techniques. These different techniques and the resolutions associated with the measurements are discussed here, together with their main advantages and limitations (see Table 2).

In general, the reference values for total connected porosity, including microfractures, are obtained from the difference between grain density and bulk density, which are measured by helium pycnometry and mercury immersion, respectively (Chalmers et al., 2012a; Chalmers et al., 2012b; Tian et al., 2013). Connected porosity can also be obtained by measuring water content porosity, but this method does not reflect effective porosity, i.e. the porosity accessible to free water, because a film of water covers the tips of crack-shaped pores and clay-bound water covers the pore walls (Saarenketo, 1998; Desbois et al., 2010). Macroporosity (according to the IUPAC classification) is characterized by mercury porosimetry (Yven et al., 2007). The surface area and pore size distribution of the mesoporosity typically result from low pressure nitrogen and carbon dioxide gas adsorption coupled with mercury injection capillary pressure (MICP) (Chalmers and Bustin, 2007a, b; Yven et al., 2007; Ross and Bustin, 2009; Mastalerz et al., 2012; Kuila and Prasad, 2013; Schmitt et al., 2013) or small and ultra-small angle neutron scattering techniques (SANS/USANS) (Clarkson et al., 2012; Mastalerz et al., 2012). Microporosity is determined by nitrogen adsorption (Yven et al., 2007). The MICP technique intrudes a non-wetting liquid into the sample at sufficiently high pressure: the higher the pressure the smaller the pore throats filled with mercury (Abell et al., 1998). Consequently, some possible artifacts can be produced by mercury injection, such as pore collapse. Together with the surface roughness of the sample, it can lead to overestimated porosity. However, while microscopic observations are typically performed on sample areas of the order of $10 \mu \mathrm{m}^{2}$, MICP and water content measurements are obtained on $\mathrm{cm}^{3}$ samples. The size of an elementary volume representative 
of porosity therefore has to be determined very carefully before extrapolating any values. As a result, the porosity depends on both the technique used to measure it and the volume of the sample investigated. Some porosity measurements on two shales using different techniques are presented in Table 3, and the variations are indicated.

\section{[Table 3 about here]}

Fossils and minerals, as well as the morphology of organic matter, are easier to characterize with three-dimensional images obtained either with focused ion beam secondary electron SEM (FIB-SE-SEM) or with X-ray microtomography techniques (Figures 3c-d, 4b). Lowdensity features, including pores (Figures 3b, 4a) and fractures (Figure 7), and also kerogen (Figures 3a, 4d) can be clearly observed, segmented, and quantified for relative abundances and volume distributions. Shape identification can be performed with synchrotron X-ray microtomography (Kanitpanyacharoen et al., 2012, 2013). However, the total porosity of a shale, which includes pores at nanoscale, is substantially smaller when measured by X-ray tomography due to the voxel resolution ( $\sim 0.3$ micrometer), which is the current limit of synchrotron microtomography. Maximum pore diameters observed in SEM micrographs are of the order of 1 to 10 micrometers (Houben et al., 2013) and in the 2-200 micrometer range when measured with multi-resolution synchrotron X-ray tomography (Figure 6c). Due to the limitation of resolution, only micrometer-scale and larger pores and fractures can be investigated adequately by these methods (Milner et al., 2010; Kanitpanyacharoen et al., 2012). Thus the porosity observed cannot account for the total porosity and fracture (and kerogen) content.

Three-dimensional mapping methods have been developed for TEM (Midgley et al., 2007), FIB etching (Elfallagh and Inkson, 2009; Keller et al., 2011), synchrotron X-ray nanotomography (Heim et al., 2009) and scanning transmission X-ray microscopy at microscale (Bernard et al., 2010; Holzner et al., 2010) or nanoscale resolutions (Kanitpanyacharoen et al., 2012). Field emission scanning electron microscopy/transmission electron microscopy (FE-SEM/TEM) and focused ion beam scanning electron microscopy (FIB-SEM) have also been successfully used to observe the shapes, sizes and distributions of shale nanoporosity (Loucks et al., 2009; Bernard et al., 2012; Chalmers et al., 2012a; Milliken et al., 2013; Tian et al., 2013). Combining ion milling techniques (focused ion beam and broad ion beam), cryogenic techniques and SEM imaging even allows elusive in-situ microstructures in wet geomaterials to be studied (Desbois et al., 2008; Desbois et al., 2010; Houben et al., 2013) (Figure 7a-c). With this range of techniques it is possible to quantify 
517

518

519

520

521

522

523

524

525

526

527

528

529

530

531

532

533

534

535

536

537

538

539

540

541

542

543

544

545

546

547

548

porosity (Figures 1d, 3a, 3b), stabilize in-situ fluids in pore spaces, preserve natural structures at nm-scale, produce high-quality polished cross-sections for high resolution SEM imaging and accurately reconstruct microstructure networks in 3D by serial cross-sectioning (Desbois et al., 2010). The broad ion beam (BIB, argon source) is suitable for producing large (representative) polished cross-sections with an area of a few $\mathrm{mm}^{2}$, which corresponds to the typical size range of microstructures and representative elementary area of geomaterials; the focused ion beam (FIB, gallium source) is better used for fine and precisely polished crosssections with areas of a few hundred $\mu \mathrm{m}^{2}$ (Desbois et al., 2009; Desbois et al., 2010). However, preparing the samples means they have to be dried (either air-dried, oven-dried or freeze-dried), which causes them to lose up to $\sim 10 \%$ in volume. It is therefore difficult to identify the origin of the visible cracks observed, which range from several to hundreds of micrometers, as they may be related to drying or stress relaxation. New non-destructive highresolution imaging methods are thus needed to show whether or not these microfractures are present in the 'in-situ' samples or form as they are dried. Moreover, the interconnectivity of the smallest pores is difficult to analyze because the current distance between slices is 500 $\mathrm{nm}$, which limits spatial resolution in the third dimension of the sample. Again, new techniques reducing slice distances to $20 \mathrm{~nm}$ will be able to produce high-resolution models of pore spaces, including nanofractures, with the possibility of modelling fluid flow and microstructure-based models of transport in clays (Fredrich and Lindquist, 1997; Bons et al., 2008; Desbois et al., 2009; Desbois et al., 2010).

The volume of porosity calculated, observed and quantified appears to be biased at several steps. Firstly, pore and microfracture sizes and distribution are highly dependent on shale deposition conditions, plug sample orientation, and sample preparation methods. Indeed, microfractures are often related to dehydration processes and possibly internal elastic strain release during core extraction and/or sample preparation. Secondly, mercury injection capillary pressure measurements involve pressure conditions that encompass different in-situ types (such as reservoir depth) while other methods are performed at ambient pressure, which may result in more open porous spaces and cracks. So, the relative distribution, scales and morphologies of pores and microfractures has to be quantified and qualified using representative elementary volumes of shale in order to smooth out the expected natural variations from sample to sample. Multiple scales and methods must also be used in upscaling the observations. Finally, many studies consider microfractures to be unrelated to 
the 'real' porosity of the rock. This questions the role of microfractures in the petrophysical properties measured and which type of objects they form. This point is considered below.

A recent technique, based on force spectroscopy using an Atomic Force Microscope, maps the mechanical properties of rocks at nanometer scale. This has been applied successfully to several shale samples, where the Young's modulus could be mapped with a spatial resolution of several nanometers (Eliyahu et al., 2015). Assuming a value of the Poisson's ratio, it was shown that the Young's modulus of the organic matter was in the 0-25 GPa range, much lower than the value measured for the other minerals constituting the shales. Moreover, this organic matter seemed to be surrounded by a stiffer shell 50-100 $\mathrm{nm}$ thick, protecting it from deformation in the sample considered in the study by Eliyahu et al. (2015). This result needs to be confirmed by analyzing other types of shale. This force spectroscopy method is complementary to micro-indenter characterization (Bobko, 2008), which can be used to probe individual constituents of the shale at scales of tens of nanometers, that could not be reached before, where rock heterogeneities are observed. Maps of the mechanical properties of the shale at scales of a micron to tens of microns are produced and can be used to upscale mechanical models of microfracture propagation. A future development would be to measure the viscous properties of the shale constituents. This would be useful in determining how microfractures in shales close slowly due to the viscous relaxation of the matrix. These micromechanical probing techniques are therefore complementary to imaging techniques. Coupling them represents a future challenge in studying the $3 \mathrm{D}$ mechanical properties of shales.

\subsubsection{Indirect methods}

Elastic waves are sensitive to the heterogeneities in the medium they travel through (e.g. Guéguen and Palciauskas, 1994). This property is fundamental when studying the elastic anisotropy of rocks. Shales are in fact the most well-known anisotropic rocks, mainly due to their clay layering microstructure. However, shale samples subjected to increasing pressure coupled with elastic wave measurements during experiments have revealed a superimposed effect of preferred orientation porosity consisting mainly of high aspect ratio features commonly designated as crack-like pores, elongated pores or microfractures. This anisotropic porosity can be observed when measuring elastic wave propagation at ultrasonic velocity. However, elongated pores and microfractures cannot be differentiated when measuring shear and compressive elastic wave velocities, $V_{p}$ and $V_{s}$, respectively. This has been demonstrated in micromechanical models, where elongated pores or microfractures can be modelled as 
582

583

584

585

586

587

588

589

590

591

592

593

594

595

596

597

598

599

600

601

602

603

604

605

606

607

608

609

610

611

612

613

open voids with a large length-to-aperture aspect ratio. For example Sarout and Guéguen (2008b) calculated elastic anisotropy and predicted wave velocity as a function of the density of the heterogeneities in a solid containing two kinds of voids, either microfractures with flat terminations or elongated ellipsoidal pores. In both cases, when the aspect ratio of the voids increases (i.e. when the elongated pores look more and more like microfractures), the predicted elastic wave velocities converge to the same values. As a consequence, these models can predict how elastic waves velocity varies with void density but they cannot separate between elongated pores and microfractures when considering the origin of the heterogeneities in the shale. In conclusion, these indirect methods of characterizing elastic anisotropy by measuring the anisotropy of elastic wave propagation can help in estimating the quantity of heterogeneities present, but cannot distinguish between elongated pores and microfractures.

\subsection{Microfracture shape, orientation and distribution}

In general, minerals and pore space in shales have a strong preferred orientation within the bedding plane due to the sheet structure of the clay platelets. Microfractures further enhance this intrinsic anisotropy as they too are most often observed parallel to the bedding plane (Vernik, 1993, 1994; Vernik and Liu, 1997; Kanitpanyacharoen et al., 2012). But some microfracture families can also be oriented perpendicular to the bedding plane (e.g. Breyer et al., 2012; Padin et al., 2014).

The common explanation for the presence of microfractures is that they are related to the stress history of the rock: the actual splitting apart of the rock fabric occurs in the direction of least resistance, i.e. perpendicular to the minimum in-situ stress direction or least principal stress. So, when the overburden produces the maximum stress, which is generally the case at depth, the least principal stress is horizontal and fracturing should be vertical (assuming a horizontally uniform stress field). However, initial flaws and microfractures, as well as kerogen particles, are usually aligned parallel to the bedding plane, as reported above. Since the early days of hydraulic fracturing research, a number of authors have argued the possible existence of horizontal fractures at high overburden pressure and depths (e.g. Howard et al., 1950; Scott et al., 1953). In fact, if the internal production of fluids due to the maturation of organic matter or the dehydration of clays creates abnormal overpressures - although these dilatant pathways might be unstable as they form, propagate and collapse following a hydro- 
mechanical process - then the effective overburden stress is much lower, meaning that it is not necessary to lift all of the overburden stress to create horizontal dilatant pathways (Padin et al., 2014). Microfractures may thus occur mainly parallel to the bedding plane (e.g. Keller et al. 2011; Harrington et al., 1999).

At micrometer scale, the experimental application of tensile stress to samples has produced artificial microfractures that are aligned within mineral grains (Slatt and O'Brien, 2011). Therefore, local density contrasts, due to either stiff mineral grains or compliant kerogen patches, also significantly account for microfracture orientation (Ding et al., 2012; Sayers, 2013).

More generally, given the diversity of shales and the dependence of preferred orientation on stress history, mineralogy and kerogen content, variations in the preferred orientation of microfractures probably cannot be attributed to a single factor. However any microfractures which appear to interconnect larger pores observed within the bedding plane can be potentially considered to have a natural origin. They may also attest of the presence of hydrocarbons (e.g. Vernik et al., 1993, 1994; Chalmers et al., 2012a).

The number of microfractures is commonly described in terms of crack density. In general and in the absence of specific information, this reflects the frequency of fracture occurrence in a borehole core and is called linear density (Zeng et al., 2013). Two other types of fracture density are also employed in oil and gas reservoir engineering: the areal density, which refers to the ratio of cumulative fracture length to a core unit area, and the volume density, which refers to the ratio of the total area of fractures to a core unit volume (van Golf-Racht et al., 1982). The density of microfractures depends on both the initial structure of the rock and the processes that control their formation, as described below.

\section{Processes of microfracture formation in shale rocks}

According to Vernik (1994), there are five possible explanations for the presence of microfractures in the borehole core samples retrieved from depth or in outcropping samples: 1) differential elastic rebound of constituent minerals caused by overburden stress relief, 2) overburden relief-induced micro-hydraulic fracturing (decrepitation) of overpressured fluid inclusions, 3) concentrated bottom-hole stressing eventually leading to core disking, 4) induced cracking due to expulsion of water or cracking of organic matter, and 5) existence of microfractures in situ due to tectonic deformations. Processes 1) to 3) appear basically to be 
technogenic ones, i.e., they are related to drilling and core recovery operations although it is not yet clear whether microfractures due to fluid overpressure effects only appear during core recovery (i.e. decompression) or can be features preserved at depth. We also note that the first two are linked to internal (non-tectonic) factors in the rock while the third one is correlated to external forces (tectonic factors). The last point 5) does not explain which processes created the microfractures. In fact, many factors influence the development and distribution of natural and induced microfractures in shale rocks and the existence of microfractures mostly depends on their combination throughout the history of the shale, from sedimentation to exhumation. But only two processes constitute the main possible explanations for their initiation: (i) induced stresses owing to tectonic forces and stiffness variations within the rock, which produces the tectoclase type, and (ii) functioning mechanisms of hydrocarbon generation and fluid migration, which produces the chemogenic type.

In all these processes, fracture propagation has several common properties rooted in the physics of solid fracturing. The propagation of a fracture corresponds to the transformation of a potential volumetric strain energy into surface energy through the creation of new interfaces in the solid. This potential energy is created by the build-up of elastic strain energy that may originate inside or outside the solid, and is released during fracture propagation. This process was first defined by Griffith (1921), who developed the basic principles of linear elastic fracture mechanics. He provided a criterion for fracture propagation, where a critical stress $\sigma_{\mathrm{c}}$ must be overcome at the tip of an existing flaw for it to propagate further as a crack: $\sigma_{\mathrm{c}}=$ $\sqrt{\frac{2 \mathrm{E} \gamma}{\pi \mathrm{a}}}$, where $\mathrm{E}$ is the Young's modulus of the solid, a is the length of the initial crack or flaw or elongated pore and $\gamma$ is the surface energy necessary to create a new surface.

From this basic physics principle, and from observations of the existence of microstructures at nanometer to micrometer scales in shale samples, it is clear that fracture propagation is extremely complex because the critical stress $\sigma_{\mathrm{c}}$, the Young's modulus E, the size a of initial flaws and the surface tension $\gamma$ all vary at various spatial scales. One difficulty arises from the existence of heterogeneities at all scales, and a second difficulty is that some of these parameters are difficult to measure. While the Young's modulus of the different minerals and kerogen can be found in the literature and measured even at nanometer resolution using atomic force spectroscopy (Eliyahu et al., 2015), surface tension measurements are less easy to collect. Surface tension between water and minerals ranges from 0.1 to $1 \mathrm{~J} / \mathrm{m}^{2}$, is materialdependent and also depends on the type of liquid (water, oil, gas) that wets the newly created 
fracture (see for example the study of Atkinson (1989) and recent studies of the surface tension of calcite (Røyne et al., 2011; Rostom et al., 2013; Bergsaker et al., 2016). Finally, upscaling the effects of these spatial heterogeneities during fracture propagation is a key challenge. Several approaches developed in the past 50 years involve the transition from ductile to brittle deformation (Rice and Thompson, 1974) and damage mechanics (Kachanov, 1958) to take into account the propagation of a fracture while the surrounding rock deforms. The challenge is that the elastic properties will evolve with the scale and damage, and could be scale-dependent. Similarly, the strength of rocks depends on the spatial scale considered (Weiss et al., 2014). Such procedures will not be developed here, as they are beyond the scope of the present review. Instead, we will focus on the internal and external processes that control stress build-up in shales.

\subsection{Internal or non-tectonic factors for microfracturing}

Several non-tectonic factors influence the degree of microfracture development in shale. The mineral composition plays a significant role, followed by the mechanical properties and mineral/organic carbon content of the shale, abnormal pressures (including fluid overpressure effects), shale thickness, dehydration and ductile properties of the clay minerals, compaction and pressure solution during shale diagenesis, thermal shrinkage, differences in dissolution processes, weathering, and erosion (e.g. Hill et al., 2002; Ding et al., 2012; Zeng et al., 2013).

\subsubsection{Mineral and organic carbon content}

During hydrocarbon generation, the thermal evolution of the organic matter generates acidic fluids (organic acids, $\mathrm{CO}_{2}, \mathrm{H}_{2} \mathrm{~S}$, etc.). These fluids probably improve the porosity by dissolving carbonate and feldspar minerals. And as porosity increases, so does the susceptibility of the shale to fracture under external forces (Jarvie et al., 2003; Zeng et al., 2013). In this context, the shape of the kerogen patches controls the orientation of microfracturing: high aspect ratios or thin flakes of kerogen favor horizontal microfractures, while low aspect ratios or round-shaped kerogen favor vertical fractures (Lash and Engelder, 2005).

High organic matter content also generates gas as it decays, which enhances fracture formation from both internal and external forces. If confirmed, this means that the total organic content is likely to be the dominant factor governing microfracture development in 
shale that has a highly homogeneous mineral distribution in the longitudinal direction (Zeng et al., 2013). Microfracturing due to the decomposition of kerogen into bitumen may thus be the rule rather than the exception (Vernik, 1993, 1994; Vernik and Liu, 1997; Lash and Engelder, 2005; Padin et al., 2014).

However, it has been observed that the fracture density can be negatively correlated with total organic content, as for instance in the Niutitang shale (Zeng et al., 2013). There, fractures and microfractures are highly developed in shales characterized by an absence of organic content. It may be said that high total organic content seems to inhibit microfracture development in this shale, but such a statement neglects the impact of mineral composition on fracture development. In fact, Slatt and Abousleiman (2011) argue in favor of crystallographic control of microfracture initiation. In this context, shale brittleness probably results from the brittle minerals it contains, namely quartz and calcite. This relationship has been pointed out in several studies (Nelson et al., 2001; Hill et al., 2002; Nie et al., 2009; Li et al., 2009; Ding et al., 2012; Zeng et al., 2013). Hill et al. (2002) determined that the high brittleness of the black shales of the Appalachian Basin (New York) was related to its quartz content and gray shales rich in calcite are said to be more "plastic" in comparison (Hill et al., 2002; Nie et al., 2009; Li et al., 2009). During artificial fracturing, silica-rich shales were more prone to fracturing than clay-rich shales (Li et al., 2007; Tan et al., 2009). Nelson et al. (2001) further added feldspar and dolomite as minerals responsible for the brittleness of dark shales. In Zeng et al. (2013), microfracture development is quantified in relation to mineral content, thereby establishing a histogram of relationship between quartz and dolomite content and linear fracture density for the Niutitang shale. Finally, it may be concluded that if a shale contains more brittle minerals than swelling clay minerals, it is likely to be brittle and thus it has a better capacity to fracture. Furthermore, in the case of shales with similar mineral compositions, it has been shown that the finer the grain size, the more conducive the shale is to fracture development (Zeng et al., 1999; Li et al., 2009).

\subsubsection{Layering}

Fractures normally develop where there is a change in lithology. Thus the change in atomic bonds between laminae in shales with developed foliation is likely to be the site of contrasting stress fields. Interlayer fractures in fact often appear at the interface between clay and carbonate laminae (Jiu et al., 2013). They are similar to the microfractures observed between clay and calcite minerals but at a larger scale. They result from the macroscopic connection of interlayer microfractures both horizontally and vertically (Jiu et al., 2013). 
Thus, they have a significant influence on the connectivity of the pore space (Jiu et al., 2013; Xu et al., 2009).

\subsubsection{Overpressure caused by organic matter maturation}

During shale formation, fluids are generated as the organic matter matures causing local volume increases with resultant anomalously high pressure. These overpressures locally lower the effective overburden stress, favoring the development of microfractures oriented mainly parallel to the bedding plane. Some observations describe these microfractures as irregular in the fracture plane, not developed in groups and mostly filled by high viscosity organic matter such as bitumen (Jiu et al., 2013; Guo et al., 2014). They are likely to be the result of elongated pore growth and coalescence at the edge of organic matter and minerals, and thus often have branches within the range of the stratum (Jiu et al., 2013). A superimposed unloading effect as a result of (natural or not) uplift can further enhance this microfracture network (e.g. Petmecky et al., 1999; Muñoz et al., 2007).

A series of laboratory experiments reproduced the maturation of organic matter in immature shales with in-situ visualization of the fracturing process, either under a scanning electron microscope (Allan et al., 2014) or using time-lapse synchrotron X-ray microtomography (Kobchenko et al., 2011; Panahi et al., 2012). These experiments show that microfractures initiate in the patch of kerogen, where fluids are produced and fluid pressure builds up, and then propagate preferentially along the direction of layering (Figure 11). One series of experiments was performed with a small amount of confining pressure and showed that two perpendicular fracture networks may form, creating a 3D connected microfracture network (Figure 11h).

To study this process, analogue experiments have been performed using a transparent brittle gel with internal gas production (Bons and van Milligen, 2001; Kobchenko et al., 2013, 2014). In these systems, $\mathrm{CO}_{2}$-producing yeast was mixed into a brittle solid (i. e. the gel). With gas production, microfractures nucleate in the elastic solid and then propagate, leading to a well-developed fracture network in which the fracture dynamics can be followed by optical means. Several conceptual results are found in these experiments. Firstly, the drainage fracture network produced has geometrical and topological properties that are intermediate between those of two end-member drainage networks found in nature, namely river systems and hierarchical fracture networks (Kobchenko et al., 2013). Secondly, the dynamics of individual fracture opening and closing are rather complex, with power-law time dependence, 
due to the long-range elastic interactions in the solid (Bons and van Milligen, 2001, Kobchenko et al., 2014). Moreover, these experiments show that fractures are intermittent and close once all the gas has been produced in the solid and escaped from it. When scaled to nature, these experiments show that the fracture dynamics are controlled by several parameters, including the amount of fluid that can be produced during maturation, the kinetics of maturation, the permeability and elastic parameters of the solid and the thickness of the elastic layer where these fluids are produced. Finally, these experiments also show that once the fractures have been formed, they may close completely when the fluid produced has escaped, leaving well-defined, low-cohesion interfaces. Making an analogy with shales, microfractures therefore appear to form during maturation and then close. When closed, their transport properties are similar to those of the shale matrix. However, if the fluid pressure increases, they can be reopened preferentially, providing for example pathways during hydraulic fracturing operations.

Based on these in-situ and analogue experiments, it may be concluded that the maturation of organic matter in shales can produce a microfracture network, with well-defined geometrical characteristics, in which the fractures remain open for a given time. The development of new experiments and models in which the solid is confined during microfracturing by internal fluid production and contains heterogeneities at several scales would be an important step. It would help to gain a better understanding of the physical process in $3 \mathrm{D}$ and its scaling to natural shale layers.

\section{[Figure 11 about here]}

\subsubsection{Dehydration/thermal shrinkage}

The hydration and/or dehydration of swelling clay minerals are rapid processes that can generate structural modifications such as opening/closing of pores and/or microfractures in the rock, which depend directly on the kind of clay present and the proportions of minerals in it (Figure 12). This process is likely to occur during burial and diagenesis, when shales can be subject to shrinkage and volume reduction (Guo et al., 2014). This is due to the fact that clay will release water during diagenesis. In performing thermodynamic calculations, it is expected that $300 \mathrm{~kg}$ of water will be released per cubic meter of dry clay when smectite minerals are dehydrated during burial (Vidal and Dubacq, 2010) and transformation into less hydrated clays. In laboratory experiments, Montes-Hernandez et al. (2004) observed progressive and complex cracking over several hydration/dehydration cycles in Bure shale. 
They found that the mode of fracturing was linked to the dominant family of clay in the rock, i.e. progressive cracking is characteristic of non-swelling clays (such as kaolinite) and complex cracking (opening/closing of cracks and/or pores) of swelling clays (such as interstratified illite/smectite). As more and more hydration/dehydration cycles are performed, the thermo-chemically induced microfractures in illite minerals open wider (Figure 12a-c), while in smectite minerals the microfractures heal during hydration except when they interact with a hard mineral (Figure 12d-f). This experimental result is supported by observations performed in the Longmaxi Shale (Zeng et al., 2013; Guo et al., 2014), where the chemogenic occurrence of natural microfractures could be identified. Microfractures due to shrinkage processes are observed particularly in shales with a high clay content and well-developed horizontal bedding, such as the lacustrine shale of the Zhanhua Depression (Jiu et al., 2013). These authors also noted that the microfractures were partly filled, usually small and widely distributed.

\section{[Figure 12 about here]}

\subsection{External or tectonic and reservoir exploitation factors}

Tectonic factors are external causes of rock failure; they relate to the accumulation and release of tectonic stresses coeval with fault activities (Zeng et al., 2013) and generally include regional tectonic stresses, tectonic position and sedimentation diagenesis (Guo et al., 2014). In reservoir contexts, they also include the release of stresses from drilling and recovery as well as hydraulic fracturing. The propagation of these tectonic fractures is also controlled by the pre-existence of microfractures and other heterogeneities in the rock.

At reservoir scale, tectonic fractures are formed during the concentration and release of tectonic stresses and develop mainly within the breaking points of fold structures as well as in the vicinity of fault zones or during the flexure of sedimentary layers caused by salt diapirs. It is highly probable that areas experiencing the greatest stress variation gradient would be most favorable to microfracture development. The Niutitang and Longmaxi shales are both black shales from the south-eastern area of the Sichuan Basin, and are within the same tectonic setting. Yet, according to Zeng et al. (2013), fractures are more developed in the Niutitang shale than in the Longmaxi shale. The authors explain this difference as being related to the high brittle mineral content of the Niutitang shale compared to the Longmaxi shale: a high 
proportion of brittle minerals would lower the tensile strength of the shale, thus facilitating the formation of microfractures under tectonic/external factors.

At meso and greater scale, most fractures develop under regional or local tectonic stresses and are classified either as tensile fractures (which include joint fractures), usually with a relatively low angle, or shear fractures, with a relatively high angle. At microscale, cracks open and shear in response to the tectonic stress in a similar way (Zeng et al., 2013; Guo et al., 2014). However, to our knowledge, direct evidence of the large-scale effect of tectonic forces on the development of microfractures at a regional scale remains to be found. This is due to the fact that, at a regional scale, a few fractures would relax most of the tectonic loading and screen the development of pervasive microfracturing in the entire volume. Gale et al. (2014) hypothesize a power law relationship for fracture width and length at mesoscale, using data from the Marcellus Shale and Austin Chalk. Extrapolating into the microfracture domain, Cuss et al. (2015) observed that the average spacing for fractures would be approximately 0.1 to $1 \mathrm{~m}$ which, according to them, would explain the paucity of microfracture data due to the low probability of microfractures being captured in core samples.

Recovering shales from depth may cause stress relief microfracturing due to decompression and gas exsolution from pore fluids (Dewhurst et al., 2011). Stress relief microfractures are often observed in scanning electron microscope images and are an unavoidable consequence of core recovery from depth. In the case of shales, they form mostly parallel to the laminations and clay particle orientation.

To conclude, the positive effect of total organic content and brittle minerals on the development of microfractures is due to the difference in compliance at the grain scale, which favors decoupling between grains and the nucleation of microfractures. As a consequence, a high density of microfractures could be related either to a high organic content, or, in the case of shales that have experienced an active tectonic environment, to the amount of deformation and also the amount of strong minerals they contain. Finally, we add here that if the influence of natural fracture populations on hydraulic fracture propagation has been considered (Gale et al., 2007; Zhao et al., 2012; Cuss et al., 2015), the potential interaction of natural and induced microfractures in shale formations and their role on hydraulic fracture propagation is poorly understood and represents a challenge for future studies.

\section{[Figure 13 about here]}




\section{Impact of microfractures on shale properties}

872

873

Microfractures in a shale will affect its mechanical and transport properties, but for this to happen they must be at least partly open. Indeed, the presence of an interface with no aperture into an elastic solid will have no effect on its elastic parameters or transport properties. With regard to microfractures effect on the strength of the shale, it is not significantly different from that in other types of rock: they will lower its overall strength. For example, samples of COx shale (Bure argillite) were cored perpendicularly, pre-confined to close all horizontal (parallel to bedding) cracks/microfractures (Sarout and Guéguen (2008a). They were then loaded axially at a confining pressure equal to $15 \mathrm{MPa}$. Measurements of elastic wave velocities $\left(\mathrm{V}_{\mathrm{p}}\right.$ and $\left.\mathrm{V}_{\mathrm{s}}\right)$ performed parallel to the bedding showed that the values decreased as axial stress increased, while the values of $\mathrm{V}_{\mathrm{p}}$ measured at $45^{\circ}$ and perpendicular to the bedding increased. The differential stresses induced microfractures (sub)perpendicular to the bedding, which could explain the variations measured in the elastic velocities. This is similar to what happens to other rocks deformed using the same kind of procedure (Sarout and Guéguen (2008a). But while shale rocks do not exhibit any specific behavior with respect to the effect of microfractures on their mechanical strength when compared to other rocks, they do exhibit specific behavior in terms of permeability and elastic anisotropy, as described below.

\subsection{Permeability}

It has been observed that in shales with similar mineral compositions, the finer the grain size, the more conducive the shale matrix will be to fracture development, (Zeng \& Xiao, 1999; Li et al., 2009). If microfractures are open and connected in 3D, they represent preferential paths for fluid circulation (Zeng et al., 2013; Padin et al., 2014). However, fluid flow may allow minerals to precipitate and seal the microfractures (Warpinski \& Teufel, 1987). Another mechanism is viscous relaxation of the shale matrix around the microfracture, which may also close it. The consequence is that the strength of the closed microfracture should increase with time because of an increase in contact surface area along the fracture interface, and even an increase in cohesion if sealing occurs (Warpinski, 1987). These processes modify the aperture of the microfractures and their compliance, and as such, modify the permeability as well. Permeability due to microfractures should therefore be transient during the history of 
902

903

904

905

906

907

908

909

910

911

912

913

914

915

916

917

918

919

920

921

922

923

924

925

926

927

928

929

930

931

932

933

934

such rocks: periods of active fluid transport are separated from periods where the rocks act as permeability seals.

In principle, fully filled microfractures act as fluid barriers and can be stiffer than the shale matrix. This is a possible explanation why, in reservoir conditions, hydraulic fractures can be blocked when they encounter natural fractures (Warpinski, 1987). However, according to Zeng et al. (2013), when the tensile strength of the contact between the sealing mineral and the shale wall rock is low, as in the case of calcite-filled fractures, the fracture-host boundary is weak and new fractures may propagate preferentially at the interface (see Figure 8f). Therefore the surfaces of microfractures are fragile as the filling material is not bound to the shale and are likely to rupture and become revitalized by internal or external loading factors.

Low microfracture permeability due to fracture wall roughness may also result in fluidsaturated fractures in shales being less compliant than those in sandstones (Dewhurst et al., 2011). As far as the microstructure is concerned, the strongly anisotropic connectivity observed in dried shale samples provides direct proof that the largest pores surrounding the quartz grains form a connected backbone $100 \mathrm{~nm}$ to several micrometers thick, oriented mainly parallel to the bedding (Desbois et al. 2010). It is therefore important to quantify the total porosity in shales and to determine as far as possible the proportion and geometry of i) the porosity involved in the transport phenomena and ii) the porosity associated with exchanges between the mineral interfaces and the fluid. Structural diagrams illustrating the organization of porosity in claystones have been proposed by Yven et al. (2007), who state that the clay domains form a fully connected porous matrix in which tectosilicate, carbonate crystals and bioclasts are enclosed, either isolated or forming clusters.

While the interaction between hydraulic fractures and natural fractures remains unclear, it is widely acknowledged that the presence of natural fractures has a positive impact on the permeability of a shale formation (Decker et al., 1992; Gale et al., 2007, 2014; Ding et al., 2012; Zeng et al., 2013). However, the effect of microfractures on shale permeability appears to be more balanced. Padin et al. (2014) propose that the microfracture networks that already exist in most organic-rich shales also act as permeable paths when fluid pressure is increased. In the context of shale gas reservoirs, developed microfractures enhance desorption of adsorbed gas and migration of shale gas (Zeng et al., 2013). However, the authors point out that, by connecting to a larger fault, developed microfractures are extremely unfavorable to the preservation of shale gas as they may lead to water breakthrough along fractures, producing water early, and this may even lead to serious water channeling. 
A comprehensive understanding of anisotropic transport phenomena fundamentally requires knowledge of the three-dimensional topology of the pore space and of the spatial distribution of the transport properties. In the context of gas transport, flow occurs in pores ranging in size from nanometers to several micrometers. Hence, information on pore connectivity, geometry and distribution over a wide range of scales is crucial (Keller et al., 2011). Therefore, when attempting to link porosity and permeability, it is important to characterize pore connectivity and the percolating network. An overall porosity can be measured for a volume sample of several cubic centimeters by using mercury injection porosimetry. Porosity characterization shows that the pore networks in fossils, pyrite aggregates and cracks are connected to the clay matrix down to FIB-SEM resolution (Figures 1d, 2b). Pore throats in the clay matrix, which form the pathways in the pore network, are close to and below SEM resolution (i.e. $10 \mathrm{~nm}$ in width, Figure 1d, 2b). This is in agreement with Keller et al. (2011), who found separated pore objects in their FIB-SEM data that are connected by pore throats smaller than $10 \mathrm{~nm}$. In addition to pore connectivity, pore morphology is also important (Coasne and Pellenq, 2004; Hilpert and Miller, 2001; Liang et al., 2000). For instance, the inner wall structure of the pores will influence fluid and/or gas flow rates through the clay.

At larger scales, comparisons between core plugs from the same reservoir but with different clay concentrations show that permeability is directly related to the amount of clay filling the pore space and to the orientation at which the permeability is measured (Padin et al., 2014). Anisotropic permeability is observed in Vaca Muerta shales from Argentina and Eagle Ford shale from the USA: the permeability is higher in the horizontal direction in specific horizontal layers within the rock. This could be interpreted as the effect of microfractures oriented parallel to the layering controlling most of the permeability.

Matrix permeability is also pressure-dependent. Firstly, it decreases as confining pressure increases and porosity is reduced. Secondly, Wang and Reed (2005) have shown that one effect of pore pressure is caused by the Klinkenberg slippage effect (Klinkenberg, 1941), and the degree of permeability reduction with confining pressure is significantly greater in shales than in consolidated sandstone or carbonate reservoir rocks. This is due to the pore throat distribution, which exhibits much narrower pores in shales (less than $100 \mathrm{~nm}$ ) than in other rocks, causing an increase in the Klinkenberg effect.

\subsection{Elastic anisotropy}


967

968

969

970

971

972

973

974

975

976

977

978

979

980

981

982

983

984

985

986

987

988

989

990

991

992

993

994

995

996

997

The preferred orientation of minerals and anisotropic pore spaces are important contributors to elastic and seismic anisotropy (Vernik and Nur, 1992; Hornby et al., 1994; Kanitpanyacharoen et al., 2011; Kanitpanyacharoen et al., 2012). Studies by Vernik (1993, 1994) suggested that the intrinsic anisotropy of organic-rich shales is further enhanced by bedding-parallel microfractures that were created during hydrocarbon generation. Due to the complex structure and poor crystallinity of clay minerals, quantifying the preferred orientation is a challenge. Several studies relying on traditional X-ray pole figure goniometry, e.g. (Curtis et al., 1980; Sintubin, 1994; Ho et al., 1995; Ho et al., 1999; Aplin et al., 2006; Valcke et al., 2006; Day-Stirrat et al., 2008a; Day-Stirrat et al., 2008b) and on synchrotron Xray diffraction techniques, e.g. (Lonardelli et al., 2007; Wenk et al., 2008; Voltolini et al., 2009; Wenk et al., 2010; Kanitpanyacharoen et al., 2011), have produced evidence that the preferred orientation of clay minerals increases with increasing clay content, burial depth, and diagenesis. Given the diversity of shales and the dependence of preferred orientation on provenance, clay mineralogy and bioturbation, the variation in preferred mineral orientation cannot be attributed to a single factor (Kanitpanyacharoen et al., 2012).

The property of elastic wave velocities to interact with the medium they travel through has been used to characterize shale microstructure indirectly. For instance, significant velocity changes were noted in the Muderong shale (Dewhurst and Siggins, 2006): the $V_{p} / V_{s}$ ratios in smectite-rich shales are intrinsically high and appear to increase with increasing mean effective stress below $25 \mathrm{MPa}$, but decrease at higher stress levels. Such high intrinsic $\mathrm{V}_{\mathrm{p}} / \mathrm{V}_{\mathrm{s}}$ ratios were interpreted as being due to the presence of smectite minerals, which contain water in their mineral structure. Conversely, the observed decrease in the $\mathrm{V}_{\mathrm{p}} / \mathrm{V}_{\mathrm{s}}$ ratio may be due to stress-induced dewatering of the smectites.

To describe the anisotropic elastic properties of shales in full, models usually assume they are a transversely isotropic medium, with an axis of rotational symmetry oriented perpendicular to the layers (e.g. Sayers, 2013, and references therein). The five independent, non-vanishing elastic stiffness parameters of the layered transversely isotropic medium are $\mathrm{C}_{11}=\mathrm{C}_{22}, \mathrm{C}_{33}$, $\mathrm{C}_{12}=\mathrm{C}_{21}, \mathrm{C}_{13}=\mathrm{C}_{31}=\mathrm{C}_{23}=\mathrm{C}_{32}, \mathrm{C}_{44}=\mathrm{C}_{55}$ in the conventional two-index notation (Nye, 1985); the sixth elastic stiffness is calculated as $\mathrm{C}_{66}=\left(\mathrm{C}_{11}-\mathrm{C}_{12}\right) / 2$. Thomsen (1986) combined these expressions in three dimensionless parameters, $\varepsilon, \gamma$ and $\delta$, defined as:

$$
\varepsilon=\frac{C_{11}-C_{33}}{2 C_{33}}, \gamma=\frac{C_{66}-C_{44}}{2 C_{44}}, \text { and } \delta=\frac{\left(C_{13}+C_{44}\right)^{2}-\left(C_{33}-C_{44}\right)^{2}}{2 C_{33}\left(C_{33}-C_{44}\right)} \text {. }
$$


998

999

1000

1001

1002

1003

1004

1005

1006

1007

1008

1009

1010

1011

1012

1013

1014

1015

1016

1017

1018

1019

1020

1021

1022

1023

1024

1025

1026

1027

These parameters can be used to characterize elastic wave propagation through weakly anisotropic layered media, such as shales (Figure 14). For instance, Vernik (1994) used Thomsen's parameters to observe that the magnitude of intrinsic anisotropy is enhanced at low effective stress by the presence of bedding-parallel (i.e. subhorizontal) microfractures (Figure 14b). Going further, Vernik (1994) proposed that these parameters can be used as a tool for identifying source rocks and mapping shale maturity, assuming that the pervasive bedding-parallel microfractures are the products of the main stage of hydrocarbon generation and migration, at least in kerogen-rich shale. Notably, upon filtering the intrinsic anisotropy, the inequality $\delta>\varepsilon>0$ is found to be characteristic of microfractures in black shales containing a free gas phase, while in oil-saturated microfractured shales, $\varepsilon>0>\delta$ applies (Vernik and Liu, 1997).

In conjunction with the associated $\mathrm{V}_{\mathrm{p}}$ and $\mathrm{V}_{\mathrm{s}}$ elastic wave velocities, models can separate the microfracture contribution and the rock matrix contribution in the overall anisotropy (e.g. Vernik, 1993; Sayers, 1994; Hornby et al., 1994; Sayers and Kachanov, 1995; Sayers, 1999; Jakobsen et al., 2003; Sayers, 2004, 2005; Sarout and Guéguen, 2008b; Ougier-Simonin et al., 2009).

$$
\begin{gathered}
C_{11}=\rho V_{P}^{2}\left(0^{o}\right), C_{33}=\rho V_{P}^{2}\left(90^{\circ}\right), \\
C_{44}=\rho V_{S V}^{2}\left(0^{o}\right), C_{66}=\rho V_{S H}^{2}\left(0^{o}\right), \\
C_{13}=-C_{44}+\sqrt{\left(C_{11}+C_{44}-2 \rho V_{P}^{2}\left(45^{\circ}\right)\right)\left(C_{33}+C_{44}-2 \rho V_{P}^{2}\left(45^{o}\right)\right)} .
\end{gathered}
$$

Using theoretical predictions to describe the rock matrix, it is possible to estimate the evolution of the anisotropy, for instance with the crack aspect ratio (Figure 14a) (e.g. Sarout and Guéguen, 2008b; Ougier-Simonin et al., 2009). Empirical evidence has shown that Thomsen's parameters are usually much less than 1 for most layered rock formations. Generally, the highest anisotropy is expected to be observed at low confinement, in dry shale with high aspect ratio porous space geometry - subsequently designated as cracks/microfractures, and will decrease with increasing depth/confinement and fluid saturation, and lower aspect ratio (Figure 14). Table 4 compiles several values of Thomsen's parameters for five different shales with different confining pressure conditions.

\section{[Figure 14 about here]}

[Table 4 about here] 


\section{Concluding remarks and future research directions}

During the last decades, petrophysical studies have provided detailed petrographic observations and analyses of shales. The present review shows that microfractures can be observed in shales, some of them being open, others being sealed by mineral precipitation or just closed elastically. These microfractures nucleate along heterogeneities initially present at all scales in the shale rocks, then propagate and may connect in 3D. The mechanisms at their origin involve dehydration of the clays and release of water, maturation of organic matter leading to the primary migration of hydrocarbons, or external tectonics or technogenic factors.

Whether microfractures are produced by internal or external loading, for a given microfracture it is not possible yet to decipher which kind of loading controlled its formation. Nevertheless, all these microfractures represent inherited damage in the rock, which could be reactivated when fluid pressure is increased. This could explain why few deep reservoirs are under high fluid pressure, most of them having a hydrostatic fluid pressure: their seal cap rock may be microfractured and has released fluid overpressures. Moreover, these inherited microfractures could act as preferential paths during hydraulic fracturing operations (Figure $15)$.

Two important parameters control the density of these microfractures: the initial organic content, and the amount of brittle minerals. However, several questions remain open. For example, it is still not possible to decipher if a microfracture observed on a rock sample extracted from depth or collected from an outcrop was open when the rock was buried. Careful analysis of the morphology of the fracture walls (i.e. roughness) could possibly provide an answer. In addition, linking the scales from nano- to micro-, meso- and macrofractures represents a challenge because this would require homogenization techniques that integrate almost ten orders of magnitude of length scales and good knowledge of the rock's heterogeneities and properties across all these scales Therefore, how microfractures link to the other fractures at larger scale remains an open question.

This review identifies several research directions that should bring new information on microfractures in shales in the coming years.

- It is necessary to measure the heterogeneities in elastic parameters and interfacial surface energy from nanometer scale to micrometer scale in order to better upscale fracture toughness (Chandler et al., 2013), which could be a scale-dependent parameter. 
- New analytical techniques such as high-resolution and time-lapse X-ray tomography (Kobchenko et al., 2011) or peak force microscopy (Eliyahu et al., 2015) can be applied to shales to characterize microfractures and mechanical properties at scales from several tens of nanometers to several tens of micrometers, thus encompassing several scales of heterogeneities identified in these rocks. In the next years, these techniques will improve and allow shale fracturing processes to be upscaled from nanometers to millimeters.

- Reproducing organic matter maturation coupled with internal fluid production and microfracturing in time-lapse 3D experiments, with confinement, is a necessary step in understanding how 3D connected microfracture networks may form and close. This should be possible soon with the development of in-situ experiments on synchrotron beamlines, where sample deformation can be followed in 4D (i.e. Kobchenko et al., 2011).

- Dating organic maturation in shales and also estimating the duration of this process during the geological history of a shale layer could be improved by using recent geochemical developments, such as osmium/rhenium geochronology (Stein and Hannah, 2015).

- Developing micromechanical models in which several scales can be linked, from the nanometer scale heterogeneities of pores in the kerogen, to the tens of nanometer sizes of clays, to the hundred nanometers to tens of micrometer sizes of carbonate grains or patches of organic matter should help to upscale the permeability and porosity variations during shale burial and thermal evolution.

All these new directions of research will open a new era in the study of microfracture generation in shales, which constitute about $75 \%$ of the sedimentary rocks on Earth and contribute to several industrial applications in the fields of georesources, civil engineering, and underground waste storage.

Acknowledgments: We would like to thank Elodie Boller (beamline ID19 at the ESRF, Grenoble) and Øyvind Hammer (Museum of Natural Science in Oslo) for their help with the tomography acquisitions. Maya Kobchenko and Anne Pluymakers (University of Oslo) performed the 3D visualizations in figures 8e-h and 11f. Kim Dalby (University of Copenhagen) provided the FIB image in figure 1d. 
1090

1091

1092

1093

1094

1095

1096

1097

1098

1099

1100

1101

1102

1103

1104

1105

1106

1107

1108

1109

1110

1111

1112

1113

1114

1115

1116

1117

1118

1119

1120

1121

1122

1123

1124

\section{References}

Ababou, R., I. C., Valera, and A. Poutrel, 2011. Macro-permeability distribution and anisotropy in a 3D fissured and fractured clay rock:'excavation damaged zone'around a cylindrical drift in Callovo-Oxfordian Argilite (Bure). Physics and Chemistry of the Earth, Parts A/B/C, 36(17), 1932-1948.

Abell, A.B., K.L. Willis and D.A. Lange, 1998. Mercury intrusion porosimetry and image analysis of cementbase materials. Journal of Colloid and Interface Science 211, 39-44.

Allan, A. M., Vanorio, T., \& Dahl, J. E., 2014. Pyrolysis-induced P-wave velocity anisotropy in organic-rich shales. Geophysics, 79(2), D41-D53.

Aplin, A.C., I.F. Matenaar, D.K. McCarty and B.A. van der Pluijm, 2006. Influence of mechanical compaction and clay mineral diagenesis on the microfabric and porescale properties of deep-water Gulf of Mexico mudstones. Clays and Clay Minerals 54, 500-514.

Anders, M. H., Laubach, S. E., Scholz, C. H., 2014. Microfractures: A review, Journal of Structural Geology, $69,377-394$.

Atkinson, B. K., 1984. Subcritical crack growth in geological materials, Journal of Geophysical Research: Solid Earth, 89 (B6), 4077-4114.

Bergsaker, A., A. Røyne, A. Ougier-Simonin, J. Aubry, and F. Renard, 2016. The effect of fluid composition, salinity and acidity on subcritical crack growth in calcite crystals. Journal of Geophysical Research, 121, doi:10.1002/2015JB012723.

Bernard, S., K. Benzerara, O. Beyssac and G.E. Brown Jr, 2010. Multiscale characterization of pyritized plant tissues in blueschist facies metamorphic rocks. Geochim. Cosmochim. Acta 74, 5054-5068.

Bernard, S., B. Horsfield, H.-M. Schulz, R. Wirth, A. Schreiber and N. Sherwood, 2012. Geochemical evolution of organic-rich shales with increasing maturity: A STXM and TEM study of the Posidonia Shale (Lower Toarcian, northern Germany). Marine and Petroleum Geology 31, 70-89.

Blatt, H. and R.J. Tracy, 1996. Petrology: Igneous, Sedimentary and Metamorphic, 2nd ed.

Bobko, C. P., 2008, Assessing the mechanical microstructure of shale by nanoindentation: the link between mineral composition and mechanical properties, $\mathrm{PhD}$ thesis, Massachusetts Institute of Technology.

Bolton, A. J., A. J. Maltman, and Q. Fisher, 2000. Anisotropic permeability and bimodal pore-size distributions of fine-grained marine sediments, Marine and Petroleum Geology, 17(6), 657-672.

Bons, P., D. Koehn, and M. W. Jessell, eds., 2007, Microdynamics simulation. Vol. 106. Springer Science \& Business Media.

Bons, P. D., and B. P. van Milligen, 2001. New experiment to model self-organized critical transport and accumulation of melt and hydrocarbons from their source rocks, Geology, 29, 919-922.

Breyer, J., 2012. Shale Reservoirs: Giant Resources for the 21st Century, AAPG Memoir 97 (Vol. 97). AAPG.

Cariou, S. 2010. Couplage hydro-mécanique et transfert dans l'argilite de Meuse/Haute-Marne: approches expérimentale et multi-échelle, PhD thesis, Ecole des Ponts ParisTech. 
Cerato, A.B., 2001. Influence of specific surface area on geotechnical characteristics of fine-grained soils, Department of Civil and Environmental Engineering. University of Massachusetts, Unpublished MSc Thesis.

Chalmers, G.R.L. and R.M. Bustin, 2007a. On the effects of petrographic composition on coalbed methane sorption. International Journal of Coal Geology 69, 288-304.

Chalmers, G.R.L. and R.M. Bustin, 2007b. The organic matter distribution and methane capacity of the Lower Cretaceous strata of Northeastern British Columbia, Canada. International Journal of Coal Geology 70, 233-339.

Chalmers, G.R.L., R.M. Bustin and I. Powers, 2009. A pore by any other name would be as small: the importance of meso- and microporosity in shale gas capacity, American Association of Petroleum Geologists annual convention and exhibition, Denver, $\mathrm{CO}$.

Chalmers, G.R., R.M. Bustin and I.M. Power, 2012a. Characterization of gas shale pore systems by porosimetry, pycnometry, surface area, and field emission scanning electron microscopy/transmission electron microscopy image analyses: Examples from the Barnett, Woodford, Haynesville, Marcellus, and Doig units. AAPG Bulletin 96, 1099-1119.

Chalmers, G.R.L., D.J.K. Ross and R.M. Bustin, 2012b. Geological controls on matrix permeability of Devonian Gas Shales in the Horn River and Liard basins, northeastern British Columbia, Canada. International Journal of Coal Geology 103, 120-131.

Chandler, M. R., P. G. Meredith, B. R. Crawford, 2013. Experimental determination of the fracture toughness and ductility of the Mancos Shale, Utah, $75^{\text {th }}$ EAGE Conference \& Exhibition incorporating SPE EUROPEC 2013.

Clarkson, C.R., M. Freeman, L. He, M. Agamalian, Y.B. Melnichenko, M. Mastalerz, R.M. Bustin, A.P. Radlinski and T.P. Blach, 2012. Characterization of tight gas reservoir pore structure using USANS/SANS and gas adsorption analysis. Fuel 95, 371-385.

Coasne, B., and R. J. M. Pellenq, 2004. Grand canonicalMonte Carlo simulation of argon adsorption at the surface of silica nanopores: effect of pore size, pore morphology, and surface roughness, Journal of Chemical Physics, 120, 6. http://dx.doi.org/10.1063/1.1632897.

Curtis, J.B., S.R. Lipshie, G. Oertel and M.J. Pearson, 1980. Clay orientation in some Upper Carboniferous mudrocks, its relationship to quartz content and some inferences about fissility, porosity and compactional history. Sedimentology 27, 333-339.

Curtis, J.B., 2002. Fractured shale-gas systems. AAPG Bulletin 86, 1921-1938.

Cuss, R.J., A.C. Wiseall, J.A.I. Hennissen, C.N. Waters, S.J. Kemp, A. Ougier-Simonin, S. Holyoake, and R.B. Haslam, 2015. Hydraulic fracturing: A review of theory and field experience. British Geological Survey Open Report, OR/15/066, pp.82.

Day-Stirrat, R., R.G. Loucks, K.L. Milliken, S. Hillier and B.A. van der Pluijm, 2008a. Phyllosilicate orientation demonstrates early timing of compactional stabilization in calcite-cemented concretions in the Barnett Shale (Late Mississippian), Fort Worth Basin, Texas (U.S.A). Clays and Clay Minerals 56, 100-111. 
Day-Stirrat, R.J., A.C. Aplin, J. Środoń and B. van der Pluum, 2008b. Diagenetic reorientation of phyllosilicate minerals in Paleogene mudstones of the Podhale Basin, southern Poland. Clays and Clay Minerals 56, 100-111. Decker, D., J. M. P. Coates, and D. Wicks, 1992. Stratigraphy, gas occurrence, formation evaluation and fracture characterization of the antrim shale, Michigan basin. Topical report, January 1990-March 1992 (No. PB-95-104634/XAB). Advanced Resources International, Inc., Lakewood, CO (United States).

Desbois, G., J.L. Urai, C. Burkhardt, M. Drury, M. Hayles and B. Humbel, 2008. Cryogenic vitrification and 3D serial sectioning using high resolution cryo-FIB-SEM technology for brine-filled grain boundaries in halite: first results. Geofluids 8, 60-72.

Desbois, G., J.L. Urai and P.A. Kukla, 2009. Morphology of the pore space in claystones - evidence from BIB/FIB ion beam sectioning and cryo-SEM observations. E-earth Discuss. 4, 1-19.

Desbois, G., J. L. Urai, and M. De Craen, 2010. In-situ and direct characterization of porosity in Boom Clay (Mol site, Belgium) by using novel combination of ion beam cross-sectioning, SEM and cryogenic methods. Motivations, first results and perspectives. External Report of the Belgian Nuclear Research Centre (http://www. sckcen. be).

Dewhurst, D. N., and A. F. Siggins, 2006. Impact of fabric, microcracks and stress field on shale anisotropy, Geophysical Journal International, 165(1), 135-148.

Dewhurst, D.N., A.F. Siggins, J. Sarout, M. Raven and H.M. Nordgard-Bolas, 2011. Geomechanical and ultrasonic characterization of a Norwegian Sea shale. Geophysics 76, WA101-WA111.

Ding, W.L., L. Chao, L. Chunyan, X. Changchun, J. Kai, Z. Weite and W. Liming, 2012. Fracture development in shale and its relationship to gas accumulation. Geoscience Frontiers 3, 97-105.

Elfallagh, F. and B.J. Inkson, 2009. 3D analysis of crack morphologies in silicate glass using FIB tomography. Journal of the European Ceramic Society 29, 47-52.

Eliyahu, M., S., Emmanuel, S., R. J., Day-Stirrat, and C. I. Macaulay, 2015. Mechanical properties of organic matter in shales mapped at the nanometer scale. Marine and Petroleum Geology 59, 294-304.

Fredrich, J.T. and W.B. Lindquist, 1997. Statistical characterization of the three-dimensional microgeometry of porous media and correlation with macroscopic transport properties. International journal of rock mechanics and mining sciences 34, 3-4.

Gale, J. F., R. M. Reed, and J. Holder, 2007. Natural fractures in the Barnett Shale and their importance for hydraulic fracture treatments. AAPG Bulletin, 91, 603-622.

Gale, J. F., S. E. Laubach, J. E. Olson, P. Eichhubl, and A. Fall, 2014. Natural fractures in shale: A review and new observations, AAPG Bulletin, 98, 2165-2216.

Ghayaza, M., F. Skoczylas, J. Robinet, and J. Talandier, 2013. Self-Sealing Capacity of Macro-Cracked Argillite under Confinement. Poromechanics V, 1580-1589, doi: 10.1061/9780784412992.187.

Guéguen, Y., and V. Palciauskas, 1994. Introduction to the Physics of Rocks. Princeton University Press. 
Guo, X., Y. Li, R. Liu, and Q. Wang, 2014. Characteristics and controlling factors of micropore structures of the Longmaxi Shale in the Jiaoshiba area, Sichuan Basin, Natural Gas Industry B, 1(2), 165-171.

Griffith, A.A., 1921. The phenomena of rupture and flow in solids. Philosophical transactions of the royal society of london. Series A, containing papers of a mathematical or physical character, 163-198.

Harrington, J. F., and S. T. Horseman, 1999. Gas transport properties of clays and mudrocks. Geological Society, London, Special Publications, 158(1), 107-124.

Heath, J.E., T.A. Dewers, B.J.O.L. McPherson, R. Petrusak, T.C. Chidsey, A.J. Rinehart and P.S. Mozley, 2011. Pore networks in continental and marine mudstones: Characteristics and controls on sealing behavior. Geosphere 7, 429-454.

Heim, S., P. Guttmann, S. Rehbein, S. Werner and G. Schneider, 2009. Energy-tunable full-field x-ray microscopy: Cryo-tomography and nano-spectroscopy with the new BESSY TXM. Journal of Physics: Conference Series 186, 012041.

Hill, D.G., T. E., Lombardi, and J. P. Martin, 2002. Fractured Shale Gas Potential in New York, Arvada, Colorado, pp. 1-16.

Hilpert, M., and C. T. Miller, 2001. Pore-morphology-based simulation of drainage in totally wetting porous media, Advances in Water Resources, 24, 243-255.

Ho, N.-C., D.R. Peacor and B.A. van der Pluijm, 1995. Reorientation of phyllosilicates in mudstones-to-slate transition at Lehigh Gap, Pennsylvania. Journal of Structural Geology 17, 345-356.

Ho, N.C., D.R. Peacor and B.A. van der Pluijm, 1999. Preferred orientation of phyllosilicates in Gulf Coast mudstones and relation to the smectite-toillite transition. Clays and Clay Minerals 47, 495-504.

Holzner, C., M. Feser, S. Vogt, B. Hornberger, S.B. Baines and C. Jacobsen, 2010. Zernike phase contrast in scanning microscopy with X-rays. Nature physics 6, 883-887.

Hooson, W., 1747. The Miner's Dictionary, Wrexham.

Hornby, B.E., L.M. Schwartz and J.A. Hudson, 1994. Anisotropic effective-medium modeling of the elastic properties of shales. Geophysics 59, 1570-1583.

Hornby, B.E., 1998. Experimental laboratory determination of the dynamic elastic properties of wet, drained shales. Journal of Geophysical Research: Solid Earth 103, 29945-29964.

Horsrud, P., E.F. Sønstebø and R. Bøe, 1998. Mechanical and Petrophysical Properties of North Sea Shales. International Journal of Rock Mechanics and Mining Sciences 35, 1009-1020.

Houben, M.E., G. Desbois and J.L. Urai, 2013. Pore morphology and distribution in the Shaly facies of Opalinus Clay (Mont Terri, Switzerland): Insights from representative 2D BIB-SEM investigations on $\mathrm{mm}$ to nm scale. Applied Clay Science 71, 82-97.

Howard, G. C., and C. R. Fast, 1950. Squeeze cementing operations. Journal of Petroleum Technology, 2(02), 53-64. 
Huang, Z., J. Chen, H. Xue, Y. Wang, M. Wang and C. Deng, 2013. Microstructural characteristics of the Cretaceous Qingshankou Formation shale, Songliao Basin. Petroleum Exploration and Development 40, 61-68. Hunt, J.M., 1996. Petroleum Geochemistry and Geology, second ed., New York.

Hutton, A.C., 1987. Petrographic classification of oil shales. International Journal of Coal Geology 8, 203-231. Jarvie, D.M., R.J. Hill, T.E. Ruble and R.M. Pollastro, 2007. Unconventional shale-gas systems: The Mississippian Barnett Shale of north-central Texas as one model for thermogenic shale-gas assessment. AAPG Bulletin 91, 475-499.

Jiu, K., W. Ding, W. Huang, Y. Zhang, S. Zhao, and L. Hu, 2013. Fractures of lacustrine shale reservoirs, the Zhanhua Depression in the Bohai Bay Basin, eastern China. Marine and Petroleum Geology, 48, 113-123.

Kachanov, L.M., 1958. Rupture time under creep conditions. Izv. Acad. Nauk. USSR 8, 26-31.

Kanitpanyacharoen, W., H.-R. Wenk, F. Kets, C. Lehr and R. Wirth, 2011. Texture and anisotropy analysis of Qusaiba shales. Geophysical Prospecting 59, 536-556.

Kanitpanyacharoen, W., F.B. Kets, H.-R. Wenk and R. Wirth, 2012. Mineral Preferred Orientation and Microstructure in the Posidonia Shale in Relation to Different Degrees of Thermal Maturity. Clays and Clay Minerals 60, 315-329.

Kanitpanyacharoen, W., D.Y. Parkinson, F. De Carlo, F. Marone, M. Stampanoni, R. Mokso, A. MacDowell and H.-R. Wenk, 2013. A comparative study of X-ray-tomographic microscopy on shales at different synchrotron facilities: ALS, APS and SLS. Journal of Synchrotron Radiation 20, 172-280.

Keller, L.M., L. Holzer, R. Wepf and P. Gasser, 2011. 3D geometry and topology of pore pathways in Opalinus clay: Implications for mass transport. Applied Clay Science 52, 85-95.

Klaver, J., G. Desbois, J.L. Urai and R. Littke, 2012. BIB-SEM study of the pore space morphology in early mature Posidonia Shale from the Hils area, Germany. International Journal of Coal Geology 103, 12-25.

Klinkenberg, L. J. 1941, The permeability of porous media to liquids and gases. Drilling and Production Practice, American Petroleum Inst., New york, pp. 200-213.

Kobchenko, M., H. Panahi, F. Renard, D. K. Dysthe, A. Malthe-Sorrenssen, A. Mazzini, J. Scheibert, B. Jamtveit, and P. Meakin, 2011. 4D imaging of fracturing in organic-rich shales during heating, Journal of Geophysical Research, 116, B12201, doi:10.1029/2011JB008565.

Kobchenko, M., A. Hafver, E. Jettestuen, F. Renard, O. Galland, J. Mathiesen, P. Meakin, B. Jamtveit and D. K. Dysthe, 2013. Drainage fracture network in an elastic solid with internal fluid generation, Europhysics Letters, 102,66002 .

Kobchenko, M., A. Hafver, E. Jettestuen, F. Renard, O. Galland, B. Jamtveit, and D. K. Dysthe, 2014. Evolution of a fracture network in an elastic medium with internal fluid generation and expulsion, Phys. Rev. E, 90, 052801.

Kranz, R.L., 1983. Microcracks in rocks: A review. Tectonophysics 100, 449-480. 
1262

1263

1264

1265

1266

1267

1268

1269

1270

1271

1272

1273

1274

1275

1276

1277

1278

1279

1280

1281

1282

1283

1284

1285

1286

1287

1288

1289

1290

1291

1292

1293

1294

1295

1296

Kuila, U. and M. Prasad, 2013. Specific surface area and pore-size distribution in clays and shales. Geophysical Prospecting 61, 341-362.

Lash, G.G. and T. Engelder, 2005. An analysis of horizontal microcracking during catagenesis: Example from the Catskill delta complex. AAPG bulletin 89, 1433-1449.

Li, X.J., S. Y. Hu, and K. M. Cheng, 2007. Suggestions from the development of fractured shale gas in North America, Petroleum Exploration and Development, 34(4), 392-400 (in Chinese with English abstract).

Li, D.H., J. Z. Li, S. J. Wang, and X. J. Li, 2009. Conditions of shale gas reservoir formation, Natural Gas Industry, 29(5), 22-26 (in Chinese with English abstract).

Lonardelli, I., H.-R. Wenk and Y. Ren, 2007. Preferred orientation and elastic anisotropy in shales. Geophysics 72, D33-D40.

Loucks, R.G., R.M. Reed, S.C. Ruppel and D.M. Jarvie, 2009. Morphology, Genesis, and Distribution of Nanometer-Scale Pores in Siliceous Mudstones of the Mississippian Barnett Shale. Journal of Sedimentary Research 79, 848-861.

Mastalerz, M., L. He, Y.B. Melnichenko and J.A. Rupp, 2012. Porosity of coal and shale: insights from gas adsorption and SANS/USANS techniques. Energy \& Fuels 26, 5109-5120.

McMullen, E., 2013. The effect of bedding laminations on crack propagation in the Marcellus Shale, Department of Geology. University of Maryland, unpublished.

Merriman, R.J., D.E. Highley and D.G. Cameron, 2003. Definition and characteristics of very-fine grained sedimentary rocks: clay, mudstone, shale and slate, British Geological Survey Commissioned Report, p. 20.

Meunier, A., 2006. Why are clay minerals small? Clay Minerals 41, 551-566.

Midgley, P.A., E.P.W. Ward, A.B. Hungria and J.M. Thomas, 2007. Nanotomography in the chemical, bioligical and materials sciences. Chemical Society Reviews 36, 1477.

Milliken, K.L., M. Rudnicki, D.N. Awwiller and T. Zhang, 2013. Organic matter hosted pore system, Marcellus Formation (Devonian), Pennsylvania. AAPG Bulletin 97, 177-200.

Milner, M., R. McLin, and J. Petriello, 2010. Imaging texture and porosity in mudstones and shales: Comparison of secondary and ion-milled backscatter SEM methods, Canadian Unconventional Resources and International Petroleum Conference. Society of Petroleum Engineers.

Mitchell, J.K., 1993. in: Sons, J.W. (Ed.), Fundamentals of Soil Behavior, 2nd edition.

Montes-Hernandez, G., J. Duplay, L. Martinez, S. Escoffier and D. Rousset, 2004. Structural modifications of Callovo-Oxfordian argillite under hydration/dehydration conditions. Applied Clay Science 25, 187-194.

Montgomery, S.L., D.M. Jarvie, K.A. Bowker and R.M. Pollastro, 2005. Mississippian Barnett Shale, Fort Worth Basin, north-central Texas: gas-shale play with multi-trillion cubic foot potential. AAPG Bulletin 89, $155-175$

Moore, D.M. and R. C. Reynolds Jr., 1997. X-ray Diffraction and the Identification and Analysis of Clay Minerals, 378 p. Oxford University Press, Oxford. 
Muñoz, Y.A., R. Littke and M.R. Brix, 2007. Fluid systems and basin evolution of the western Lower Saxony Basin, Germany. Geofluids 7, 335-355.

Nelson, P.H., 2009. Pore-throat sizes in sandstones, tight sandstones, and shales. AAPG Bulletin 93, 329-340.

Nie, H. K., X. Tang, and R. K. Bian, 2009. Controlling factors for shale gas accumulation and prediction of potential development area in shale gas reservoir of South China. Acta Petrolei Sinica, 30(4), 484-491.

Nye, J. F., 1985. Physical properties of crystals: Oxford University Press.

Ougier-Simonin, A., J., Sarout, and Y. Guéguen, 2009. A simplified model of effective elasticity for anisotropic shales, Geophysics, 74(3), D57-D63, doi: 10.1190/1.3096616.

Padin, A., A.N. Tutuncu and S. Sonnenberg, 2014. On the Mechanisms of Shale Microfracture Propagation. SPE Hydraulic Fracturing Technology Conference, Society of Petroleum Engineers.

Panahi, H., M. Kobchenko, F. Renard, A. Mazzini, J. Scheibert, D. K. Dysthe, B. Jamtveit, and P. Meakin, 2013. 4D X-ray tomography imaging of hydrocarbon escape pathway formation in heated organic-rich shales: a proxy for primary migration?, SPE Journal, SPE162939, 366-377.

Petmecky, S., L. Meier, H. Reiser and R. Littke, 1999. High thermal maturity in the Lower Saxony Basin: intrusion or deep burial?. Tectonophysics, 304(4), 317-344.

Pollastro, R.M., D.M. Jarvie, R.J. Hill and C.W. Adams, 2007. Geologic framework of the Mississippian Barnett Shale, Barnett-Paleozoic total petroleum system, Bend arch-Forth Worth Basin, Texas. AAPG Bulletin 91, 405-436.

Robinet, J. C. 2008. Minéralogie, porosité et diffusion des solutés dans l'argilite du Callovo-Oxfordien de Bure (Meuse, Haute-Marne, France) de l'échelle centimétrique à micrométrique, $\mathrm{PhD}$ thesis, University of Poitiers.

Rouquerol, J., Avnir, D., Fairbridge, C. W., Everett, D. H., Haynes, J. M., Pernicone, N.,. \& Unger, K. K., 1994. Recommendations for the characterization of porous solids (Technical Report). Pure and Applied Chemistry, 66(8), 1739-1758.

Rice, J.R. and R. Thompson, 1974. Ductile versus brittle behaviour of crystals. Philos. Mag. 29, 73-79.

Rostom, F., A. Røyne, D. K. Dysthe, and F. Renard, 2013. Effect of fluid salinity on subcritical crack propagation in calcite, Tectonophysics, 583, 68-75.

Ross, D.J.K. and R.M. Bustin, 2008. Characterizing the shale gas resource potential of Devonian-Mississippian strata in the Western Canada sedimentary basin: application of an integrated formation evaluation. AAPG Bulletin 92, 87-125.

Ross, D.J.K. and R.M. Bustin, 2009. The importance of shale composition and pore structure upon gas storage potential of shale gas reservoirs. Marine and Petroleum Geology 26, 916-927.

Røyne, A., J. Bisschop, and D. K. Dysthe, 2011. Experimental investigation of surface energy and subcritical crack growth in calcite, Journal of Geophysical Research: Solid Earth, 116, B04204.

Saarenketo, T., 1998. Electrical properties of water in clay and silty soils. Journal of Applied Geophysics 40, 73 88 . 
1332

1333

1334

1335

1336

1337

1338

1339

1340

1341

1342

1343

1344

1345

1346

1347

1348

1349

1350

1351

1352

1353

1354

1355

1356

1357

1358

1359

1360

1361

1362

1363

1364

1365

1366

Sarout, J. and Y. Guéguen, 2008a. Anisotropy of elastic wave velocities in deformed shales: Part 1Experimental results. Geophysics 73, D75-D89.

Sarout, J. and Y. Guéguen, 2008b. Anisotropy of elastic wave velocities in deformed shales: Part 2-Modeling results. Geophysics 73, D91-D103.

Sayers, C.M., 2013. The effect of kerogen on the elastic anisotropy of organic-rich shales. Geophysics 78, D65D74, doi: 10.1190/GEO2012-0309.1.

Schmitt, M., C.P. Fernandes, J.A.B. da Cunha Neto, F.B. Wolf and V.S.S. dos Santos, 2013. Characterization of pore systems in seal rocks using nitrogen gas adsorption combined with mercury injection capillary pressure techniques. Marine and Petroleum Geology 39, 138-149.

Scott, P.P.J., W.G. Bearden and G.C. Howard, 1953. Rock rupture as affected by fluid properties. AIME Trans. $198,111$.

Shaw, D.B. and Weaver, C. E., 1965. The mineralogical composition of shales. Journal of Sedimentary Petrology 35, 213-222.

Simmons, G., and D. Richter, 1976. Microcracks in rocks, in The Physics and Chemistry of Minerals and Rocks, edited by R. J. G. Strens, Interscience, New-York, pp. 105-137.

Sing., K.-S.-W., D. H. Everett, R. A. W. Haul, L. Moscou, R. A. Pierotti, J. Rouquerol, F. Rouquerol, and T., Siemieniewskat, 1985. Reporting physisorption data for gas/solid systems, with special reference to the determination of surface area and porosity, Pure Appl. Chem., 57, 603-619.

Sintubin, M., 1994. Clay fabrics in relation to the burial history of shales. Sedimentology 41, 1161-1169.

Skurtveit, E., A. Eyvind, M. Soldal, M. Angeli, and Z. Wang, 2012. Experimental investigation of $\mathrm{CO}_{2}$ breakthrough and flow mechanisms in shale, Petroleum Geoscience, 18(1), 3-15, doi: 10.1144/1354-079311016.

Slatt, R.M. and Y. Abousleiman, 2011. Merging sequence stratigraphy and geomechanics for unconventional gas shales. The Leading Edge 30, 274-282.

Slatt, R.M. and N.R. O'Brien, 2011. Pore types in the Barnett and Woodford gas shales: Contribution to understanding gas storage and migration pathways in fine-grained rocks. AAPG Bulletin 95, 2017-2030.

Sondergeld, C.H., C.S. Rai, R.W. Margesson and K.J. Whidden, 2000. Ultrasonic measurement of anisotropy in the Kimmeridge shale, 69th Annual International Meeting, SEG, pp. 1858-1861.

Stein, H., and J. Hannah, 2015. Rhenium-Osmium Geochronology: Sulfides, Shales, Oils, and Mantle, Encyclopedia of Scientific Dating Methods, 707-723.

Tan, R.R., 2009. Shale gas becomes the mainstay of the newly increased proven reserves, Natural Gas Industry, 29(5), 81 (in Chinese with English abstract).

Tian, H., L. Pan, X. Xiao, R.W.T. Wilkins, Z. Meng and B. Huang, 2013. A preliminary study on the pore characterization of Lower Silurian black shales in the Chuandong Thrust Fold Belt, southwestern China using low pressure N2 adsorption and FE-SEM methods. Marine and Petroleum Geology 48, 8-19. 
Ulm, F.-J., G. Constantinides, A. Delafargue, Y. Abousleiman, R. Ewy, L. Duranti and D.K. McCarty, 2005. Material invariant poromechanics properties of shales, in: Balkema, A.A. (Ed.), Poromechanics III - Biot Centennial (1905-2005), pp. 637-644.

Ulm, F.-J. and Y. Abousleiman, 2006. The nanogranular nature of shale. Acta Geotechnica 1, 77-88.

Valcke, S.L.A., M. Casey, G.E. Lloyd, J.-M. Kendall and Q.J. Fisher, 2006. Lattice preferred orientation and seismic anisotropy in sedimentary rocks. Geophysical Journal International 166, 652-666.

van Golf-Racht, T. D., 1982. Fundamentals of fractured reservoir engineering, Elsevier.

Vanorio, T., T. Mukerji and G. Mavko, 2008. Emerging methodologies to characterize the rock physics properties of organic-rich shales. The Leading Edge 27, 780-787.

Vernik, L. and A. Nur, 1992. Ultrasonic velocity and anisotropy of hydrocarbon source rocks. Geophysics 57, 727-735.

Vernik, L., 1993. Microcrack-induced versus intrinsic elastic anisotropy in mature HC-source shales. Geophysics 58, 1703-1706.

Vernik, L., 1994. Hydrocarbon-generation-induced microcracking of source rocks. Geophysics 59, 555-563.

Vernik, L. and X. Liu, 1997. Velocity anisotropy in shale: a petrophysical study. Geophysics 62, 521-532.

Vernik, L. and J. Milovac, 2011. Rock physics of organic shales. The Leading Edge 30, 323-318.

Vidal, O., and B. Dubacq, 2009. Thermodynamic modelling of clay dehydration, stability and compositional evolution with temperature, pressure and $\mathrm{H}_{2} 0$ activity, Geochmimica et Cosmochimica Acta 73, 6544-6564.

Voltolini, M., H.-R. Wenk, N.H. Mondol, K. Bjørlykke and J. Jahren, 2009. Anisotropy of experimentally compressed kaolinite-illite-quartz mixtures. Geophysics 74, 13-23.

Walsh, J.B., 1965a. The effect of cracks on the compressibility of rock. J. Geophys. Res. 70, 381-389.

Walsh, J.B., 1965b. The effect of cracks on the uniaxial elastic compression of rocks. J. Geophys. Res. 70, 399411.

Walsh, J.B., 1965c. The effect of cracks in rocks on Poisson's ratio. J. Geophys. Res. 70, 5249-5257.

Warpinski, N. R., and L. W. Teufel, 1987. Influence of Geologic Discontinuities on Hydraulic Fracture Propagation (includes associated papers 17011 and 17074), Society of Petroleum Engineers, SPE-13224-PA, doi: 10.2118/13224-PA.

Wenk, H.-R., M. Voltolini, M. Mazurek, L.R. Van Loon and A. Vinsot, 2008. Preferred Orientations and Anisotropy in Shales: Callovo-Oxfordian Shale (France) and Opalinus Clay (Switzerland). Clays and Clay Minerals 56, 285-306.

Wenk, H.-R., W. Kanitpanpanyacharoen and M. Voltolini, 2010. Preferred orientation of phyllosilicates: Comparison of fault gouge, shale and schist. Journal of Structural Geology 32, 478-489.

Weiss, J., L., Girard, F. Gimbert, D. Amitrano. and D. Vandembroucq, 2014. (Finite) size effects on compressive strength, PNAS, 111 (17), 6231-6236. 
1401 Xu, S.L., and S. J. Bao, 2009. Preliminary analysis of shale gas resource potential and favorable areas in Ordos 1402 Basin, Natural Gas Geoscience, 20, 460-465 (in Chinese with English abstract).

1403 Yang., Y. and A. C. Aplin, 2007. Permeability and petrophysical properties of 30 natural mudstones, Journal of 1404 Geophysical Research, 112, B03206, doi:10.1029/2005JB004243.

1405 Yven, B., S. Sammartino, Y. Geraud, F. Homand and F. Villieras, 2007. Mineralogy, texture and porosity of 1406 Callovo-Oxfordian argillites of the Meuse/Haute-Marne region (eastern Paris Basin). Mémoires: Société 1407 Géologique de France 178, 73-90.

1408 Zeng, L.B., and S.R., Xiao, 1999. Fractured mudstone reservoir bodies in low permeability reservoirs, 1409 Petroleum Geology and Experiment, 21 (3), 266-269 (in Chinese with English abstract).

1410 Zeng, W., J. Zhang, W. Ding, S. Zhao, Y. Zhang, Z. Liu and K. Jiu, 2013. Fracture development in Paleozoic 1411 shale of Chongqing area (South China). Part one: Fracture characteristics and comparative analysis of main 1412 controlling factors. Journal of Asian Earth Sciences 75, 251-266. 


\section{Figures and tables}
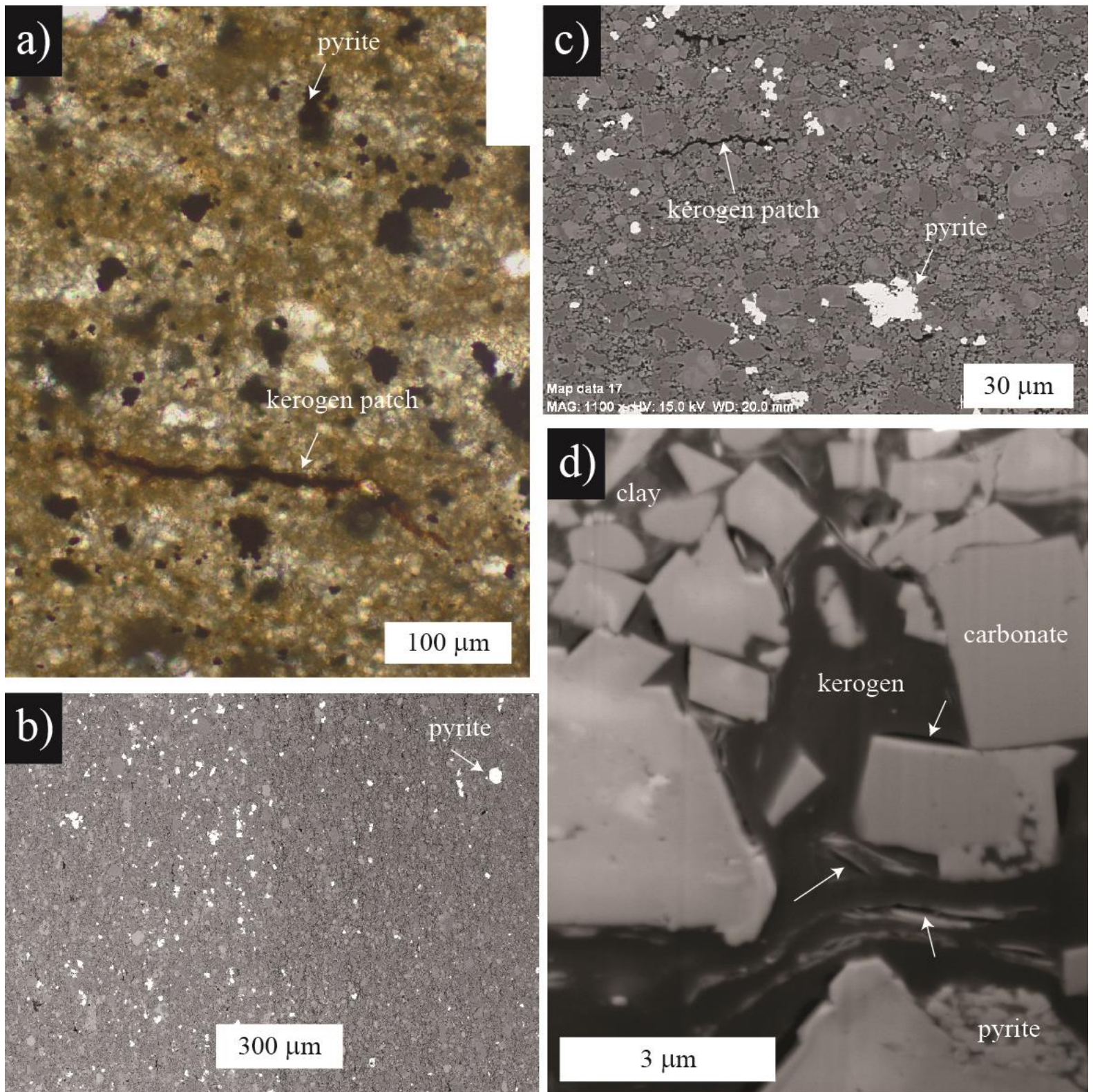

1415 Figure 1: Views of a thin section of an immature Green River shale sample at different resolutions, illustrating the microstructure of a shale at various spatial scales. a) Optical

1417 microscopy: elongated kerogen patches and pyrite grains are embedded into a matrix rich in 1418 clays and carbonate grains. b-c) Scanning electron microscopy views of the same sample 1419 where bedding anisotropy is visible: vertical in b) and horizontal in c). d) Focused Ion Beam section and high resolution scanning electron microscopy of the same samples. The white arrows point to micropores located either inside the kerogen or at the interface between the kerogen and the grains. Both pictures show a highly heterogeneous material, with various grain sizes, low porosity, and bed-parallel anisotropy. 


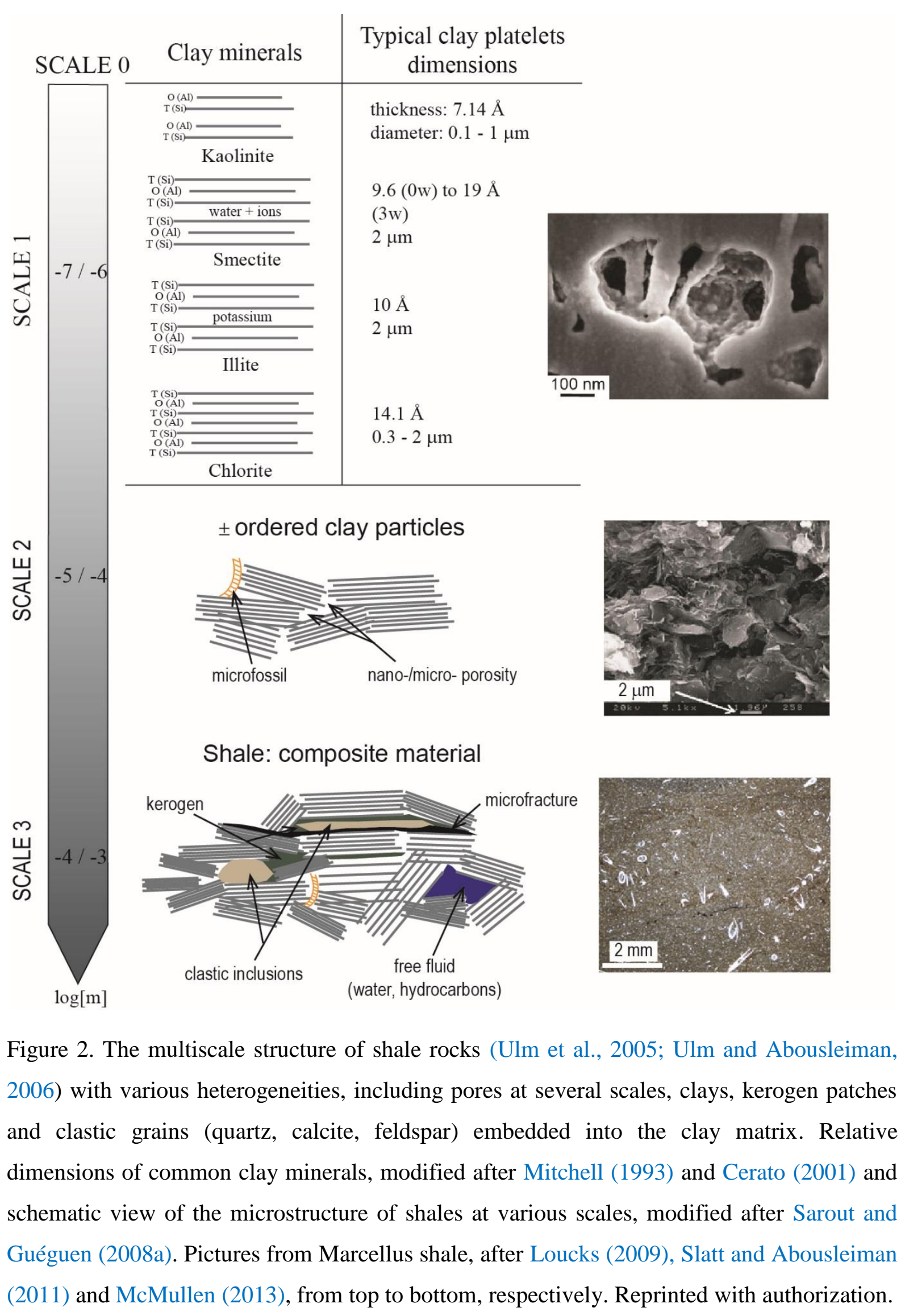



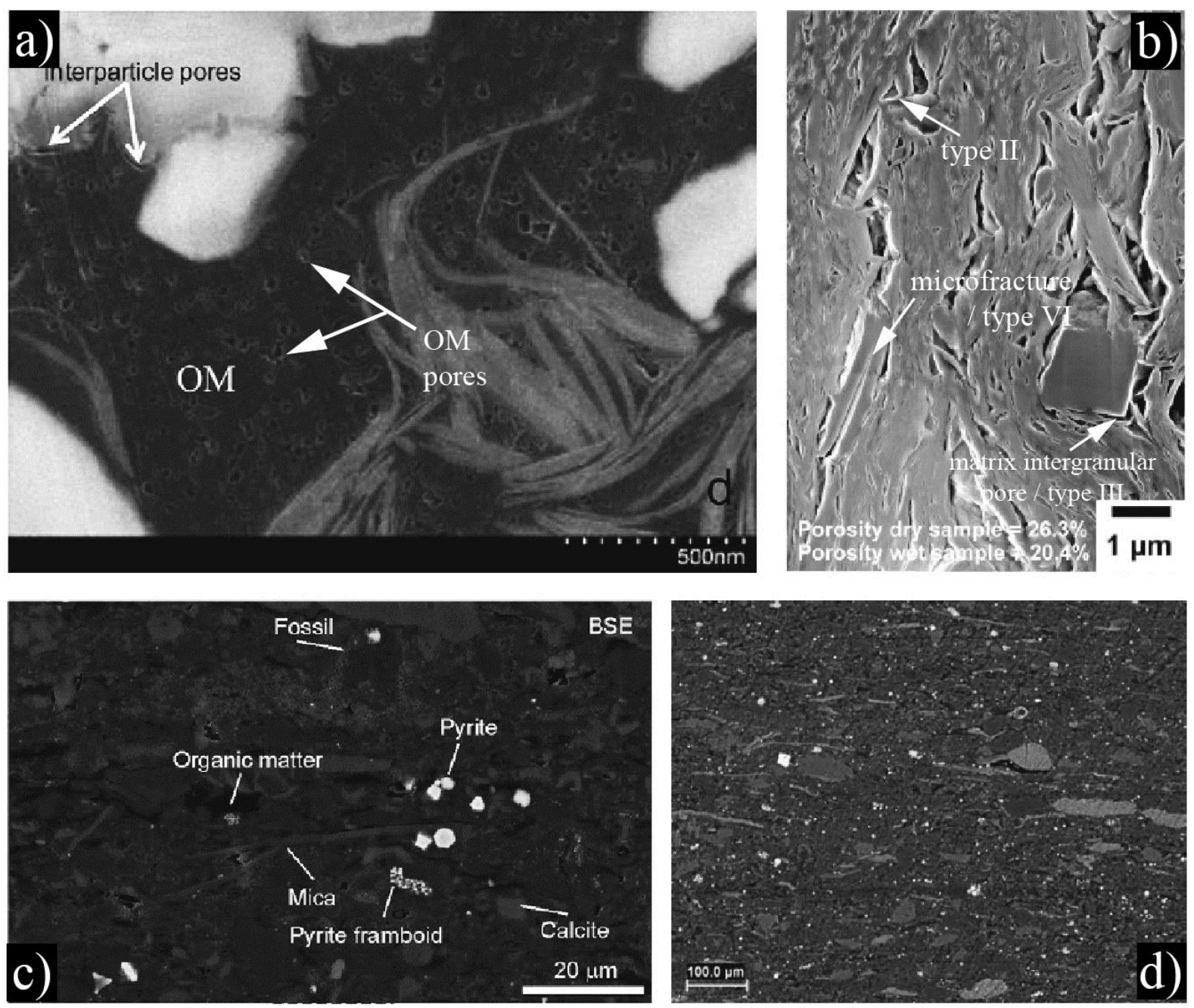

1433 Figure 3. Porosity spanning several scales in shales. Scanning electron microscopy pictures of 1434 a) Longmaxi black shale showing organic matter (OM) pores, modified from Tian et al. 1435 (2013); b) Boom clay showing the organization of the 2D pore space, modified from Desbois 1436 et al. (2010); c) Posidonia shale, modified from Klaver et al. (2012); and d) Qusaiba shale 1437 (BSE-SEM overview) where pyrite minerals are in white, quartz and clay minerals appear as 1438 intermediate grey shades and porosity in black, modified from Kanitpanyacharoen et al. 1439 (2011). Reprinted with authorization. 

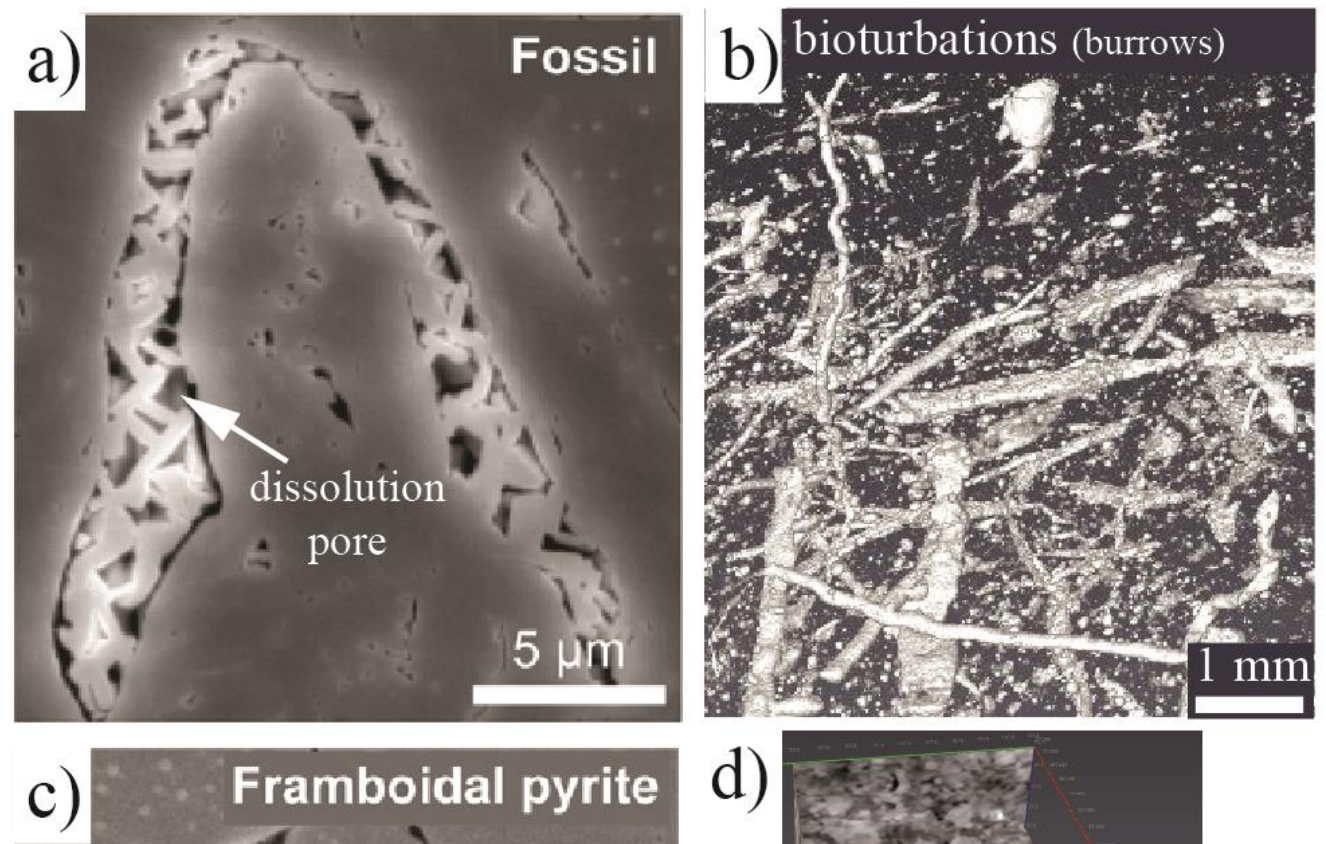

d)
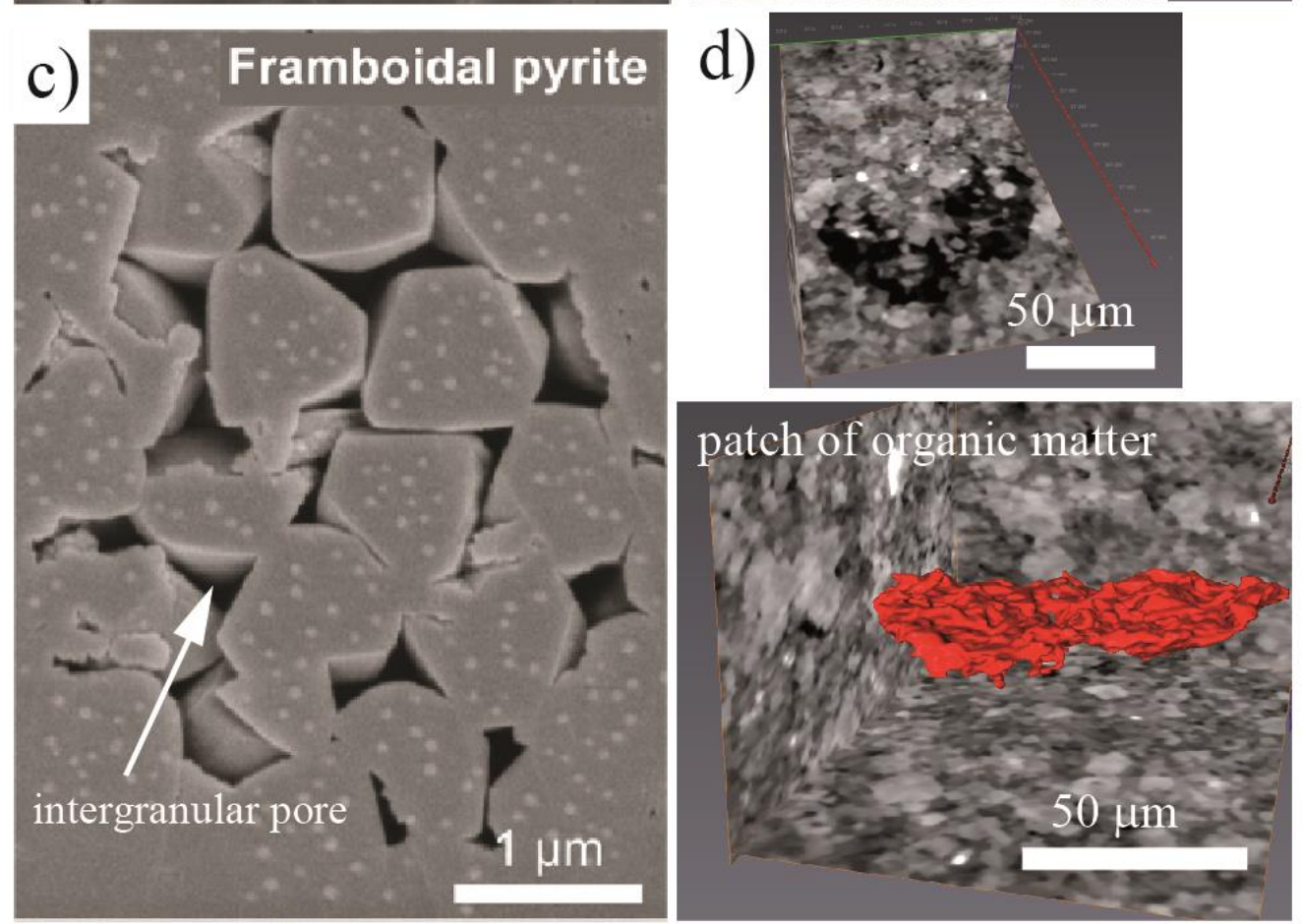

Figure 4. Bioturbation or paleo-life related microstructures: a) scanning electron image of a 1442 fossil, b) X-ray microtomography 3D view of micro-burrows; c) scanning electron 1443 microscopy image of framboidal pyrite; d) 3D view of patch of kerogen in a Green River 1444 shale imaged with X-ray microtomography. The top view shows a 2D slice of the kerogen 1445 patch (dark), the 3D bottom view shows the whole kerogen patch, oriented parallel to the 1446 bedding. Data acquired on beamline ID19 at the European Radiation Synchrotron Facility 1447 with a voxel resolution of 0.16 micrometer. Pictures a) and c) modified from Houben et al., 1448 (2013). Reprinted with authorization. 


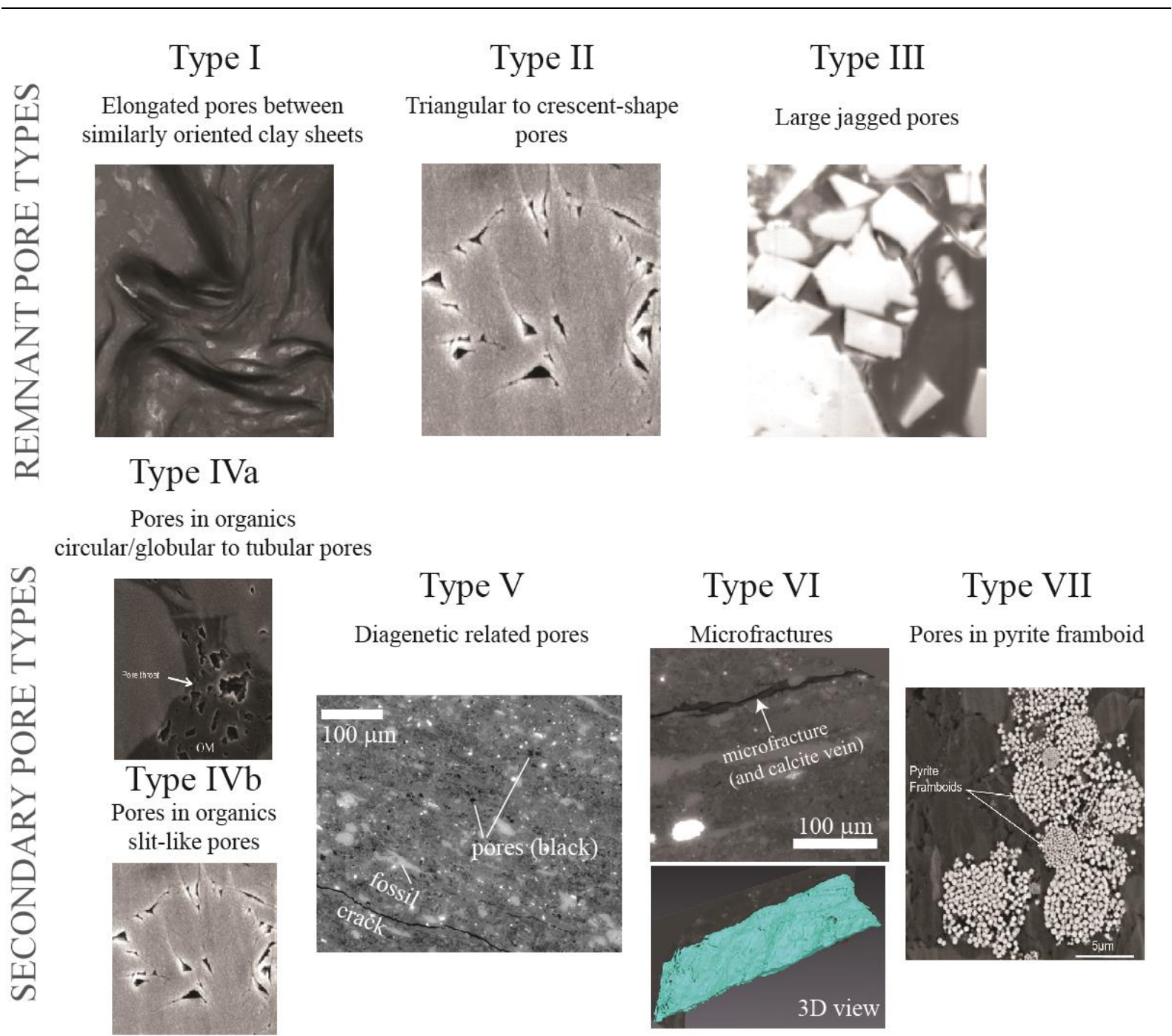

Figure 5. Pore type classification following Desbois et al. (2010) and Heath et al. (2011).

1451 Pores appear in black. Type I pores illustrated with a picture extracted from Chalmers et al. 1452 (2012a), type II with a picture from Houben et al. (2013), types IVa and VII with pictures 1453 from Tian et al. (2013). Type III pores imaged in Green River shale. Type V and VI pore 1454 images come from shales collected from a borehole at $3 \mathrm{~km}$ depth (Argentina) and the 1455 samples were scanned in 3D using X-ray microtomography at the European Synchrotron 1456 Radiation Facility, beamline ID19 and BM05, voxel size 0.62 micrometer. Reprinted with authorization. 

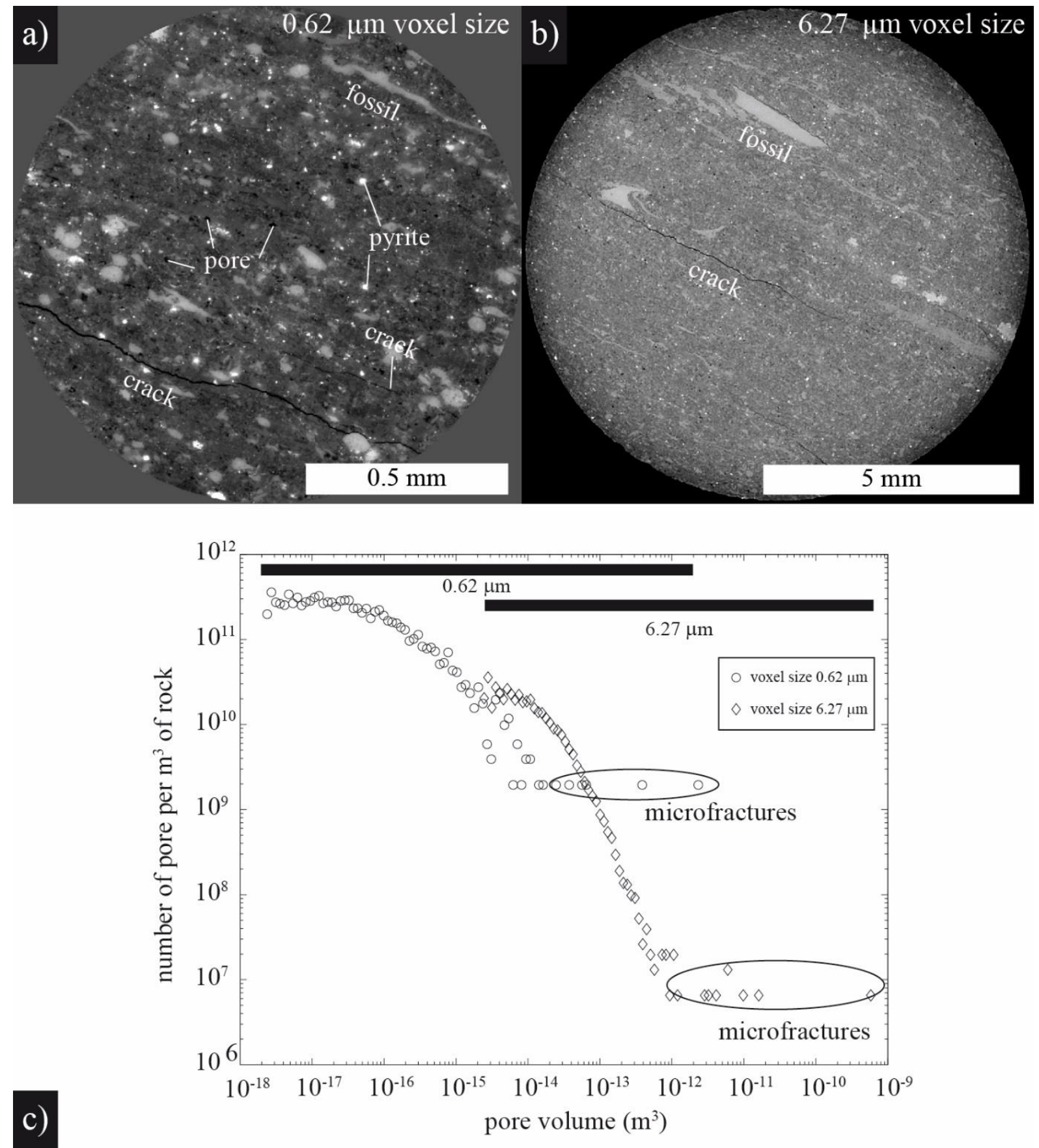

1459 Figure 6: Synchrotron X-ray tomography acquisition of a shale sample collected from a 1460 borehole at $3 \mathrm{~km}$ depth (Vaca Muerta shale, Argentina) and pore size distribution analysis. a1461 b) Views of the same sample at two voxel size resolutions (0.62 and 6.27 micrometers) 1462 scanned in 3D at the European Radiation Synchrotron Facility, beamlines BM05 and ID19. c) 1463 Pore size analysis based on the segmentation of the 3D data. The pore size distributions of the 1464 data sets at two resolutions overlap and show a linear trend in a log-log plot (power law 1465 relationship between number of pores and pore volume). The largest pores correspond to the 1466 fractures shown in a) and b) and depart from the linear trend in the log-log plot. 

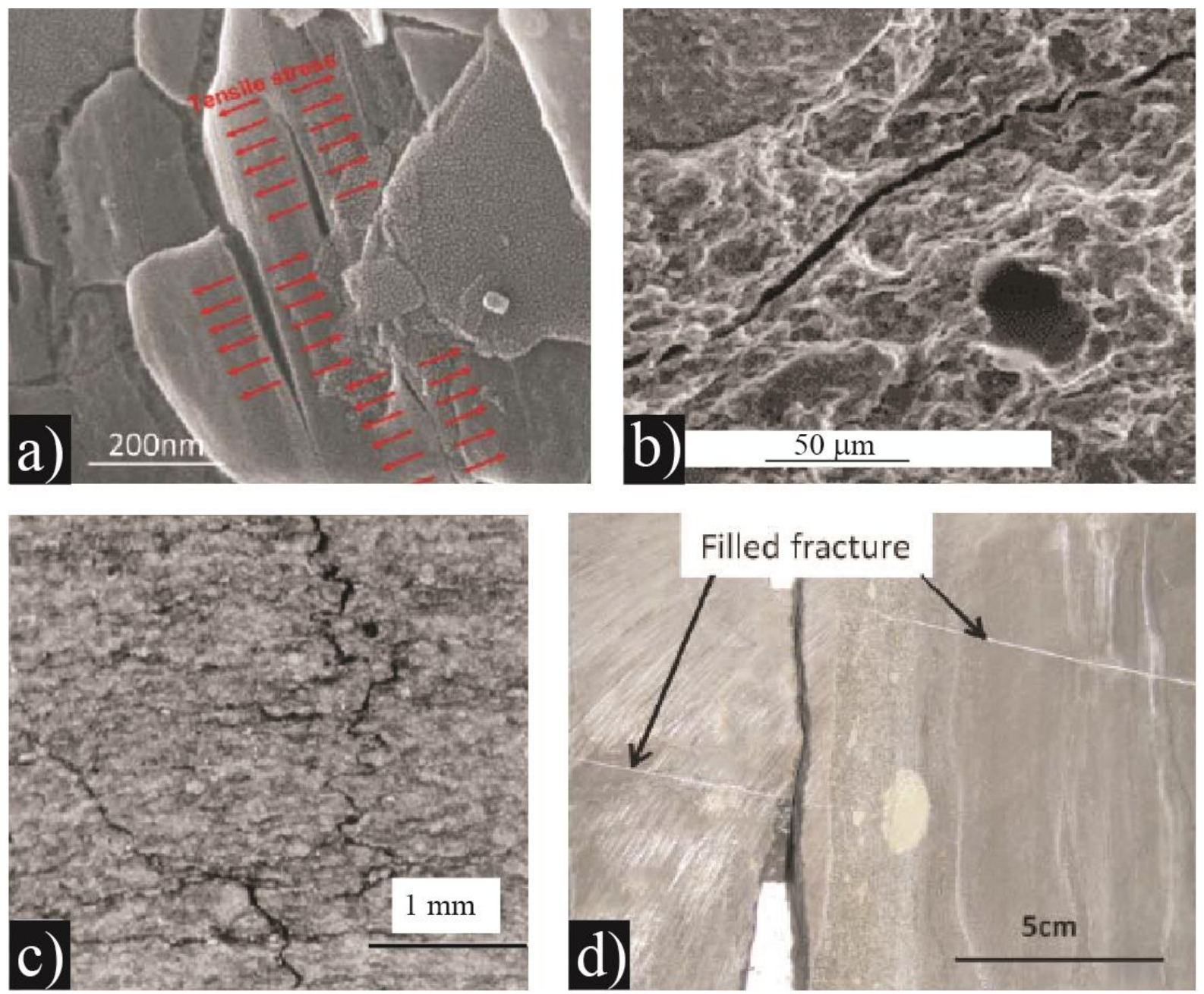

Figure 7. Microfractures through scales in shale rocks. SEM pictures a), c) and d) from Slatt

1469 and Abousleiman (2011) in Woodford shale and Barnett shale respectively; b) from Montes-

1470 Hernandez et al. (2004) in Bure shale. Reprinted with authorization. 

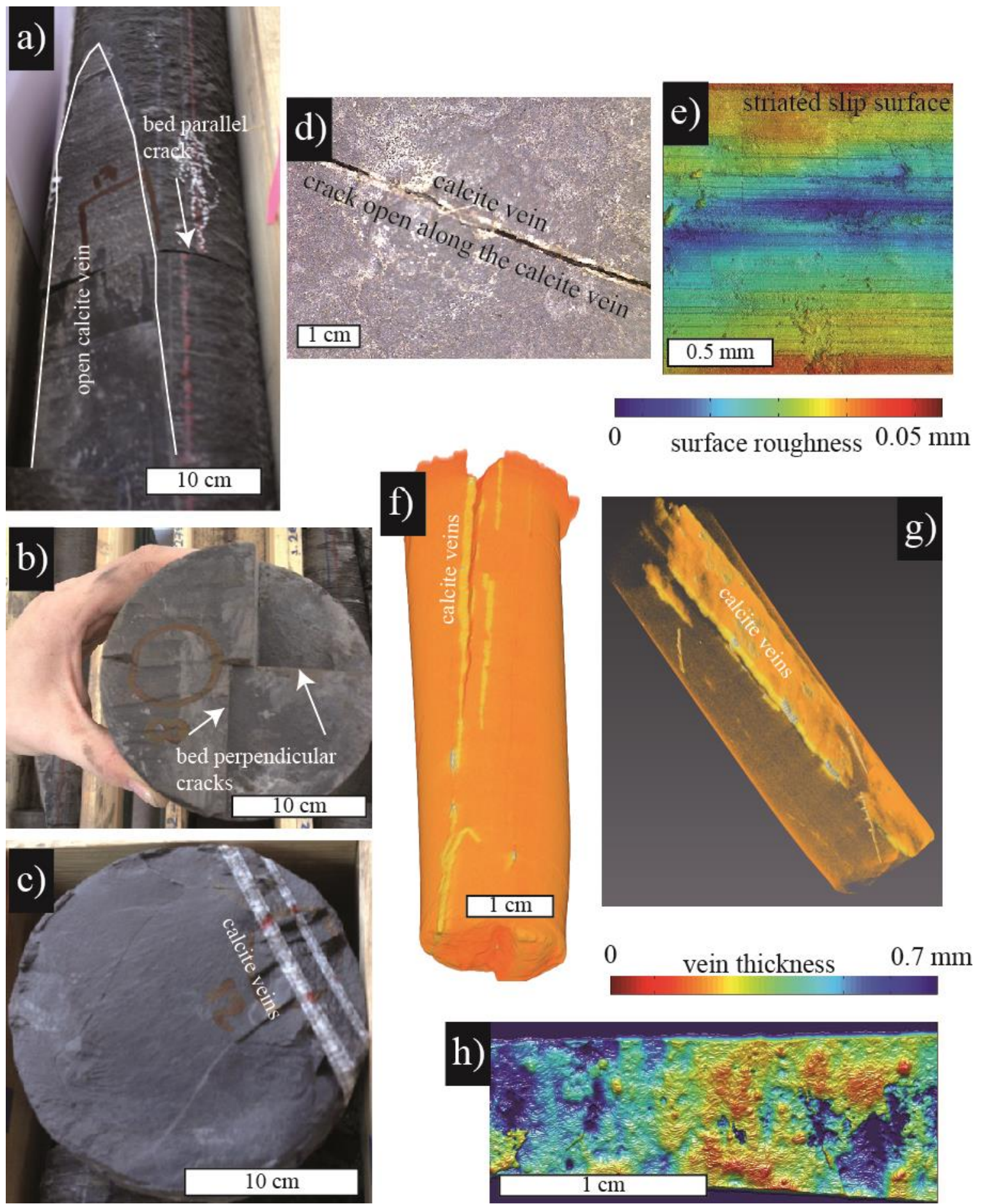

0

vein thickness

$0.7 \mathrm{~mm}$

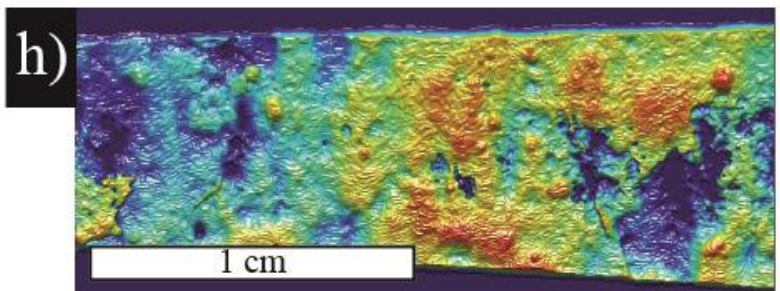

1472 Figure 8: Fractures and veins in samples of Pomeranian shales (Poland) collected at $3 \mathrm{~km}$

1473 depth. a-d). Open cracks parallel or perpendicular to the bedding are observed on the core

1474 sample, as well as calcite veins that are fully or partially sealed. e) Some fractures show 1475 evidence for shear with striation topography (i.e. surface roughness) that can be measured 1476 using white light interferometry. f-g) Laboratory X-ray computed-tomography images of a 1477 core sample showing several calcite veins. h) Spatial variation of vein thickness for the main 1478 calcite vein displayed in g). 


\section{2-D views}
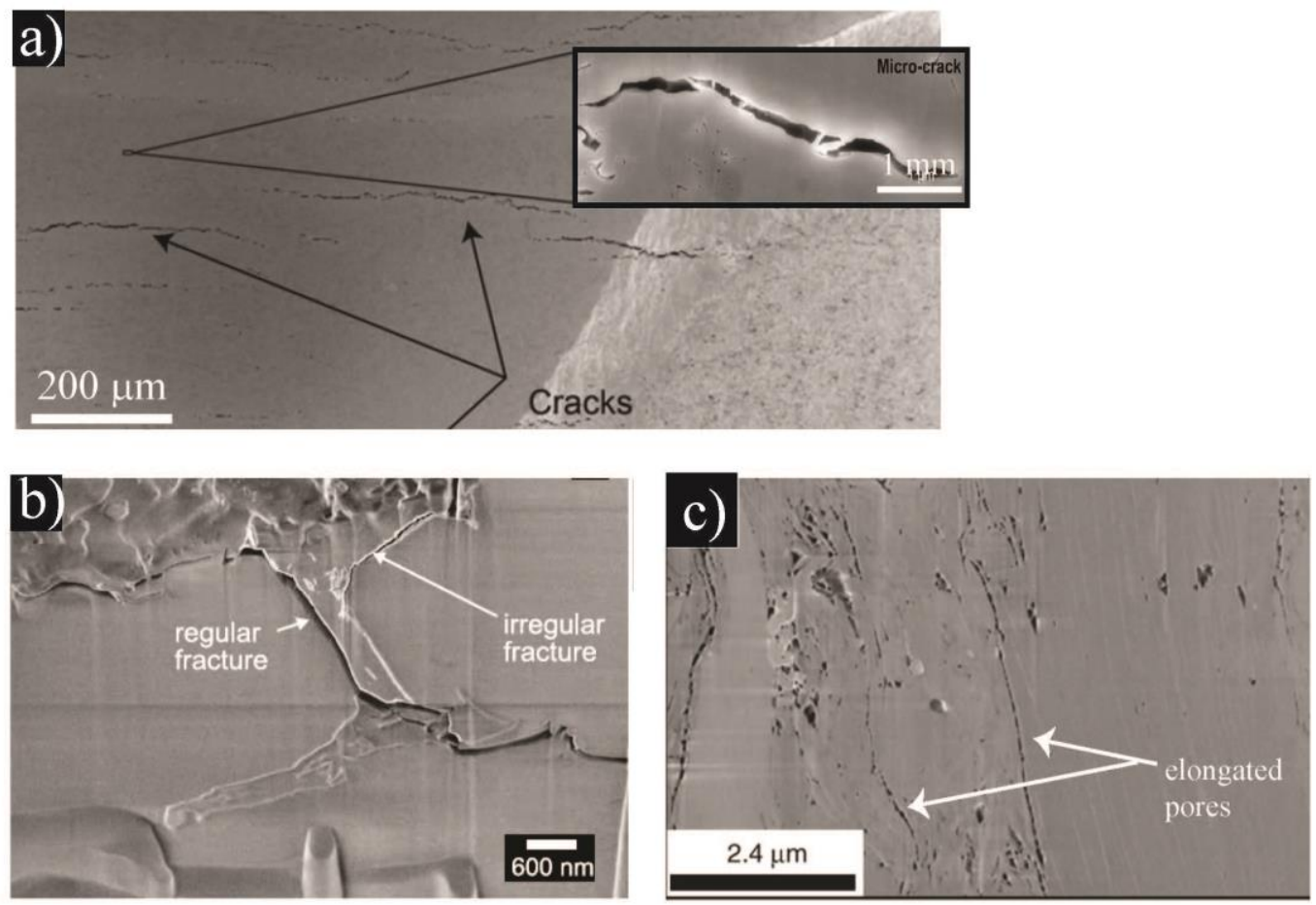

\section{3-D views}
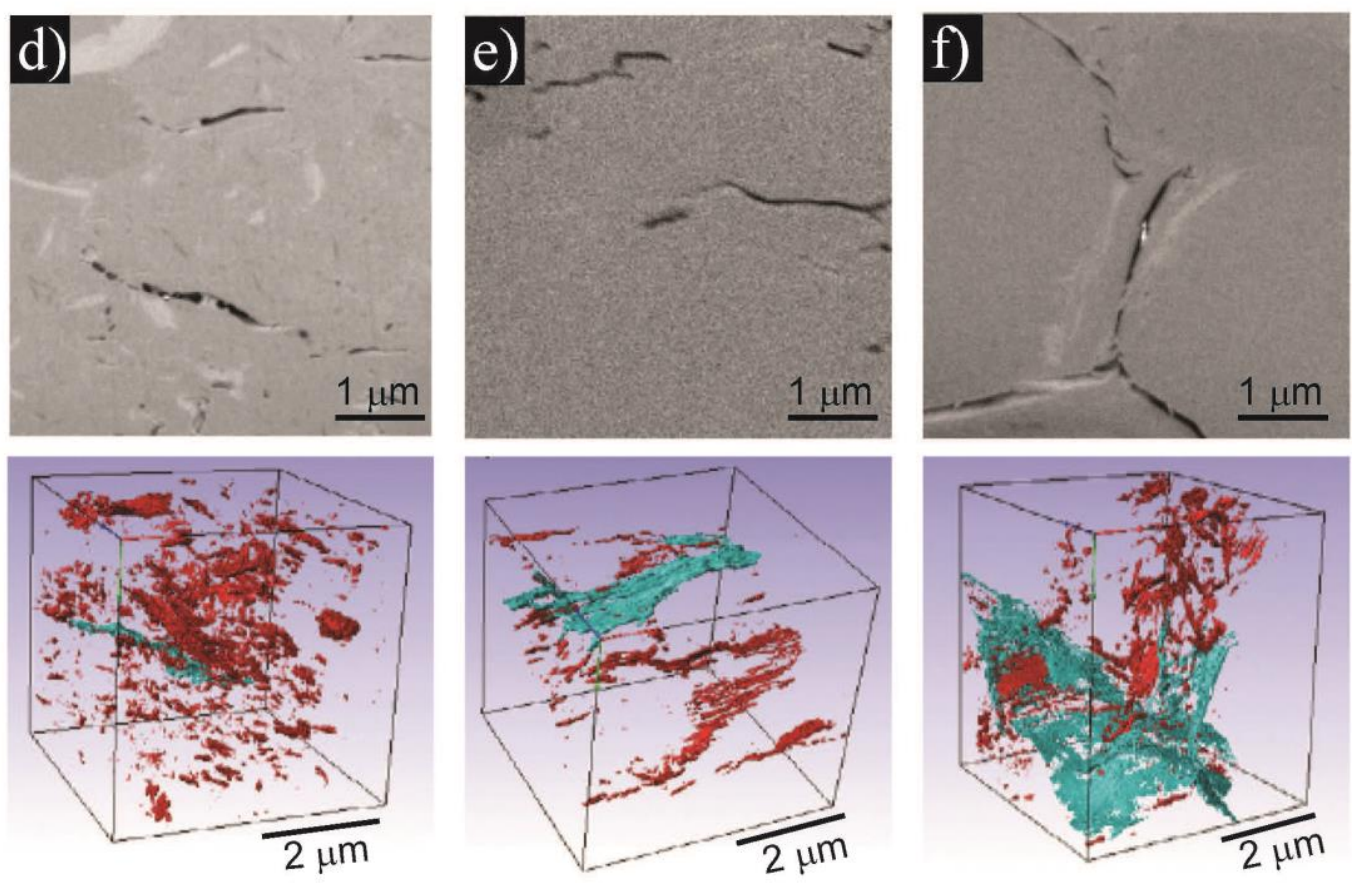

1480 Figure 9. From elongated pores to microcracks. Pictures a) from Houben et al. (2013) and c)

1481 Keller et al. (2011), in Opalinus clay, and b) from Chalmers et al. (2012a), in Woodford 1482 shale. Pictures d-f) from Heath et al. (2011) showing 2D slices and 3D views with connected 1483 (blue) and non-connected (red) porosity at the scale of the volume investigated. Reprinted 1484 with authorization. 

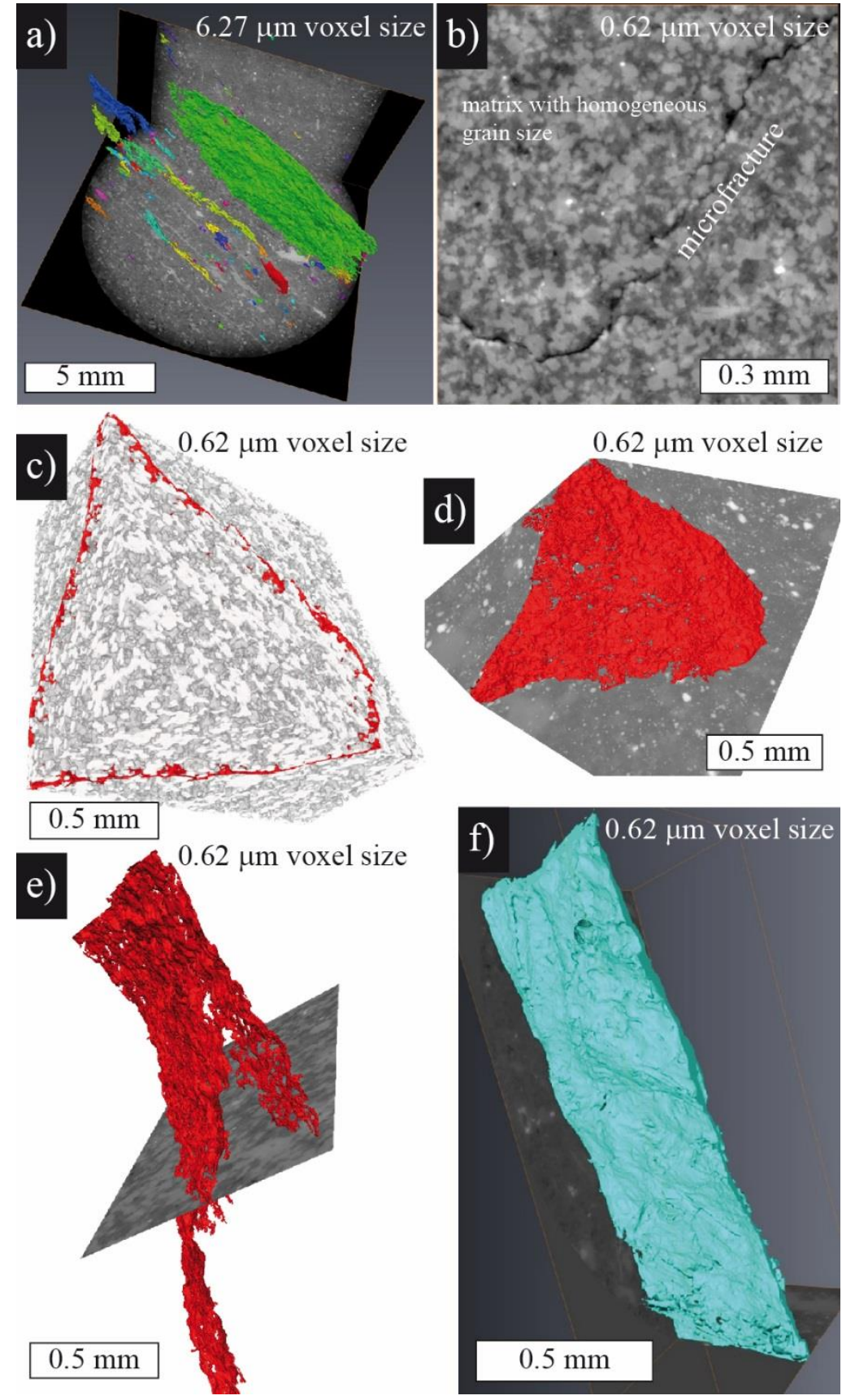

1486 Figure 10: Synchrotron X-ray microtomography images of fractures in the Vaca Muerta shale

1487 (Argentina) sample collected from a borehole at $3 \mathrm{~km}$ depth. a) Heterogeneous sample with 1488 microfractures segmented (each color corresponds to one fracture) and oriented parallel to the 1489 bedding. b) 2D slice of a homogeneous sample showing a microfracture that has propagated 1490 into a homogeneous matrix. c-d) Microfracture shown in 3D with the matrix around it (c) and 1491 without (d). e) Branched microfracture. f) Calcite vein shown in 3D. The data were acquired 1492 at the European Radiation Synchrotron Facility, beamlines BM05 and ID19 at two voxel 1493 sizes, 0.62 and 6.27 micrometers. 

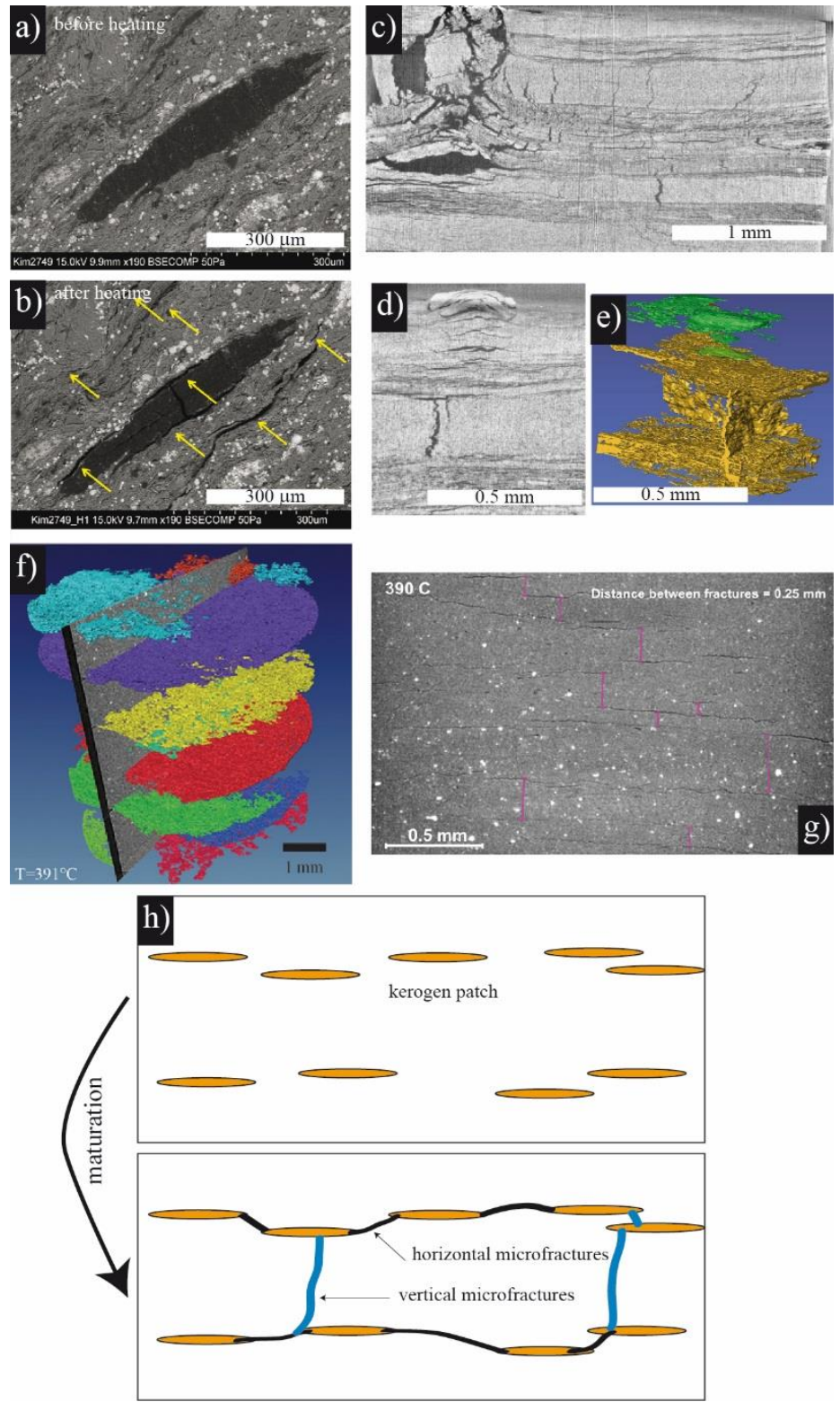

Figure 11: Microfracture development related to organic matter maturation. a-b) Scanning electron microscopy view of a shale before (a) and after (b) a stage of heating and the 1497 formation of fractures around a patch of organic matter (Allan et al., 2014); the arrows 1498 identify regions of microcracking, severe or correlated to small lenticular bodies. c-e) X-ray 1499 tomography views in 2D (c-d) and 3D (e) of a Green River shale after artificial maturation at $1500350^{\circ} \mathrm{C}$ and 50 bar pressure for 1 hour. $\mathrm{f}-\mathrm{g}$ ) Synchrotron X-ray microtomography views of a 1501 Green River shale sample heated in situ to $390^{\circ} \mathrm{C}$. The gas produced by the maturation of the organic matter escaped by producing a network of cracks (see Kobchenko et al., 2011 and 1503 Panahi et al., 2014). h) Concept of microfracture development due to kerogen maturation: 1504 local increase in kerogen patch volume creates horizontal microfractures. When vertical 1505 microfractures form as well, this produces a 3D connected network. 

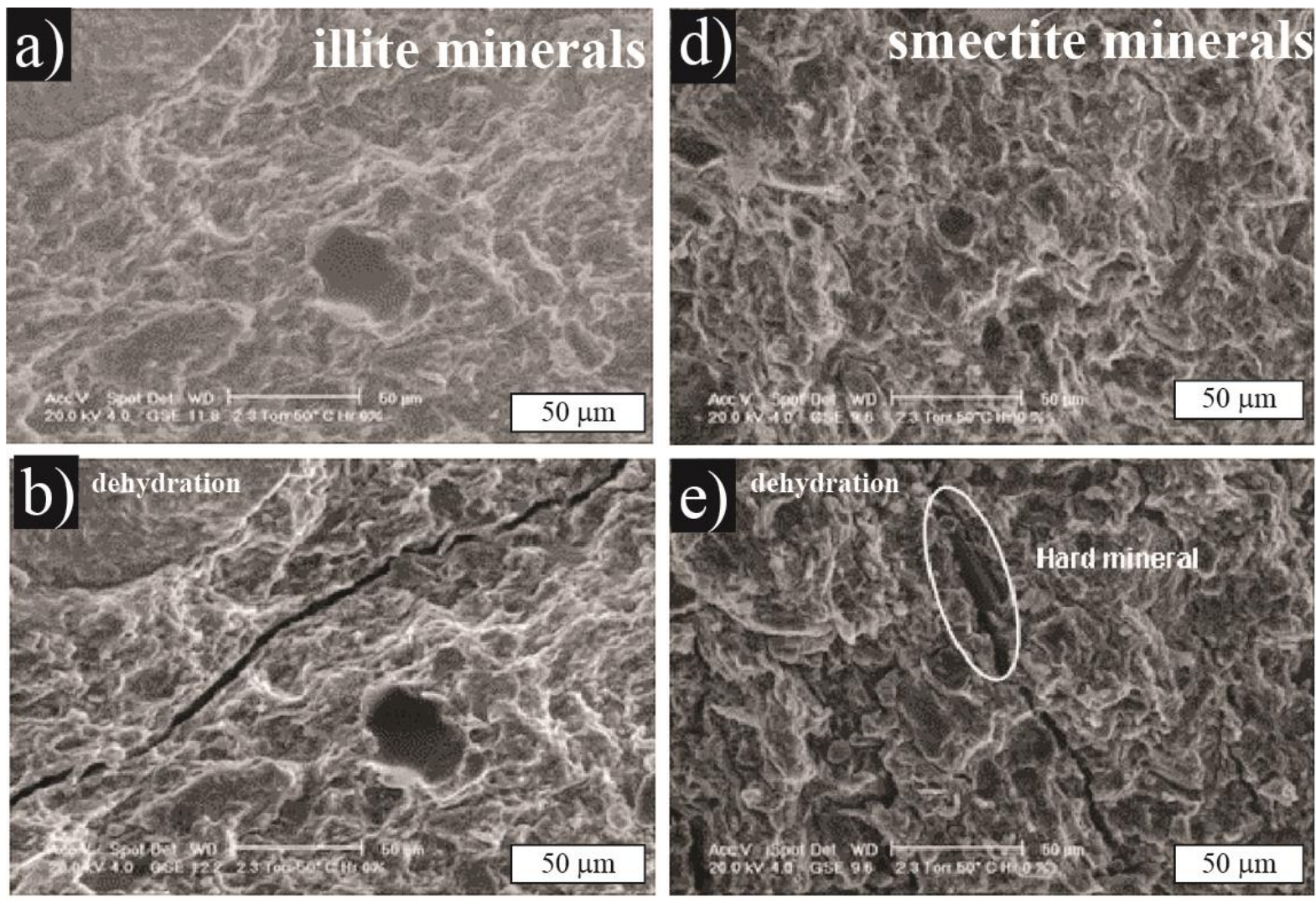

1506
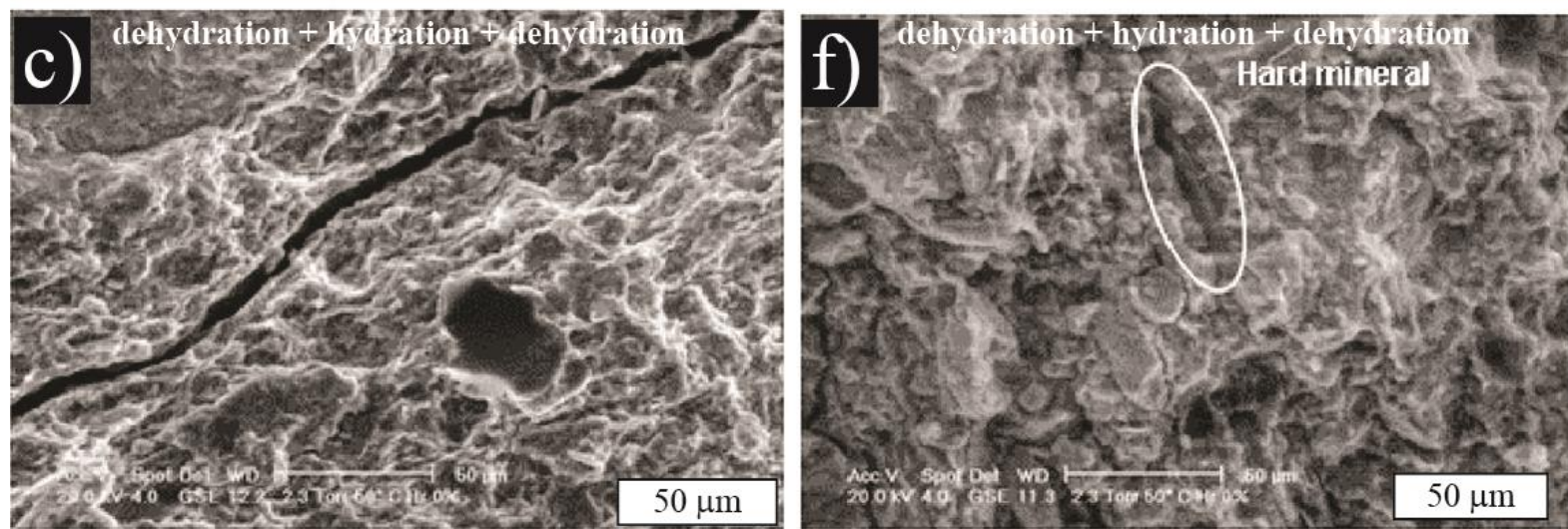

1507 Figure 12: Thermo-chemically induced microfractures. Dehydration/hydration cycles

1508 performed in Bure shale sample observed with SEM from Montes-Hernandez et al. (2004): a-

1509 c) in illite minerals, d-f) in smectite minerals. a) and d) are pictures of initial states; pictures

1510 b) and e) were taken after the first dehydration step, and c) and f) after a second dehydration

1511 step (one dehydration/hydration cycle + one dehydration). Reprinted with authorization. 

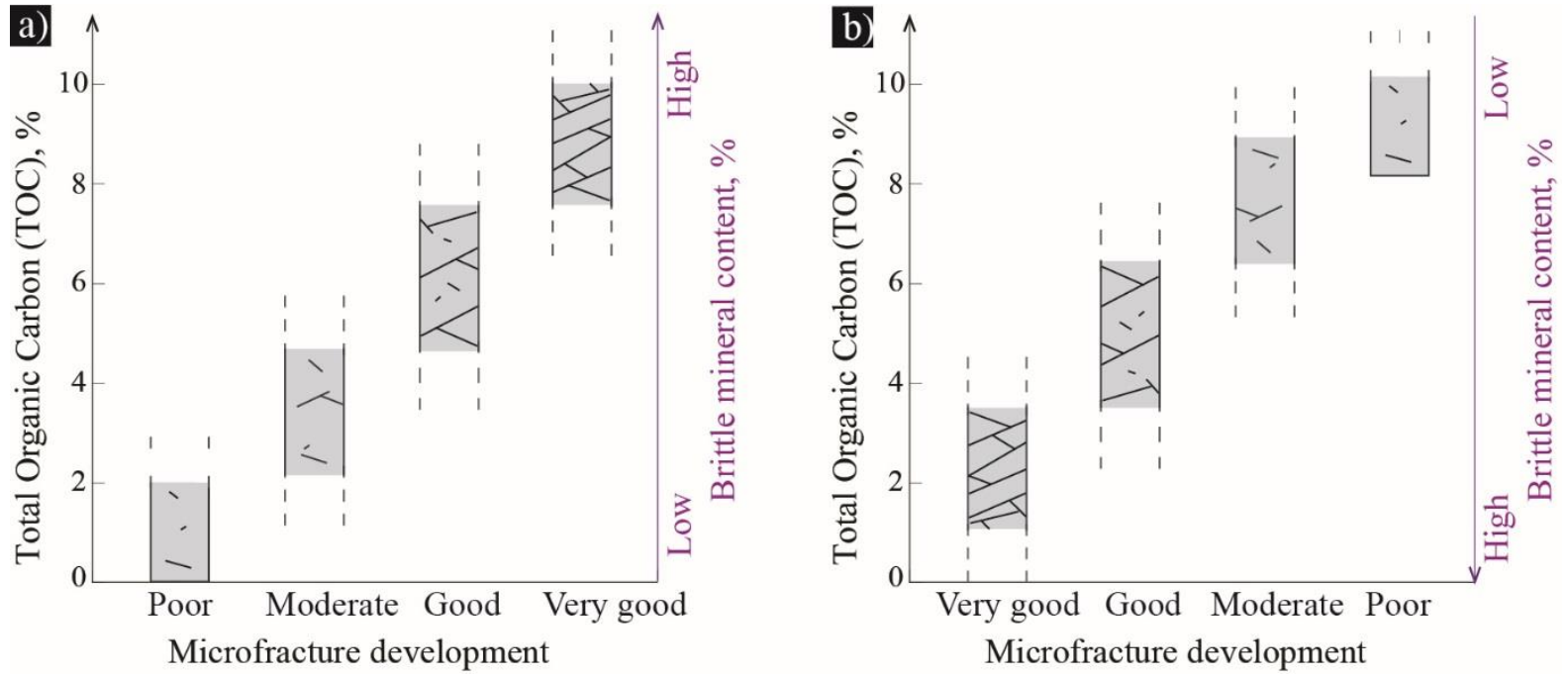

1513 Figure 13: Schematic representation of the relationship between total organic content and 1514 fracture development in shale, adapted from Ding et al. (2012). a) With an increase in total 1515 organic carbon, the number of microfractures should increase as more and more hydrocarbon 1516 is produced. This is similar to what is observed in analogue experiments (Kobchenko et al., 1517 2014). b) Conversely, in geological contexts where some tectonic activity has deformed the 1518 shales, the presence of a large quantity of brittle minerals favors a larger number of 1519 microcracks. 


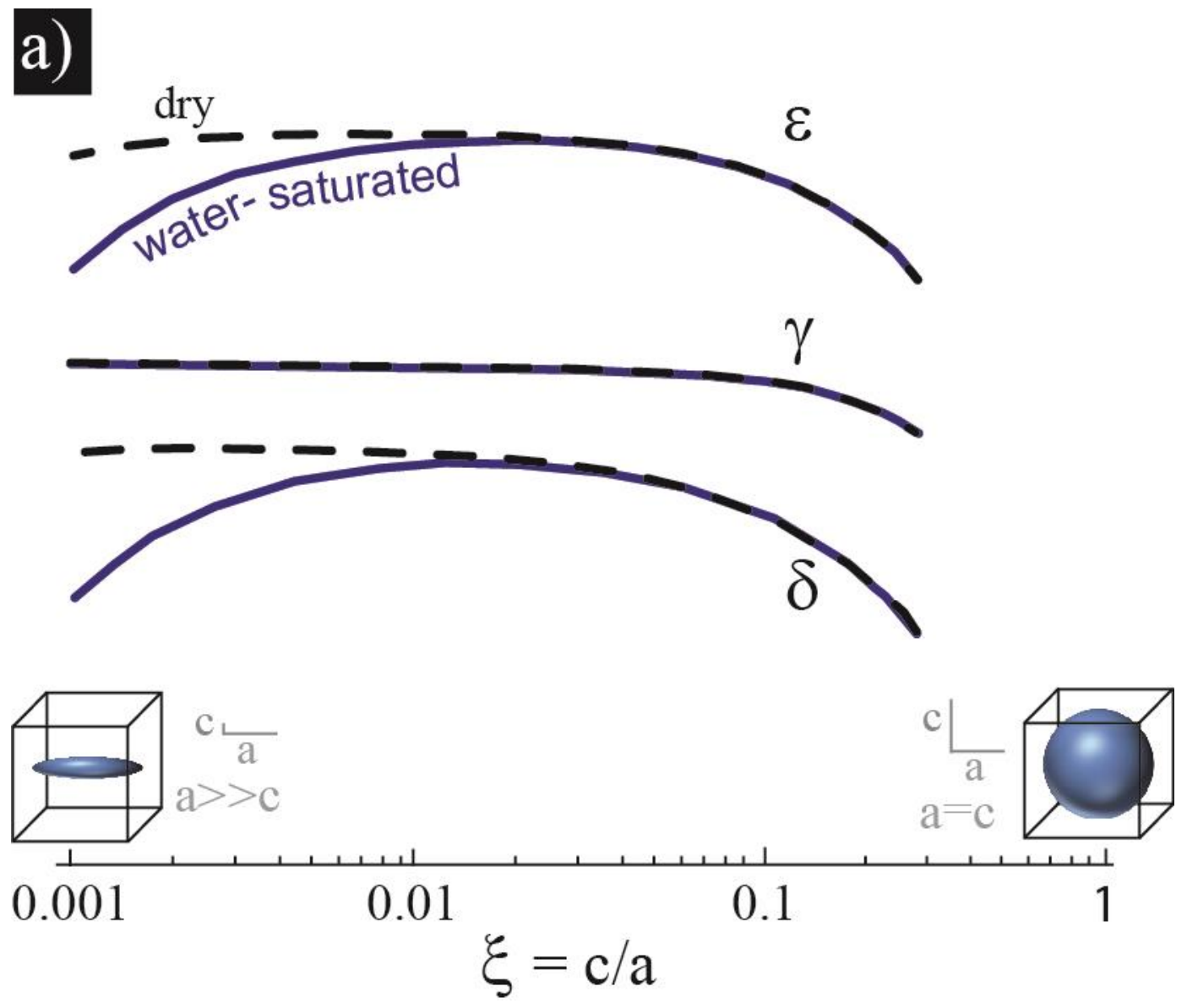

\section{b)}

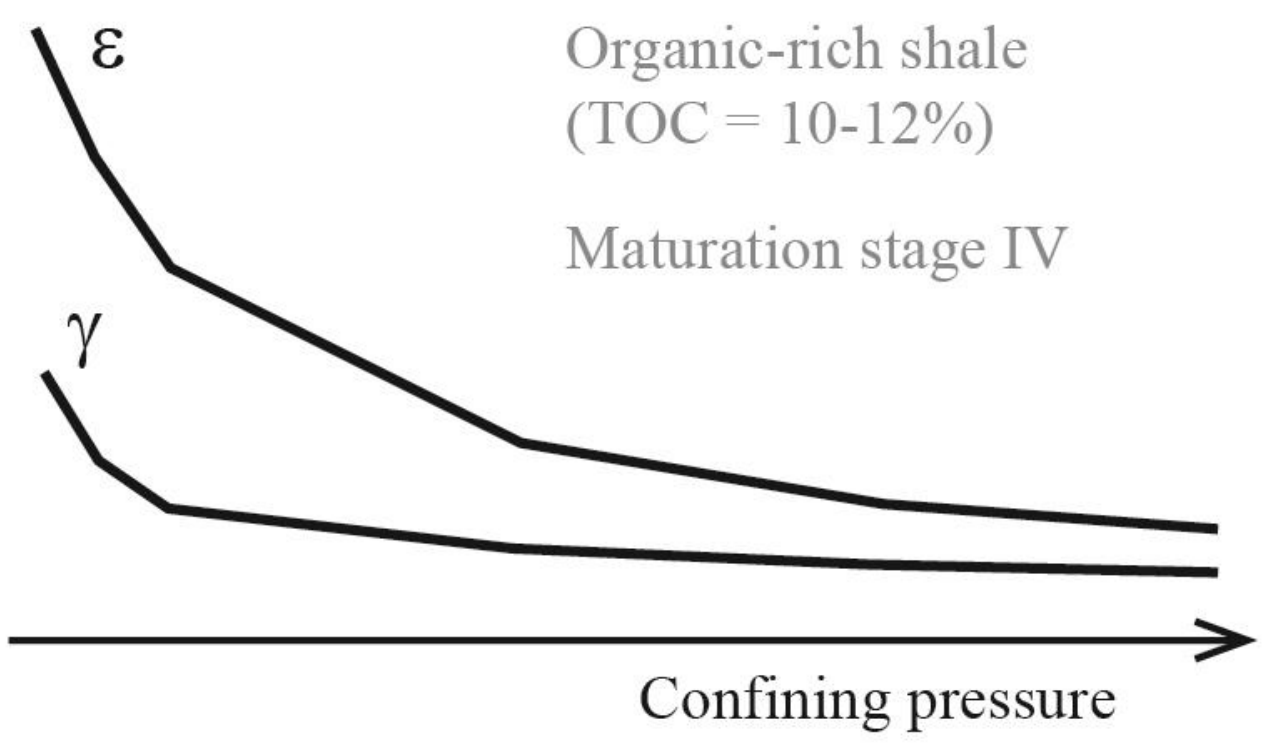

1521 Figure 14: Schematic plots of the evolution of Thomsen's parameters ( $\varepsilon, \gamma, \delta$, see text) with a) 1522 pore aspect ratio (from microfractures/elongated pores to almost spheroidal pores; adapted 1523 from Sarout and Guéguen, 2008b, and Ougier-Simonin et al., 2009) and b) confining pressure 1524 (adapted from Vernik, 1994). 


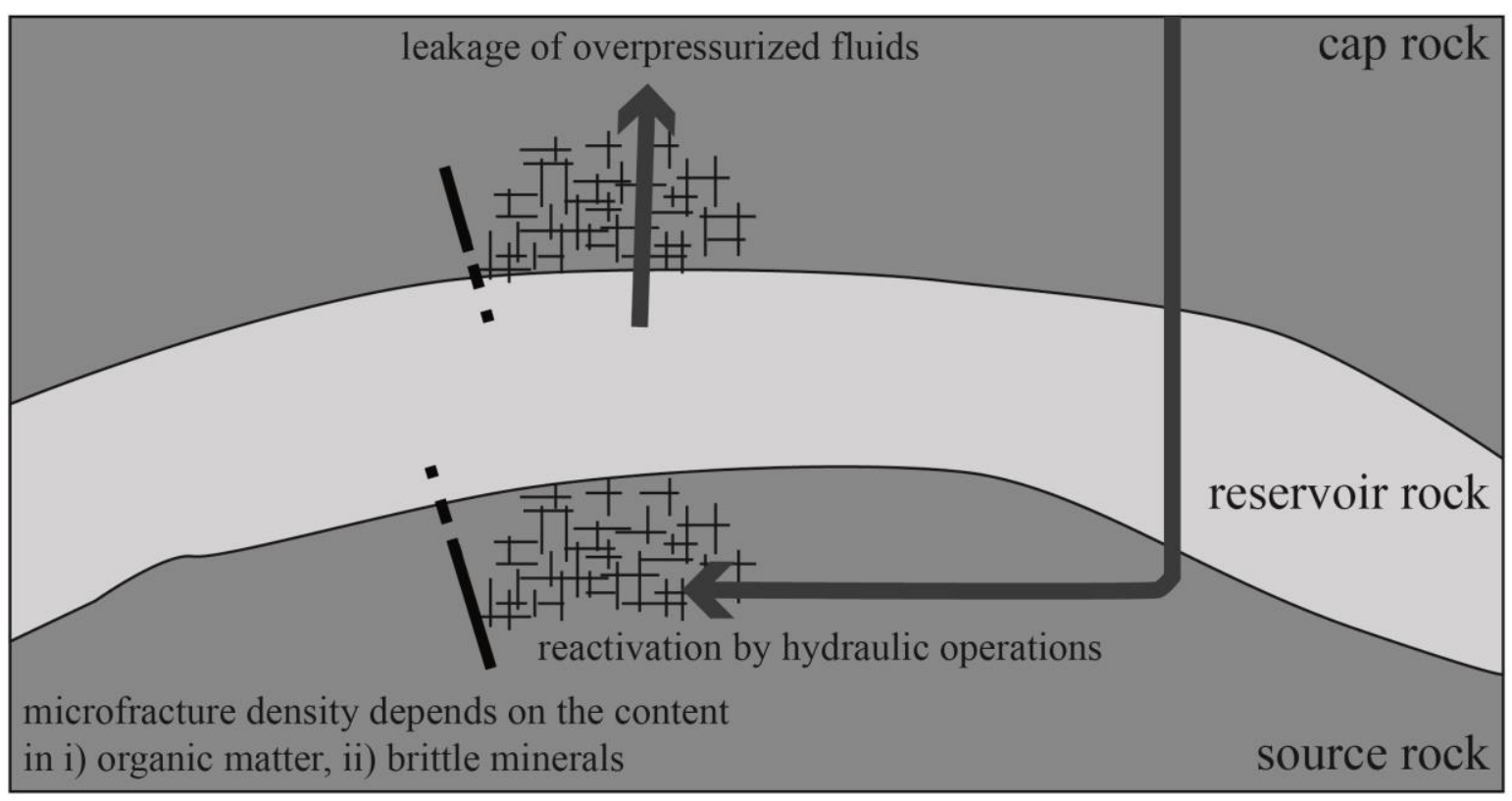

1526 Figure 15: Microfractures in shales, whether sealed or still open, have two major 1527 consequences: they can release overpressures in reservoir rocks or be reactivated during 1528 injection of fluids at high pressures. In both source and cap rocks, the density of 1529 microfractures is dependent on two main parameters: the initial organic matter content, which 1530 could produce microfractures during maturation, and the initial content of brittle minerals, 1531 which can act as stress concentrators for fracture propagation. An important consequence is 1532 the role of microfracture development on tectonic fractures and faults, which may create 1533 transport paths over distances much larger than the distance of influence of individual 1534 microfractures. 


\begin{tabular}{|c|c|c|c|c|c|c|c|c|c|c|c|c|c|c|c|c|}
\hline shale name & geological fomation & age (millilion yr) & mineralogical composition & chy minerals content & porsity $(\%)$ & $\begin{array}{l}\text { pore throat size } \\
(\mu \mathrm{mm})\end{array}$ & permeability $\left(m^{2}\right)$ & $\operatorname{depht}(\mathbf{m})$ & $\mathrm{P}(\mathrm{MPa})$ & $T(C)$ & $\operatorname{TOC}(\mathrm{w} \%)$ & Ro $(\%)$ V & kerogen type & $\begin{array}{l}\substack{\text { gas sasturtion } \\
\text { misthonj }} \\
\end{array}$ & $\begin{array}{l}\text { micerfocturur/micrecrack } \\
\text { deverponent }\end{array}$ & reference \\
\hline Anclope & Monterey-Tenblor Basin (USA) & $-8.11 \mathrm{Ma}$ & 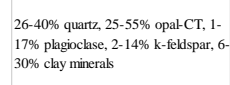 & 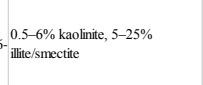 & -29 & $0.01-10$ & $-10^{177}$ & $1205-1495$ & -18 & -71 & & & & & 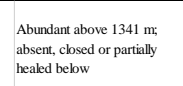 & Montgonery \& Morea (2001), Morea (1998) \\
\hline Brown & Monterey-Tenblor Basin (USA) & -6.5 .8 & 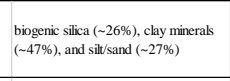 & $\begin{array}{l}\text { kaalinite }(0.5-6 \%) \text {, Iiteresnectile } \\
(5-25 \%)\end{array}$ & -27 & $<0.25$ & $-10^{17}$ & $1249-1273$ & & & & & & & 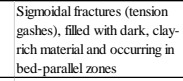 & y.- Mongonery \& Morea (2001), Morea (1998) \\
\hline Banert & Fort Worth Basin (USA) & $320-345$ & 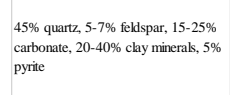 & 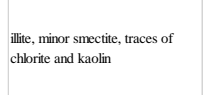 & -2.8 & $<10^{2}$ & $-10^{20}$ & $1888-2591$ & -65 & 82-100 & $2.5-511.47$ & 1-1.1.6 & $\begin{array}{l}\text { 95\% type II; } 5 \% \text { type } \\
\text { III }\end{array}$ & $7.08-9.91$ & Mirro-fissures well developed & 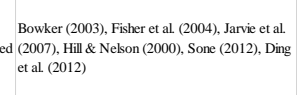 \\
\hline Banert-Woodford & Dehware Basin (USA) & $-358-370$ & $30-45 \%$ quart, $45-60 \%$ chy minerals & & & & - & 213454486 & & & $1.7-4.9(6.8)$ & $0.55-2.02$ & & & & Comer (2005), Janivi (2008) \\
\hline Fayeterevile & Arroma Basin (USA) & $-331-359$ & 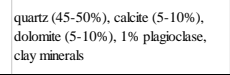 & 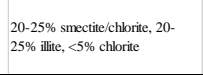 & & & & ${ }_{457-1981}$ & & 49-104 & 4.9 .5 & & $\begin{array}{l}\text { Type IV conereted from } \\
\text { type III }\end{array}$ & & & Baic al (2013) \\
\hline Haynessile & East Texas-North Lousiana Basin & $-150-156$ & 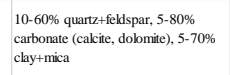 & ilite with traces of chborie & -3.6 & & & $3300-5000$ & -85 & & $-1-6$ & & & & - & $\begin{array}{l}\text { Hammes tal (2011), Deville tal (2011), Sone } \\
\text { (2012) }\end{array}$ \\
\hline Bossier & East Texas-North Lousina Basin & $\sim 138-150$ & 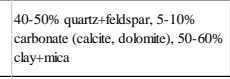 & $\begin{array}{l}\text { ilite, chboric, wiht racese of } \\
\text { sunctie }\end{array}$ & & & & & & & & & & & Developed & Ding tal (2012) \\
\hline Lewis & San Juan Basin (USA) & $-72-100$ & $56 \%$ quartz & & 3.5 .5 & $5.100 \times 10^{-3}$ & & 914-1829 & $6.9-10.3$ & 54.77 & $0.45-3$ & . & & $0.37-1.27$ & - & $\begin{array}{l}\text { Gentris (2013), Hill \& Nekon (2000), Curis } \\
(2002)\end{array}$ \\
\hline $\begin{array}{l}\text { Marcellus } \\
\end{array}$ & Appalchian Basin (USA) & $384-390$ & $40-60 \%$ quartz, $20-45 \%$ chy minerals & & -7.5 & - & $-10^{-19}$ & $1219-2591$ & - & - & $2-10$ & -1.4 & & - & - & DOE report(2011) \\
\hline Ohio & Appalachian Basin (USA) & & $\cdot$ & - & 4.7 & - & - & $610-1524$ & $3.4-13.8$ & 38 & 0.5 .23 & 0.41 .3 & & 1.72 .83 & Groups of high-nagel fractures & Ces Hill \& Nebon (2000), Dingetal (2012) \\
\hline Antrim (back win) & Michigan Basin (USA) & & 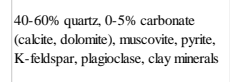 & $\begin{array}{l}\text { mainy Iilite, ninor kaolinite and } \\
\text { chlorite }\end{array}$ & 9 & & & $183-671$ & 2.8 & 24 & $5-24$ & 0.40 .6 & & 1.1.13-2.83 & 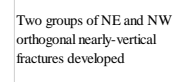 & $\begin{array}{l}\text { Ryder (1996), Hit\& \& Neken (2000), Curris } \\
\text { (2002), Ding etal (2012) }\end{array}$ \\
\hline Antrim (gasy wit) & Michien Basin (USA) & & 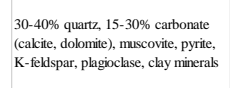 & $\begin{array}{l}\text { mainy ilite, , nioro kaolinite and } \\
\text { chlobic }\end{array}$ & & & & 184671 & & 24 & $<1$ & & & 1.13-2.283 & 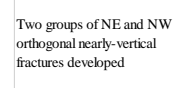 & $\begin{array}{l}\text { Ryder (1996), Hill \& Nebon (2000), Ding ct al } \\
\text { (2012) }\end{array}$ \\
\hline New alanyy & Inino B Basin (USA) & $-350-390$ & 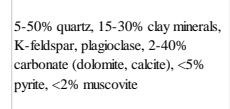 & ilite, chborie & $5-14$ & & & $152-610$ & $2.1-4.1$ & $27-41$ & $1-25$ & $0.4-1$ & & $1.13-2.64$ & & Hill \& Nekon (2000), Curtis (2002) \\
\hline Woodiord & Carey Arkoma (USA) & -345.365 & 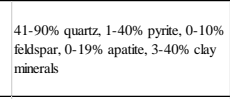 & iiliessmectite, ilitic & -5 & & $-10^{20}$ & 1219.3658 & & & $0,71-14.81$ & & & & 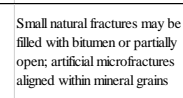 & 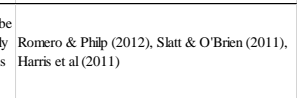 \\
\hline Bakken shales & Wiliston Basin (USA) & $-346-382$ & 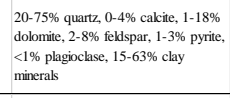 & 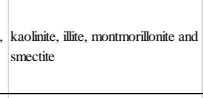 & ${ }^{2-14}$ & & & $2300-3500$ & & & -5.20 & $0.2-1$ & Type I and II & & 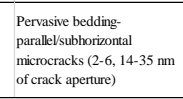 & Vemik (1992), Mba (2010) \\
\hline $\begin{array}{l}\text { Chatanooga } \\
\text { Vaca muerta stale }\end{array}$ & $\begin{array}{l}\text { Bhack Warior Basin(USA) } \\
\text { Neuquén Basin (Argentina) }\end{array}$ & $\begin{array}{l}-360-385 \\
-152-139\end{array}$ & 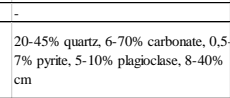 & 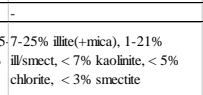 & $-4.6 \%$ & & $-510^{-19}-210^{20}$ & $2315-2419$ & $31-50$ & & 0.5.111\% & 1 & & & 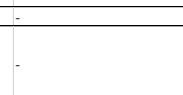 & $\begin{array}{l}\text { Hass (1956) } \\
\text { Padine tal (2014) }\end{array}$ \\
\hline Kimmeridge & Wessex Basin (UK) & $-146-202$ & 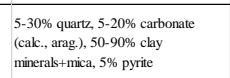 & 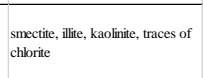 & $-17-45$ & & $-10^{22^{2}-10^{22}}$ & & & & -1.49 .6 & $\begin{array}{l}<0.510> \\
1.3\end{array}$ & & & & Seley (2012) \\
\hline Posidonia & Hilis Syctine (Gemmany) & 180 & 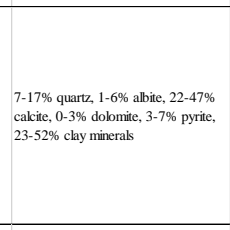 & $\begin{array}{l}\text { 22-36\% ilite-kaalinite, 0-3.4\% } \\
\text { snectile }\end{array}$ & $2-22$ & $0.0022-0.06$ & & -2200 & & & 6.3 .13 .3 & $0.5-1.45$ & Type II & & 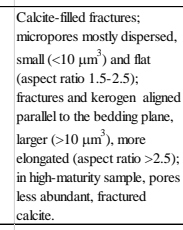 & 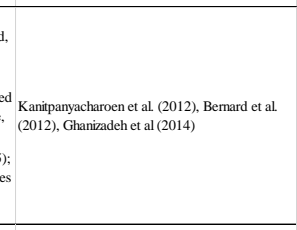 \\
\hline Alum Shale & (SwedenDemanaks) & 480.510 & 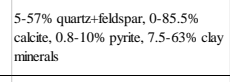 & 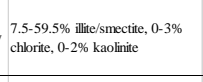 & $2.5-13$ & & $-10^{1-18}-10^{22}$ & & & & -3.20 & & & & & Ghanizadeh et a (2014) \\
\hline Norvegain Sea & & & 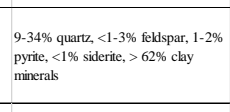 & 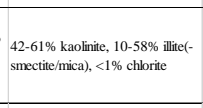 & -12 & $<0.02$ & & & & & $<2.2$ & & & & 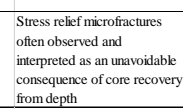 & Ie Dewhurst tet al (2011) \\
\hline North sea & & 5-200 & $-32-82 \%$ c chy ninerals & 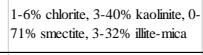 & -3.55 & 0.0040 .4 & $-10^{19}-10^{21}$ & $-1370-4870$ & & & & & & & 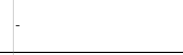 & Horsud et al (1998) \\
\hline Shak Drape & Usiras Sand (North Sea) & & 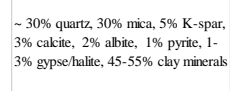 & 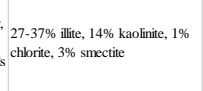 & & $0.014-0.04$ & & & & & $0.68-1.28$ & & & & & Chadwick etal (2004) \\
\hline Bure argilite & Paris Basin (France) & $155.7-16.7 .7$ & 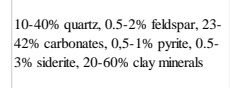 & 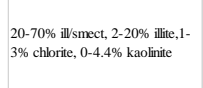 & -421 & $0.06-300$ & & 420.550 & & & $0-1.1$ & & 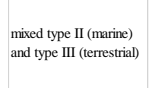 & & & 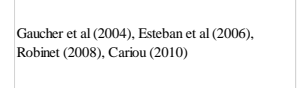 \\
\hline Toarcin shakes & Tournenire massiff (France) & 175-183 & 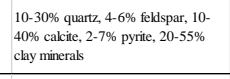 & 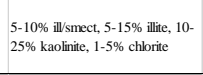 & & & & & & & 0.9 & & $\begin{array}{l}\text { mixed type III (marive) } \\
\text { and Iype III (eresstrail) }\end{array}$ & & & Deniau eta (2008) \\
\hline Boom chy & Boom Chy Formation (Belgium) & 28.433 .9 & 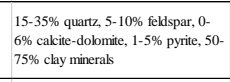 & 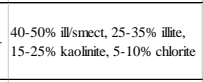 & $\cdot-39-42$ & & & $180-280$ & & & -3 & & $\begin{array}{l}\text { mixed type II (narine) } \\
\text { and type III (eresstrial) }\end{array}$ & & & $\begin{array}{l}\text { Wouters and Vandenherghe (1994), Wemanere et } \\
\text { al (2008), Yue ta } 1 \text { (2012) }\end{array}$ \\
\hline opalums chy & Switertand & $171.6-175.6$ & 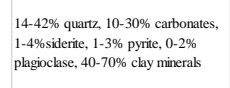 & 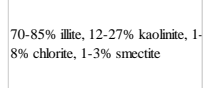 & $1-5-18$ & & & 270 or $550-650$ - & & & & & & & & Wenk tat (2008) \\
\hline Yayu & Yayu Basin (Ehtiopia) & $14-28$ & 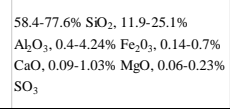 & snectite, kaobinite, and chboric & & & & $-26 \cdot 463$ & & & 5.61.2 & $0.1-0.8$ & Type I and II, rarely III & & & Wokh (2010) \\
\hline Senbar & Lower Indus Basin (Pakikian) & & - & bow chy conent & - & - & & 1219-4999 & & & -2 & $0.85-1.5$ & & & - & US Energy Information Adminisitration (2013) \\
\hline Rankot & Lower Indus Basin (Pakiktan) & & - & bw chy content & - & - & & $1829-3962$ & & & -2 & 0.85 & & - & - & US Energy Information Adninistration (2013) \\
\hline $\begin{array}{l}\text { Longmaxi Formation, } \\
\text { Chuandong Thust Fold Belt }\end{array}$ & Sichuan Basin (China) & -428.446 & 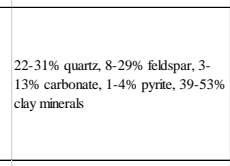 & $\begin{array}{l}19-28 \% \text { illie, } 8-19 \% \% \\
\text { montumorllonite, } 2-17 \% \text { chlorite }\end{array}$ & $2.6-4.74$ & $0.001-0.3$ & & $2100-2160$ & & & $-1.01-3.98$ & 20.3 .0 & $\begin{array}{l}\text { dominated by types I } \\
\text { and II }\end{array}$ & & 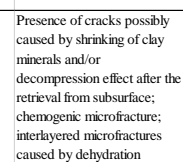 & Thine tal (2013) \\
\hline Qiongegusis Formation & Sichuan Basin (China) & -500.541 & 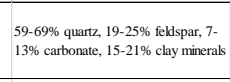 & & & & & & & & & & & $0.27-1.03$ & 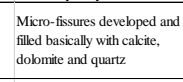 & Dingetal (2012) \\
\hline $\begin{array}{l}\text { Qing:shankou Fomation } \\
\text { shlale }\end{array}$ & Songlia Basin (China) & 66-146 & 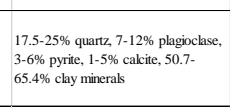 & 20-45\% Alieressnectie & & & & $-510-23300$ & & & $-1.73-4.21$ & & mainy ypes I Iand II & & 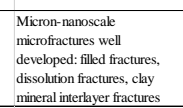 & Huang e ta l (2013) \\
\hline Muderong S Slake & Camaron Basin (Ausrralia) & $-119-138$ & 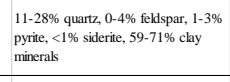 & 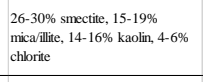 & $-21 \%$ & & & $-1000-3500$ & & $\sim 70$ & & & & & & Dewhurst te tal (2002) \\
\hline $\begin{array}{l}\text { Lancer Slakes (Kanpa and } \\
\text { Hussar Formations) }\end{array}$ & Oficer Basin (Australia) & $-720-800$ & 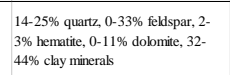 & $\begin{array}{l}29-42 \% \text { illie, } 2-4 \% \text { chlorite, } 0- \\
2 \% \text { kadin }\end{array}$ & $-6 \%$ & & & - 600-1115 & & $<65$ & & & & & 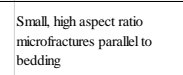 & Kuila tal (2011) \\
\hline
\end{tabular}




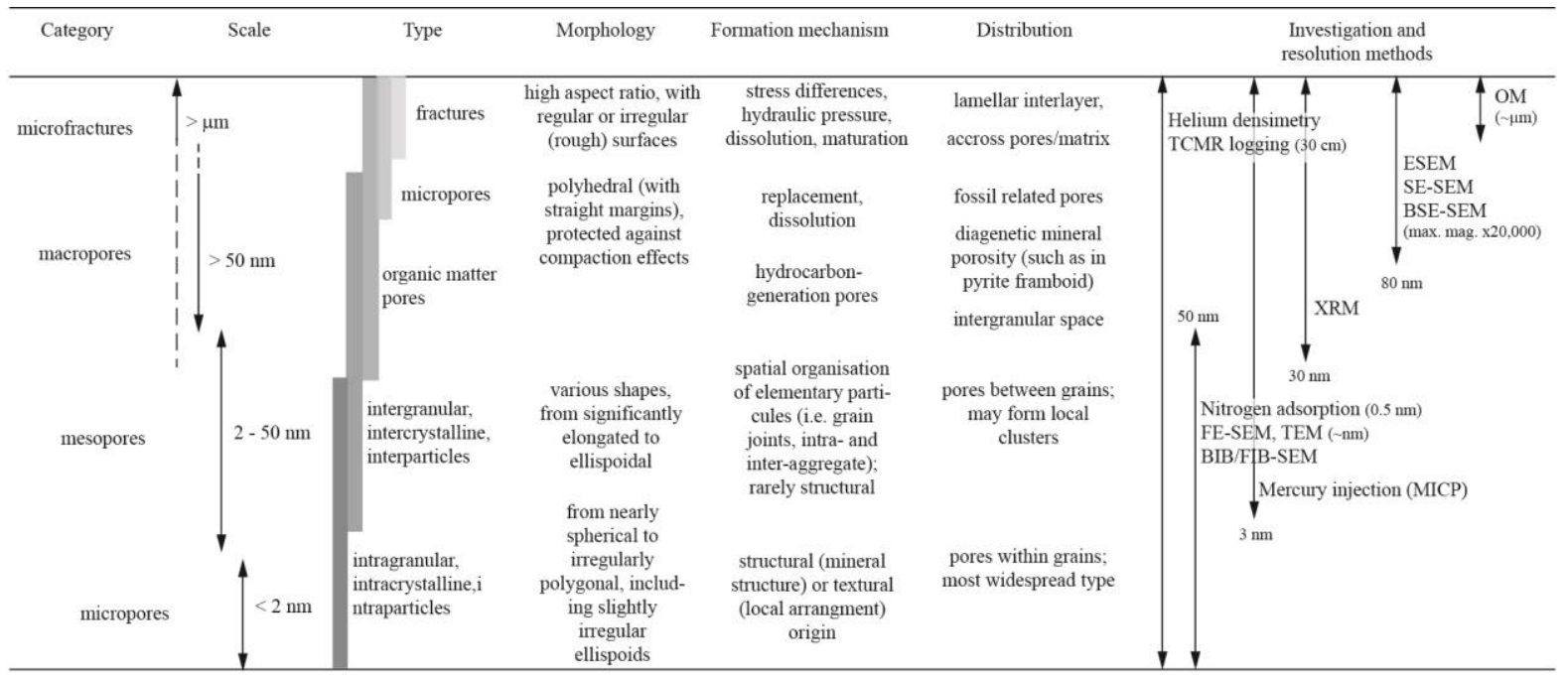

1540 Table 2: Classification of shale pores according to their size (after Yven, 2007; Loucks et al., 1541 2009; Milner et al., 2010; Chalmers et al., 2012a; Huang et al., 2013). TCMR = total 1542 combinable magnetic resonance porosity, TEM = transmission electron microscope, FE-SEM $1543=$ field emission scanning electron microscopy, $\mathrm{XRM}=\mathrm{X}$-ray microscopy, $\mathrm{ESEM}=$ 1544 environmental scanning electron microscope, SE-SEM = secondary electron scanning 1545 electron microscope, BSE-SEM = backscattered electron mode of scanning electron 1546 microscope, $\mathrm{OM}=$ optical microscope. 


\begin{tabular}{|l|l|l|l|}
\hline & method & porosity (\%) & reference \\
\hline Bure shale & water-accessible & 18 & Wenk et al., 2011 \\
\hline & oil-accessible & 18 & Cariou, 2010 \\
\hline helium pycnometry & 15 & Cariou, 2010 \\
\hline & mercury injection & $11.26-16.94$ & Yven et al., 2007 \\
\hline & 13.5 & Cariou, 2010 \\
\hline nitrogen adsorption & $9.26-14.2$ & Yven et al., 2007 \\
\hline $\begin{array}{l}\text { autoradiography } \\
\text { scanning electron microscopy }\end{array}$ & $2.18-5.27$ & Yven et al., 2007 \\
\hline $\begin{array}{l}\text { total combinable magnetic } \\
\text { resonance }\end{array}$ & $13.4-18$ & Cariou, 2010 \\
\hline $\begin{array}{l}\text { combinable magnetic free fluid } \\
\text { free fluid porosity) }\end{array}$ & $0-3.9$ & Robinet, 2008 \\
\hline Opalinus clay & $\begin{array}{l}\text { water-accessible } \\
\text { mercury injection }\end{array}$ & $12-16$ & Yven et al., 2007 \\
\hline nitrogen & $\begin{array}{l}\text { Yven et al., 2007 } \\
\text { focused ion beam scanning } \\
\text { electron microscopy }\end{array}$ & $1-2.8$ & Wenk et al., 2008 \\
\hline
\end{tabular}

1548 Table 3: Porosity measured on the same samples using different methods. These data show

1549 that a given value of porosity in shales depends to a great extent on the analytical technique used to measure it. This is due to the various kinds of porosity, from nanometer spaces between clay particles to macropores, explored with each technique. 


\begin{tabular}{|c|c|c|c|c|c|c|c|c|c|c|c|}
\hline \multirow{3}{*}{ Shale } & \multirow{3}{*}{$\begin{array}{c}\text { Confining } \\
\text { Pressure } \\
(M P a) \\
\end{array}$} & \multicolumn{5}{|c|}{ Elastic Stiffnesses } & \multirow{2}{*}{\multicolumn{3}{|c|}{$\begin{array}{l}\text { Anisotropy Parameters } \\
\text { (Thomsen's parameters) }\end{array}$}} & \multirow{3}{*}{$\begin{array}{l}\text { RMS } \\
\text { Error } \\
m s / m \\
\end{array}$} & \multirow{3}{*}{ References } \\
\hline & & \multicolumn{5}{|c|}{$(G P a)$} & & & & & \\
\hline & & C11 & C33 & C13 & C66 & $\mathrm{C} 44$ & $\varepsilon$ & $\gamma$ & $\delta$ & & \\
\hline & 5 & $33.4 \pm 0.9$ & $22.5 \pm 0.5$ & $14.8 \pm 0.5$ & $9.6 \pm 0.1$ & $5.0 \pm 0.1$ & $0.24 \pm 0.02$ & $0.46 \pm 0.01$ & $0.11 \pm 0.03$ & 4.1 & \multirow{14}{*}{ Hornby (1998) } \\
\hline Jurassic & 10 & $36.0 \pm 1.1$ & $24.2 \pm 0.6$ & $15.5 \pm 0.6$ & $10.6 \pm 0.0$ & $5.9 \pm 0.1$ & $0.24 \pm 0.02$ & $0.41 \pm 0.00$ & $0.13 \pm 0.03$ & 4.4 & \\
\hline \multirow[t]{2}{*}{ shale } & 20 & $39.3 \pm 0.7$ & $27.0 \pm 0.4$ & $16.4 \pm 0.4$ & $11.9 \pm 0.1$ & $6.9 \pm 0.1$ & $0.23 \pm 0.01$ & $0.37 \pm 0.00$ & $0.12 \pm 0.02$ & 2.6 & \\
\hline & 40 & $43.3 \pm 0.8$ & $29.7 \pm 0.5$ & $17.2 \pm 0.4$ & $13.3 \pm 0.1$ & $7.8 \pm 0.1$ & $0.23 \pm 0.01$ & $0.36 \pm 0.00$ & $0.11 \pm 0.02$ & 2.6 & \\
\hline fully water saturated & 60 & $45.1 \pm 1.0$ & $31.6 \pm 0.6$ & $17.9 \pm 0.5$ & $14.0 \pm 0.1$ & $8.3 \pm 0.1$ & $0.21 \pm 0.02$ & $0.34 \pm 0.00$ & $0.10 \pm 0.02$ & 3,0 & \\
\hline \multirow[t]{2}{*}{ drained } & 80 & $46.1 \pm 2.0$ & $32.9 \pm 1.2$ & $18.5 \pm 1.1$ & $14.3 \pm 0.1$ & $8.8 \pm 0.2$ & $0.20 \pm 0.01$ & $0.31 \pm 0.04$ & $0.11 \pm 0.04$ & 5.2 & \\
\hline & 5 & $48.4 \pm 2.1$ & $27.3 \pm 1.0$ & $16.4 \pm 1.0$ & $17.0 \pm 0.1$ & $7.8 \pm 0.2$ & $0.39 \pm 0.04$ & $0.58 \pm 0.01$ & $0.19 \pm 0.05$ & 5.7 & \\
\hline \multirow[t]{2}{*}{ Kimmeridge Clay } & 10 & $49.8 \pm 2.5$ & $29.5 \pm 1.2$ & $17.2 \pm 1.3$ & $17.3 \pm 0.1$ & $8.5 \pm 0.2$ & $0.34 \pm 0.04$ & $0.51 \pm 0.00$ & $0.18 \pm 0.05$ & 6.5 & \\
\hline & 15 & $50.8 \pm 3.3$ & $30.8 \pm 1.5$ & $17.8 \pm 1.6$ & $17.5 \pm 0.1$ & $8.9 \pm 0.3$ & $0.32 \pm 0.05$ & $0.48 \pm 0.01$ & $0.18 \pm 0.06$ & 7.7 & \\
\hline fully water saturated & 20 & $52.1 \pm 3.6$ & $32.1 \pm 1.7$ & $18.7 \pm 1.8$ & $17.9 \pm 0.1$ & $9.2 \pm 0.3$ & $0.31 \pm 0.06$ & $0.47 \pm 0.01$ & $0.17 \pm 0.07$ & 8.2 & \\
\hline \multirow[t]{4}{*}{ drained } & 30 & $53.3 \pm 3.5$ & $33.1 \pm 1.7$ & $19.0 \pm 1.7$ & $18.2 \pm 0.1$ & $9.5 \pm 0.3$ & $0.31 \pm 0.05$ & $0.45 \pm 0.01$ & $0.16 \pm 0.07$ & 8,0 & \\
\hline & 40 & $54.7 \pm 3.7$ & $34.3 \pm 1.8$ & $19.8 \pm 1.8$ & $18.5 \pm 0.1$ & $9.8 \pm 0.3$ & $0.30 \pm 0.05$ & $0.44 \pm 0.01$ & $0.17 \pm 0.07$ & 7.9 & \\
\hline & 60 & $55.3 \pm 4.2$ & $35.5 \pm 2.1$ & $20.1 \pm 2.1$ & $18.7 \pm 0.2$ & $10.2 \pm 0.4$ & $0.28 \pm 0.06$ & $0.42 \pm 0.01$ & $0.15 \pm 0.07$ & 8.8 & \\
\hline & 80 & $56.2 \pm 4.4$ & $36.4 \pm 2.3$ & $20.5 \pm 2.3$ & $18.9 \pm 0.1$ & $10.3 \pm 0.4$ & $0.27 \pm 0.06$ & $0.41 \pm 0.01$ & $0.14 \pm 0.08$ & 9.1 & \\
\hline Bure Argilite & 0 & 32.2 & 16.3 & 2.9 & 10.8 & 7.4 & 0.49 & 0.23 & 0.092 & \multirow{4}{*}{$\begin{array}{c}\text { error on } C_{i j:} \\
9.3 \%<D C i j / C i j<18.7 \%\end{array}$} & \multirow{4}{*}{ Sarout \& Gueguen (2008) } \\
\hline dry & 15 & 32.9 & 17.4 & 3.6 & 11 & 7.6 & 0.23 & 0.21 & 0.086 & & \\
\hline \multirow[t]{2}{*}{ wet $(\mathrm{RH}=98 \%)$} & 0 & 35.3 & 22.0 & 10.9 & 10.5 & 7.1 & 0.3 & 0.24 & 0.155 & & \\
\hline & 15 & 38.6 & 26.3 & 12.3 & 11.3 & 7.8 & 0.2 & 0.22 & 0.063 & & \\
\hline Bakken & 5 & 53.2 & 23.2 & 8.4 & 19.0 & 11.0 & 0.65 & 0.36 & 0.4 & & \multirow{3}{*}{ Vernik (1993) } \\
\hline shale & 70 & 56.2 & 36.7 & 13.6 & 19.3 & 14.4 & 0.27 & 0.17 & 0.17 & & \\
\hline gas-oil saturated & 5 (crack free backcalculated) & 53.2 & 32.3 & 10.4 & 19,0 & 13.2 & 0.32 & 0.22 & 0.16 & & \\
\hline Muderong & 5 & $20.5 \pm 0.5$ & $13.5 \pm 0.5$ & $7.5 \pm 0.5$ & $6.5 \pm 0.5$ & $3.0 \pm 0.5$ & $0.26 \pm 0.05$ & $0.57 \pm 0.02$ & $0.05 \pm 0.03$ & & \multirow{5}{*}{ Dewhurst \& Siggins (2006 } \\
\hline \multirow[t]{2}{*}{ shale } & 10 & $21.0 \pm 0.5$ & $14.5 \pm 0.5$ & $10 \pm 0.5$ & $7.0 \pm 0.5$ & $3.5 \pm 0.5$ & $0.27 \pm 0.02$ & $0.58 \pm 0.01$ & $0.13 \pm 0.02$ & & \\
\hline & 20 & $22.5 \pm 0.5$ & $15.5 \pm 0.5$ & $11 \pm 0.5$ & $7.5 \pm 0.5$ & $3.5 \pm 0.5$ & $0.23 \pm 0.01$ & $0.62 \pm 0.02$ & $0.15 \pm 0.01$ & & \\
\hline \multirow[t]{2}{*}{ saturated } & 40 & $24.5 \pm 0.5$ & $16.5 \pm 0.5$ & - & $8.0 \pm 0.5$ & $4.0 \pm 0.5$ & $0.23 \pm 0.01$ & $0.50 \pm 0.01$ & - & & \\
\hline & 60 & $26.5 \pm 0.5$ & $17.5 \pm 0.5$ & $16 \pm 0.5$ & $8.2 \pm 0.5$ & $4.0 \pm 0.5$ & $0.24 \pm 0.01$ & $0.48 \pm 0.01$ & $0.48 \pm 0.01$ & & \\
\hline
\end{tabular}

1553 Table 4: Elastic stiffness parameters and Thomsen's parameters for five shales at different 1554 confinements and fluid saturations. 